Portland State University

PDXScholar

Winter 3-5-2013

\title{
Finding the Gifted Child's Voice in the Public Elementary School Setting: A Phenomenological Exploration
}

Keely S. Porter

Portland State University

Follow this and additional works at: https://pdxscholar.library.pdx.edu/open_access_etds

Part of the Curriculum and Instruction Commons, Curriculum and Social Inquiry Commons, Elementary and Middle and Secondary Education Administration Commons, and the Gifted Education Commons

Let us know how access to this document benefits you.

\section{Recommended Citation}

Porter, Keely S., "Finding the Gifted Child's Voice in the Public Elementary School Setting: A Phenomenological Exploration" (2013). Dissertations and Theses. Paper 640.

https://doi.org/10.15760/etd.640

This Dissertation is brought to you for free and open access. It has been accepted for inclusion in Dissertations and Theses by an authorized administrator of PDXScholar. Please contact us if we can make this document more accessible: pdxscholar@pdx.edu. 
Finding the Gifted Child's Voice in the Public Elementary School Setting:

A Phenomenological Exploration

by

Keely S. Porter

A dissertation submitted in partial fulfillment of the requirements for the degree of

Doctor of Education

in

Educational Leadership: Curriculum and Instruction

\author{
Dissertation Committee: \\ Christine Chaille, Chair \\ Emily de la Cruz \\ Samuel Henry \\ William Parnell \\ Ben Anderson-Nathe
}

Portland State University

2013 
(C) 2013 Keely S. Porter 


\begin{abstract}
Who are talented and gifted (TAG) students and how do we meet their unique needs in the elementary school setting? The body of literature clearly articulates the unique intellectual, social and emotional needs and characteristics of TAG students. Additionally, the literature supports the implementation of differentiated teaching strategies and affective curriculum to help meet these unique needs. This descriptive phenomenological study allowed gifted children, in fifth grade from a Pacific Northwest suburban elementary school, to share their lived experiences through reflective narratives and art. The data collected generated a central theme of Friends and general themes of Awareness, Feelings, Learning, and TAG Programming. Experiences that included friends were, by far, the most commonly shared; however, the participants also shared stories of wanting to be challenged and how they appreciated teachers who were more creative in curriculum delivery. Delisle (2012), Jessiman (2001) and Bergmark (2008) assert that in order to make progress in school reform and/or improvement we need to listen to our consumers and by consumers they are referring to our students. This study captures the gifted child's experience in elementary school and allows their voice to be heard.
\end{abstract}




\section{Dedication}

To all the gifted students who have inspired me...

May your journeys be filled with joy and may your voices always be heard 


\section{Acknowledgements}

This journey was a long one filled with challenges and celebrations. If it weren't for the support of many, the end would not have come and this important work would not have been accomplished.

First, I want to thank the participants in this study: Wilma, Trudy, Theo, and Finn. Without their willingness to openly and honestly share their experiences, none of this would have been possible. Thank you for sharing some of your summer with me and I want to thank your families for their support of this project.

I also want to thank the principal, elementary school, and school district for trusting me enough to share the stories of children in their care. Their willingness to participate was paramount in sharing the children's stories and is greatly appreciated.

Next, I want to thank my advisor, Dr. Christine Chaille and my dissertation committee: Dr. Samuel Henry, Dr. Emily de la Cruz, Dr. Will Parnell, and Dr. Ben Anderson-Nathe. It has been a long journey, but I always felt your support during the process. Dr. Chaille, thank you for challenging and encouraging me throughout this process. Your support and guidance has opened a window to a whole new world for me and I am excited by what I see out there!

I would also like to thank Megan, Nick, and Ryan for sharing stories so compelling during my proposal that I was armed and able to defend why this study was so important. It was a joy and a privilege to be your teacher. Thank you!

Next, I couldn't have achieved this goal without the support of my friends and family, particularly my parents, Jim and Shirley Blighton, who stepped in to help and 
support me in whatever manner was needed. I truly could not have done this without them. Thanks Mom and Dad, I love you!

I want to thank God for His guidance throughout this process, His sustenance when I needed it most and His helping hand in providing me an incredible career working with gifted children.

Finally, I want to thank my husband, John, for believing in me and seeing something in me that I would never have thought possible. His vision, support and love inspired me to impact education in a way that is both meaningful and real. For that, I am eternally grateful. This accomplishment was only possible because of how well we work together as a team. Thank you for dreaming and achieving with me, I love you! 
TABLE OF CONTENTS

Page

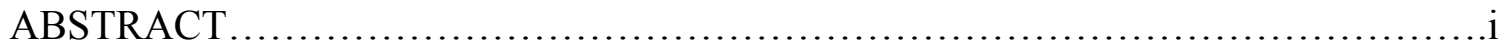

DEDICATION .......................................................................

ACKNOWLEDGEMENTS .......................................................ii

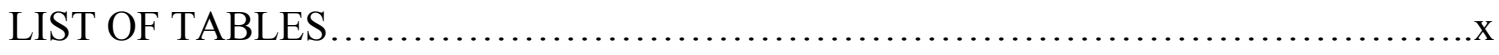

LIST OF FIGURES..............................................................

CHAPTER 1 -STATEMENT OF PROBLEM...................................

CHAPTER 2 -LITERATURE REVIEW ............................................

Definitions, Historical Perspective and Milestones...............................9

Defining Giftedness...................................................

Historical Perspectives of Gifted Education.............................14

Milestones in Gifted Education......................................16

Differentiation.......................................................... 18

Differentiation: Definitions and Models................................18

Social/Emotional Needs and Affective Characteristics........................27

Social/Emotional Needs: Background \& Characteristics................27

Affective Characteristics..........................................29

Bronfenbrenner's Ecological Systems Theory...........................35

Gifted Development Theories.............................................

Asynchronous Development........................................41

Gifted Programming/Curriculum Delivery ................................. 44

Providing an Emotional Education...................................44 
FINDING THE GIFTED CHILD'S VOICE vi

Delivery of Gifted Services....................................46

Defining Inclusive and Exclusive TAG Programming.................47

Phenomenology..................................................49

Gifted Studies Using Phenomenological Research Method..............49

Conclusion of Literature Review.......................................55

CHAPTER $3-$ METHODOLOGY ...........................................56

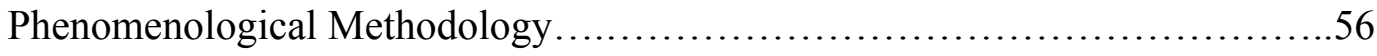

Descriptive Versus Interpretive Approaches.........................58

Purpose $/$ Rationale..................................................59

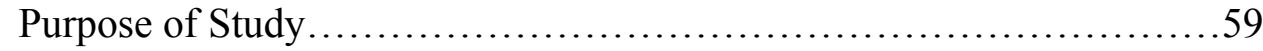

Rationale for Type of Research...............................61

Research Setting .................................................6 62

Study Participants............................................62

Participating School...........................................64

Data Collection......................................................67

The Epoch................................................68

Interviews.................................................. 70

Data Collection Timeline....................................... 72

Data Analysis.............................................73

Ethical Considerations.........................................79

Conclusion......................................................80

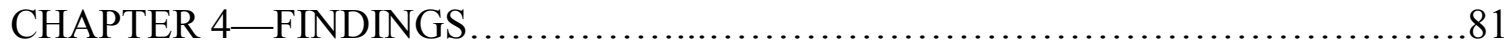

Findings and Analysis.............................................. 82 
FINDING THE GIFTED CHILD’S VOICE vii

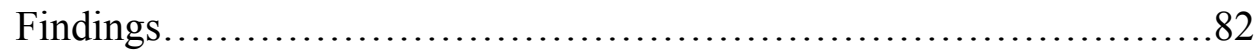

Data Collection...........................................82

Participants............................................83

Identification Implications.................................84

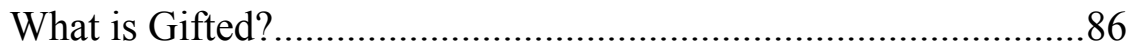

Different Students and Different Experiences..................87

Analysis......................................................91

Delineating Units of General Meaning........................92

Delineating Units of Meaning Relevant to Research Question.....93

Clustering Units of Relevant Meaning.......................94

Awareness...........................................96

Feelings.........................................98

Learning........................................... 100

TAG Programming................................ 102

Friends...........................................104

Determining Themes from Clusters of Meaning................106

Analysis of Distinct Experiences....................107

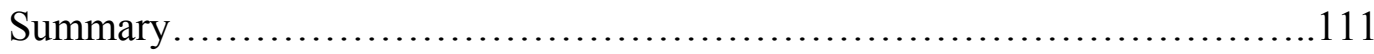

Interview Summaries........................................111

Wilma.................................................112

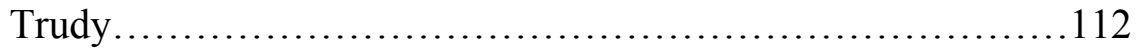

Theo...................................................113

Being Finn: An Expanded Summary......................114 
FINDING THE GIFTED CHILD'S VOICE viii

Composite Summary........................................118

Epoch and its Role...........................................119

Summary of Findings......................................... 126

CHAPTER 5-DISCUSSION.............................................. 130

Reflection on the Research Process..................................... 130

Importance of the Epoch....................................... 132

Implications for Practice.............................................. 132

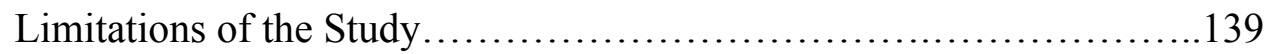

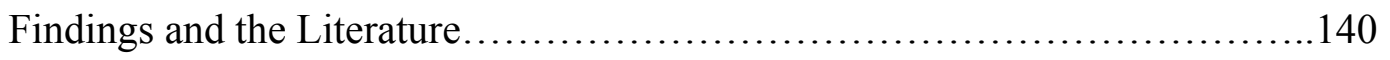

Differentiation.................................................. 141

Affective Characteristics........................................143

Ecological Systems Theory....................................143

Theory of Overexcitabilities................................ 145

Recommendation for Further Research.................................146

Conclusion.......................................................... 148

REFERENCES .......................................................... 150

APPENDIX A............................................................. 162

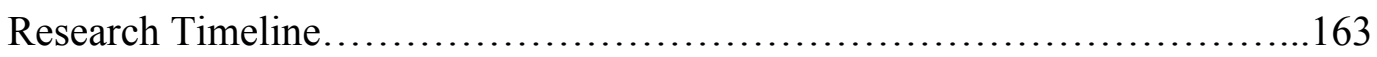

Protocol Agenda................................................... 165

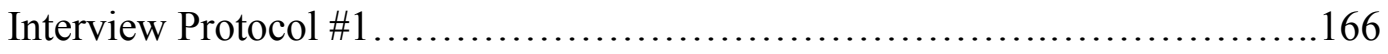

Work Session Instruction Protocol....................................168

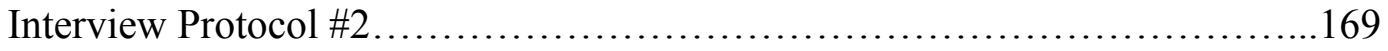

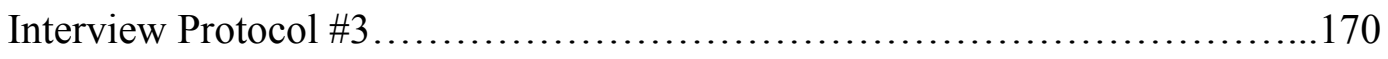


FINDING THE GIFTED CHILD'S VOICE

Epoch....................................................... 171

APPENDIX B........................................................ 178

Parent Consent....................................................179

Child Consent...................................................181

Administrator Consent............................................. 182

Profile Questionnaire.............................................. 184 


\section{LIST OF TABLES}

Table 1. Social and Emotional Characteristics of Gifted Children That May Pose

Challenges.......................................................29

Table 2. Participant Self-descriptions...................................63

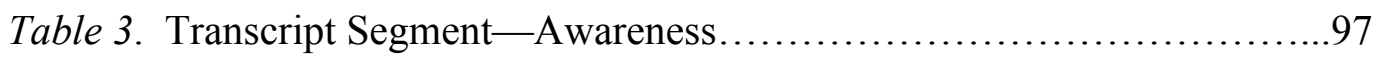

Table 4. Transcript Segment-Feelings.................................99

Table 5. Transcript Segment_-Learning............................... 101

Table 6. Transcript Segment_-TAG Programming........................ 103

Table 7. Transcript Segment —Friends................................. 105

Table 8. Frequency Table of Keywords Representing Essences from General Meaning Units.................................................... 108

Table 9. Researcher's Epoch Analysis................................ 120 


\section{LIST OF FIGURES}

Figure 1.Renzulli's Three-ring Conception of Giftedness..................... 12

Figure 2. Gagne's Differentiated Model of Giftedness and Talent...............13

Figure 3. Bronfenbrenner's Ecological Systems Theory...................... 36

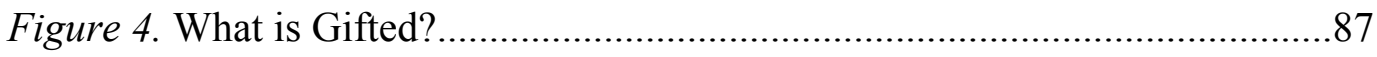

Figure 5. Elementary School in One Word $\ldots \ldots \ldots \ldots \ldots \ldots \ldots \ldots \ldots \ldots \ldots \ldots \ldots . \ldots . \ldots \ldots$

Figure 6. Gifted Child in One Word....................................... 89

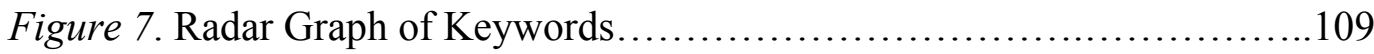

Figure 8. Researcher and Participant Thematic Comparison...................126

Figure 9. Expressiveness of Participants................................ 127

Figure 10. Central Theme: Friends................................... 128 


\section{Chapter 1-Statement of Problem}

"Research and interest both political and social have surged and faltered since the inception of the field of gifted education in the early $20^{\text {th }}$ century, and public perceptions of gifted education range from its critical need to its elitist luxury" (Jolly \& Kettler, 2008, p.427). When addressing public perception, research and political interest in educating the gifted child, there is one important voice missing in the literature - the voice of the gifted child. In an effort to fill this void, this study asked gifted children to share their actual lived experiences while attending public elementary school in the Pacific Northwest.

The following paper discusses gifted children and the difficulties they experience attending public school. While there are comparisons made between the gifted and other labeled populations in schools (such as Special Education students and English Language Learners), this paper in no way implies one group is more deserving of support than another. On the contrary, all children regardless of label or circumstances deserve a fair educational experience. As Costley (2012) points out, diversity in our classrooms has taken on a whole new meaning that moves beyond race, ethnicity and culture. Academic and behavioral diversity in schools has become a prevalent concern to classroom teachers. Costley says it is more important than ever, with the enactment of No Child Left Behind legislation, to engage all learners in the classroom in an effort to help students reach their full potential. Capturing the lived experiences of gifted children in elementary school is only one step in this process.

According to the August 27, 2007 issue of Time magazine, we have a genius problem. Cloud (2007, August 27) has written an article that hit the cover of Time 
magazine and, to the delight of many professionals working in the field of gifted education, hit the nation with a topic that has historically not been covered in the mainstream press. Cloud writes, "In a no-child-left-behind conception of public education, lifting everyone up to a minimum level is more important than allowing students to excel to their limit" (p. 42). Cloud proceeds to ask the question of why the highest achievers are challenged the least, and discusses the impact this has on America's future. Included in the article are vignettes of children who are gifted and the struggles they have endured to find challenge and support in America's public schools. While this article may be a catalyst for thought about gifted education in public schools, the students profiled in this article have found their enriching and supportive learning environments outside the public school system. These profiled families have made great sacrifices to support their gifted children, but not all gifted students can move from the public sector to the private sector of education. This leaves the need for increased understanding and support within the public school system. Cloud states,

We take for granted that those with IQs at least three standard deviations below the mean (those who score 55 or lower on IQ tests) require "special" education. But students with IQs that are at least three standard deviations above the mean (145 or higher) often have just as much trouble interacting with average kids and learning at an average pace. Shouldn't we do something special for them as well? (2007, August 27, p. 42)

In the March/April 2008 issue of Instructor magazine, the cover is dedicated to an article titled Smart \& Bored: Are We Failing Our High Achievers? Cleaver (2008) has written this article about differentiation in the classroom, as an argument that now is the 
time to reevaluate our teaching methods for engaging our most capable learners. She shares that in December 2007 the Organization for Economic Cooperation and Development reported "...students in the U.S. scored lower than 16 other countries in science and lower than 23 others in math" (p. 30). These are numbers that are reminiscent to comparisons made during the "Sputnik Era" which will be discussed later in this paper, however, the comparisons being made here are more of a tell-tale of the gifted not having the opportunities necessary in public school to excel and achieve at the level they are capable. Cleaver (2008) states, "Ignore high-achieving students and they may end up frustrated, disciplined for bad behavior, or even depressed. At best, they're bored; at worst, they won't make it to graduation" (p. 30).

Both Cleaver (2008) and Cloud (2007) address the necessity of differentiation in the classroom as well as recognizing the additional issues that the gifted face socially and emotionally. They believe gifted students are not given the opportunity to engage in a learning environment that provides challenge and fosters an attitude that school is worth the effort.

Over the past twelve years as a Talented and Gifted (TAG) Specialist I have witnessed a drastic change in the delivery of TAG programming as a result of the national and state educational funding crises. Due to this progressive change, I have witnessed many of the same frustrations as the families profiled in Cloud's article. It is overwhelming how many families who qualify for TAG services in my school district struggle with the same challenges described in these articles. 
Funding for gifted programs is only part of the equation needed to meet all the needs of gifted students. Glass (2004) states, "In this country, the overriding quest for equity has been purchased at the expense of excellence" (p. 28) adding that, America's brightest young people have quit learning. Since curricula have been “dumbed down" to help weaker students, gifted students perceive no need to work in order to achieve or succeed. This policy often amounts to expecting the brightest students to tutor other youngsters while waiting for their own instruction at the expense of their own educational development. (Glass, 2004, p. 28) As Cloud so aptly coined our current education paradigm as a “...no-child-leftbehind conception of public education..." (2007, August 27, p.42), other researchers believe that this new philosophy is creating a new left behind population - the gifted. According to Pfeiffer and Jarosewich (2007), “American society today does not place a high priority on educating its most talented young citizens, even though they will be tomorrow’s leaders” (p. 39). Lee and Olszewski-Kubilius (2006) add ...educators, as well as lawmakers, in this country are less concerned about the education of students with talents than of students with disabilities or issues of underachievement or misbehavior in school; thus, gifted students are vulnerable to not having educational opportunities and programs that match their abilities. (p. 216)

Van Tassel-Baska (2006) articulates that part of the problem with policy makers not prioritizing gifted education programming comes from a lack of credibility due to many misconceptions regarding giftedness. She also states that this lack of credibility is attributable to limited research in this area as well as that "we have failed to convince 
policy makers at all levels of the serious need to view gifted education as an important concern for our society" (p. 199). Due to this lack of convincing, there are political dynamics associated with operating programs for gifted children. Van Tassel-Baska adds:

Charges of elitism and perceived lack of sensitivity to those less fortunate plague program developers at all levels. The specter of No Child Left Behind makes gifted programming even more a pariah as greater emphasis is placed on students who are not performing at adequate levels. (p. 199)

Many districts have had to cut budgets while at the same time develop programming to comply with the rigorous demands of the reauthorization of the Elementary and Secondary Education Act (United States Department of Education, 2002), more commonly known as the No Child Left Behind Act (NCLB). Because of these cuts, many TAG students have been placed full time into the "regular" classroom for their learning experiences without any support from TAG specialists or alternative TAG programming. With this current model of inclusive programming, the delivery of TAG services falls solely on the classroom teacher. According to Rogers (2002) and Story (1985), this means leaving gifted students in the hands of those with the least amount of understanding and/or skills in meeting their unique needs.

Districts often approach NCLB, and the lack of funding that came along with the legislation, with concern, as they make very difficult programming and funding decisions. TAG programs, across the nation and locally, are falling victim to funds being transferred out of gifted programs and into programming for lower achieving students. Requirements for testing all children have resulted in funds being channeled into other 
special education programs dealing with these low achievers (Golden, 2003). The students in TAG programs are feeling the impact as programs are eliminated out of a necessity to free up more funds for remedial and literacy support programs. As Cloud writes,

To some extent, complacency is built into the system. American schools spend more than $\$ 8$ billion a year educating the mentally retarded. Spending on the gifted isn't even tabulated in some states, but by the most generous calculation, we spend no more than $\$ 800$ million on gifted programs. (2007, August 27, p. 42) Dweck (2006) addresses this complacency with her work on the psychology of a mindset. She suggests there are two mindsets that affect the success of individuals. First is the fixed mindset, which she describes as believing your qualities are set in stone and your mission is to repetitively prove this complacency. The second mindset, known as the growth mindset is described as "based on the belief that your basic qualities are things you can cultivate through your efforts" (2006, p.7).

Dweck states, "With the right mindset and the right teaching, people are capable of a lot more than we think" (p. 64). Additionally, Dweck argues:

The fixed mindset limits achievement. It fills people's minds with interfering thoughts, it makes effort disagreeable, and it leads to inferior learning strategies. What's more it makes other people into judges instead of allies...important achievements require a clear focus, all-out effort, and a bottomless trunk full of strategies. Plus allies in learning. This is what the growth mindset gives people, and that's why it helps their abilities grow and bear fruit. (2006, p.67) 
Dweck additionally states, "Since the dawn of time, people have thought differently, acted differently, and fared differently from each other" $(2006$, p. 4). If Dweck is correct in her beliefs, then we have, perhaps, become complacent in meeting the unique needs of gifted elementary students. We can blame a lot of factors for this complacency, such as a focus on No Child Left Behind issues and funding shortfalls, within education. However, if the literature says we need differentiated curriculum and affective experiences to meet the needs of gifted children, why are we willing to remain with the status quo? According to Dweck, (2006) for change and growth, we need to find allies in education and what better allies are there than the gifted children themselves? They are experiencing the phenomenon of being gifted in elementary school and they have the knowledge to best explain how gifted students think, act and fare differently in elementary school. Delisle (2012) adds: "In the quest for solutions to make school as rigorous and relevant as possible, one particular vibrant source of information is often omitted: the opinions of our students" (p. 63).

The researcher suggests it is really only through deliberate dialogue and understanding that the parties involved in educating the gifted child in the elementary school can truly begin to embark on a journey of change in how these students experience school. The catalyst for this new dialogue begins with what gifted students have to say about their experiences and their desired changes (if any) in their overall elementary school experience.

This paper investigated a question that was generated out of a thorough exploration of the literature in the area of gifted education and developed through twelve years of working within the TAG program of a suburban elementary school. 
Additionally, finding the gifted child's voice in answering this question was inspired by numerous 5 through 11 year olds and their families who still wonder why school is such a struggle even though they are smart.

The research question below may seem simple in context; however, it is very complex in terms of thoroughly understanding the answer and influencing the mindset surrounding elementary gifted education.

\section{Research Question:}

- What are the lived experiences of gifted children in the public elementary school setting?

The literature review in this paper says we need a better overall understanding of gifted students so we can recognize their unique characteristics as well as social, emotional and intellectual needs. Finding the gifted child's voice or perspective is one way to inform the literature, the common beliefs, and/or mindsets out there.

Before the above question can be addressed, however, it is important to understand the definitions of giftedness, the historical perspective that underlies gifted education in today's schools, and the role differentiation and affective instruction can play in the elementary classroom for gifted learners. 


\section{Chapter 2-Literature Review}

In an effort to create a solid framework for understanding the current body of knowledge regarding gifted children and their suggested educational experience, the following review of literature includes five sections.

The five areas of review are:

- definitions, historical perspectives and milestones in gifted education;

- differentiation, including definitions and models;

- $\quad$ social/emotional needs and affective characteristics of gifted children, including developmental theory;

- gifted programming and curriculum delivery, including examples and definitions;

- review of gifted studies using phenomenology as a research method.

This research collects and shares the experiences of the gifted child in public elementary school; therefore, this literature review includes a vast collection of information to help understand the gifted child and their experience according to the following researchers and authors.

\section{Definitions, Historical Perspectives and Milestones}

Defining giftedness. Sternberg (2004) argues that one of the most contentious areas surrounding gifted education has been the inability to agree on a definition of giftedness. When a 10 year old girl in Michigan was asked "What do you think being gifted means?" she replied with this:

Being gifted means being able to comprehend and do things the average person does not know how to or does not want to know how to do. Being gifted also 
means having to do harder, more advanced work. To be frank and simple, being gifted is when you're more intelligent than most. (Delisle, 1984, p. 4)

A 12 year old boy, also from Michigan, further articulates the difficulty of defining giftedness:

Gifted is something that is hard to put down in print on paper. It is definitely not, in my mind, someone who is just a straight " $\mathrm{A}$ " student, though that might be one of the criteria. You must have that extra bit more of motivation that most kids don't have. You must be able to grasp complicated concepts and ideas easily and you must be responsible. Giftedness may not be something you always cherish, for it's a burden in many ways. But, being gifted, I find I have that urge to learn. (Delisle, 1984, p. 6)

While it might be understandable that children cannot fully develop an official definition for giftedness, it is amazing the transformation definitions have gone through over the years. There are some constant themes, but each new definition seems to try to incorporate a new aspect of giftedness that further broadens the previous definition.

In 1920, Guy M. Whipple was credited with using the actual term "gifted" to describe children with supernormal ability (Sternberg, 2004). Pritchard (1951) appreciated Leta S. Hollingsworth's definition written in 1931, "By a gifted child, we mean one who is far more educable than the generality of children are" (p. 49). In 1955, A. Harry Passow defined talent as the capacity for superior achievement in any socially valuable area of human endeavor and in 1958, Paul A. Witty recommended that the definition be expanded and that any child be considered gifted whose performance, in a potentially valuable line of human activity, is consistently remarkable (Sternberg, 2004). 
FINDING THE GIFTED CHILD'S VOICE

A report titled Education of the Gifted and Talented Volume 1: Report to the Congress of the United States by the U.S. Commissioner of Education, more commonly referred to as the Marland Report (Marland, 1972), presented the nation's first official definition of the gifted and talented:

Gifted and talented children are those identified by professionally qualified persons who, by virtue of outstanding abilities, are capable of high performance.

These are children who require differentiated educational programs and/or services beyond those normally provided by the regular school program in order to realize their contribution to self and society. (Marland, 1972, p.10)

Children capable of high performance include those with demonstrated achievement and/or potential ability in any of the following areas, singly or in combination:

- General intellectual ability

- $\quad$ Specific academic aptitude

- Creative or productive thinking

- Leadership ability

- Visual or performing arts

- Psychomotor ability (Marland, 1972, p.10).

Renzulli (1978) created an operational definition that is commonly used to define giftedness (see Figure 1). Renzulli proposed that:

Giftedness consisted of an interaction among three basic clusters of human traits: above-average general abilities, high levels of task commitment, and high levels of creativity. Talented and gifted children are those possessing or capable of developing this composite set of traits and applying them to any potentially 
valuable area of human performance. Children who manifest or are capable of developing an interaction among the three clusters require a wide variety of educational opportunities and services that are not ordinarily provided through regular instructional programs. (p. 261)

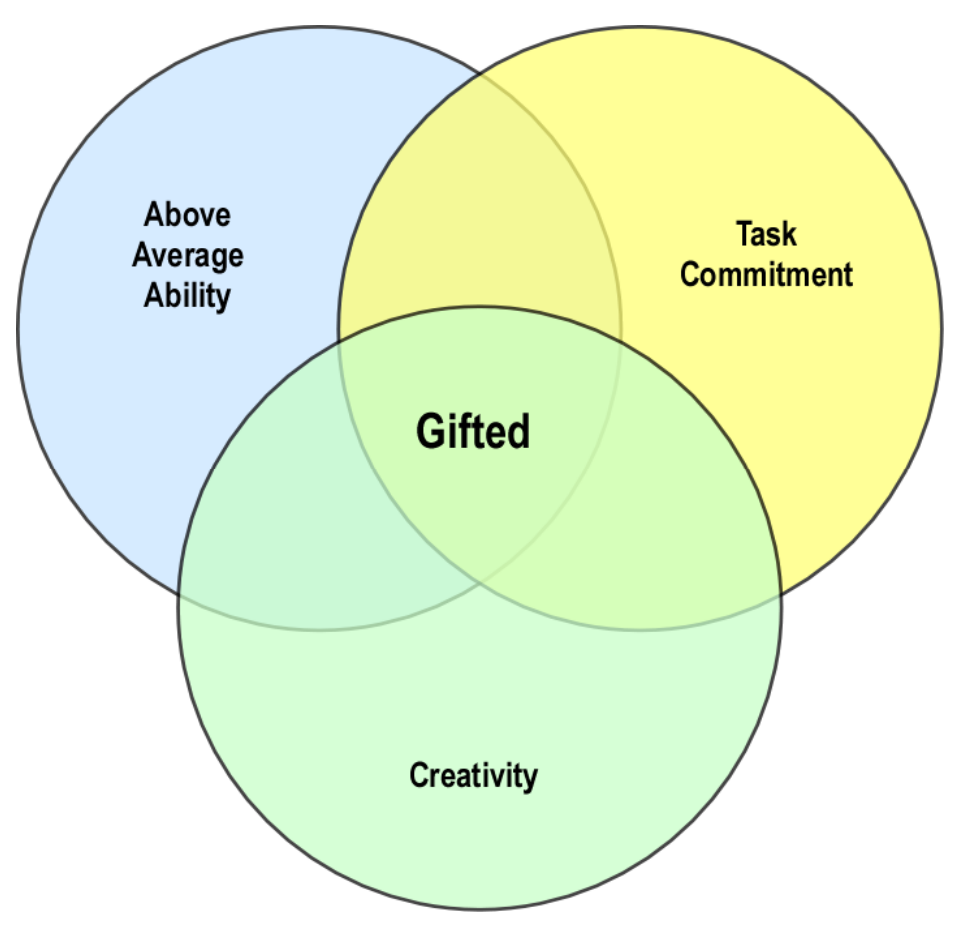

Figure 1. Renzulli's Three-ring Conception of Giftedness illustrates the interaction of human traits found in gifted children. Adapted from Renzulli, J. S. \& Reis., S. M. (1985). The schoolwide enrichment model: A comprehensive plan for educational excellence. Mansfield, CT: Creative Learning Press. Copyright 1985 by Creative Learning Press.

Francoys Gagné (1993) developed the Differentiated Model of Giftedness and Talent (DMGT) in which he posits that gifts and talents are defined differently and should not be lumped together in one definition. According to Gagné (2000) the term giftedness refers to "the possession and use of untrained and spontaneously expressed superior natural abilities" and talent "designates the superior mastery of systematically developed abilities (or skills) and knowledge" (p. 1). He believed that the talent development in children 
occurred at both a micro and macro level incorporating both genetic endowment and the surrounding environmental factors. His model (see Figure 2) shows the interconnectedness of talents, gifts, environment and intrapersonal tendencies.

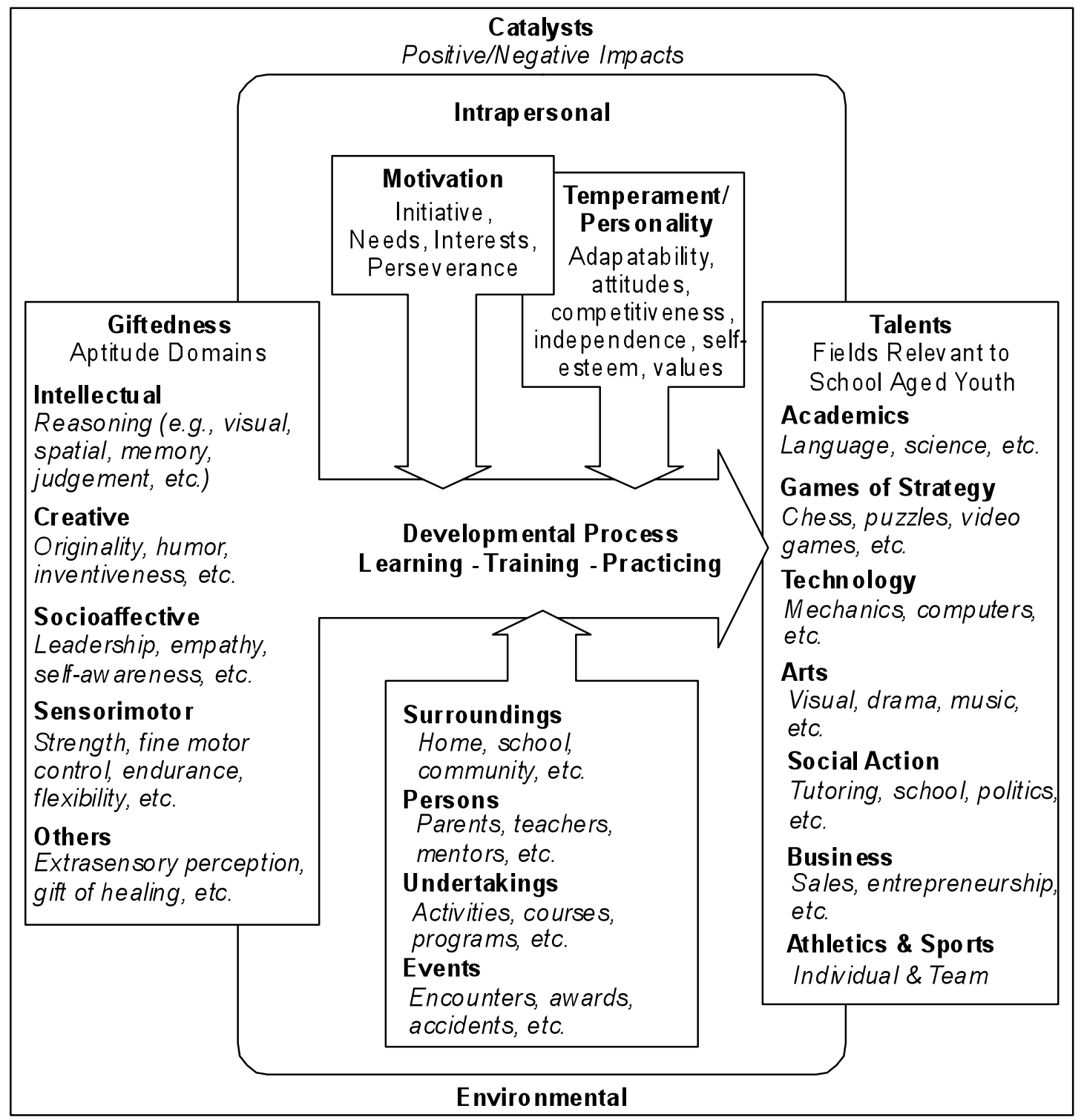

Figure 2. Gagné's Differentiated Model of Giftedness and Talent. This figure illustrates the differences between gifts and talents, while also showing the interconnectedness of environmental and intrapersonal tendencies at play in both areas. Adapted from Gagné, F. (1993). Constructs and models pertaining to exceptional human abilities. In K. A. Heller, F. J. Monks \& A. H. Passow (Eds.), International Handbook of Research and Development of Giftedness and Talent (pp. 63-85). Oxford: Pergamon Press. Copyright 1993 by Pergamon Press. 
In 1993 the U. S. federal definition evolved:

Gifted and talented children are children and youth with outstanding talent performance or show the potential for performing at remarkably high levels of accomplishment when compared with others of their age, experience, or environment. These children and youth exhibit high performance capability in intellectual, creative, and/or artistic areas; possess an unusual leadership capacity; or excel in specific academic fields. They require services or activities not ordinarily provided by the schools. Outstanding talents are present in children and youth from all cultural groups, across all economic strata, and in all areas of human endeavor. (O’Connell-Ross, 1993, p.3)

While each definition has built on previously mentioned characteristics, the movement has been to broaden the definition to include a wider variety of students (Delisle, 2003, Renzulli, 2004, Renzulli \& Purcell, 1996, Sternberg, 2004). The newest definitions include those students who are clearly gifted and those with potential. With a more diverse population included in programs with identification processes using the broader definition, there is a greater need to meet a variety of academic challenges. The need for differentiated curriculum and affective learning experiences seems to be the common thread among these definitions.

Historical perspectives of gifted education. While investigating the definition of giftedness, historically speaking, it is clear there have been concerns about differentiated curriculum and affective learning experiences for the gifted. The perspectives listed in this section reflect over sixty years of discussions relating to the need for different learning experiences for gifted children. 
The National Education Association, in conjunction with the Educational Policies Commission, issued a report with findings that all students should have some experiences that are common because of some generalities amongst children, but that additionally there should be different experiences for those students who warrant them, specifically the gifted (Norton \& Selke, 1950). In 1959, Portland Public Schools issued a report that reflected information gathered over a five year period. This report highlighted concerns regarding the educational experiences of the gifted and recommended programming alternatives for TAG students (Edwards, 1959). Another organization concerned with the education of gifted students, the U. S. Department of Health, Education and Welfare, published a report financed by a grant from the U.S. Office of Education. This report recommended the educational support and experiences of gifted children be further examined (Hall \& Clark, 1960). According to the U.S. Commissioner of Education in 1972, S. P. Marland, Jr., in letters written to Speaker of the House Carl B. Albert and the Honorable Spiro T. Agnew, there was a need for an alternative educational experience for students who are gifted (Marland, 1972). Following these letters is the document titled Education of the Gifted and Talented Volume 1: Report to the Congress of the United States by the U.S. Commissioner of Education. This report not only speaks of the need for changes in how we educate our gifted youth, but it addresses the needs of minority students specifically and how their gifted potential is not being achieved in the current system.

In an effort to get a more current perception on TAG in Oregon, the Oregon Department of Education (ODE) conducted a survey and study of Talented and Gifted students, their parents, teachers, administrators and district supervisors that also 
confirmed the need for differentiated instruction and experiences (Oregon Department of Education, 2004). However, after the survey findings were compiled and reported it was noted that due to state budget restraints there would be no changes in TAG funding or programming at the state level.

After sixty years of reports stating that the educational needs of the gifted are not being met, it would seem that changes in the bureaucracy and current system would be made to address these concerns. Unfortunately, this is not the case and the struggles to meet the potential and educational needs of the gifted student remain. Certain milestones further point to the need of understanding who TAG students are and what their experiences are in elementary school.

Milestones in gifted education. In 1957 a world-wide event occurred and, according to Karnes and Nugent (2004), it brought America to the realization that we might not be the smartest and most advanced country in the world. This event was the launching of Sputnik, a Russian satellite that was officially earth's first artificial satellite. After this historical event, there was a movement to focus on improving the math and science skills of American students. Additionally there were recommendations for local, state, federal, higher education, and private sector initiatives in gifted education (Karnes \& Nugent, 2004).

In 1983 A Nation at Risk (The National Commission on Excellence in Education, 1983) outlined the concerns for the well being of all students in the United States and their educational experience as well as their preparedness to become productive citizens in a competitive world market. This report called attention to the plight of TAG students 
in the United States, reporting that over half the population of gifted students did not show a match in comparable achievement to their tested ability in school.

National Excellence: A Case for Developing America's Talent was the next report to hit the nation in 1993 (O’Connell-Ross, 1993). Again, the general dissatisfaction associated with programming, services and the quality of education for the gifted was highlighted.

In 2002, No Child Left Behind (NCLB) legislation was passed at the federal level (U.S. Department of Education, 2002) and the latest blow to gifted education was delivered. Through this new legislation all previous funding for gifted education was redirected to the Jacob K. Javits Gifted and Talented Students Education Program. This movement of funds created a system in which states had to apply for grants through the Javits program with NCLB restrictions. States without "official" TAG programs at the state level would not be eligible. Oregon has been a state with fluctuation in dollars to fund state level TAG programming. Some bienniums have funded a TAG representative at the Oregon Department of Education; however, in years when that position wasn't funded, Oregon has been ineligible to apply for grants.

According to Karnes \& Nugent (2004) in the United States in 2002, 5\% of the students enrolled in kindergarten through grade 12 were identified as gifted and talented and approximately 11.1 million dollars were spent on these students. The national education budget in 2002 was approximately 56 billion dollars. This equates to about 2\% of the education budget dollars being spent on TAG students (Karnes \& Nugent, 2004). According to the Davidson Institute for Talent Development (2006), in the 2001-2002 school year Oregon had an education budget of approximately 4.5 billion dollars and just 
over $\$ 54,000$ was spent on TAG education, representing approximately less than $1 / 10^{\text {th }}$ of a percent of spending dedicated to TAG programming.

While the past has provided a definition of giftedness, it has not identified or agreed on methods for meeting the needs of talented and gifted students or identifying them for programming. These discoveries, again, force the questions of how do we know what the actual lived experiences of our gifted students are and how do we meet their unique academic, social and emotional needs in the current educational environment?

\section{Differentiation}

Definitions and models. According to Hertzog (1998), "The application of curricular differentiation - providing different learning experiences to a selected group of children, one critical component of gifted education — is perhaps the most debatable issue in the field. Yet, it is the least understood for practitioners" (p. 214). In understanding that regular classroom teachers are becoming solely responsible for the learning needs of gifted students, due to the movement of inclusion for these students, it would make sense that differentiation is something that should be explored and better understood by teachers. What follows is an introduction to the term differentiation as well as some models that are useful for further understanding of this topic.

The term differentiation has evolved over several decades. Tomlinson (2004) offers the following brief history of differentiation. In 1961 Virgil Ward authored what is referred to as the first book on differentiated curriculum. Tomlinson refers to Ward as the grandfather of differentiation for his impact on theory and pedagogical principles. Ward advocated that gifted children be given the opportunity for different processes, products and content of curriculum when learning. He also had a similar philosophy as Dewey, 
whose perspective is explored later in this paper, in regards to the experience of learners. Ward (as cited in Tomlinson, 2004) states,

The education of the gifted child and youth should emphasize enduring methods and sources of learning, as opposed to a terminal emphasis upon present states of knowledge...learning should be conceived as the continuous, ongoing acquisition of data pertinent to problem situations, not as a set of given facts which, it is hoped, will apply to problems that arise subsequently in the life career. (p. 156) While Ward began the important work of differentiation in the field of gifted education, some of his work has fallen under criticism because of his narrow definition of giftedness; however his work is still referred to over 40 years later when creating current day curricular models.

The Marland Report (Marland, 1972) included three characteristics of differentiation for educational programming: gifted children should have the opportunity to be grouped with other gifted students in special classes or resource rooms; students should have access to a differentiated curriculum that promotes higher cognitive processes; and students should be taught using strategies that accommodate both the learning styles and curriculum content needed for gifted children.

In 1976, according to Tomlinson (2004), the Office of the Gifted and Talented defined differentiated education or services as:

...that process of instruction which is capable of being integrated into the school program and is adaptable to varying levels of individual learning response in the education of the gifted and talented and includes but is not limited to: 
FINDING THE GIFTED CHILD'S VOICE

1. A differentiated curriculum embodying a high level of cognitive and affective concepts and processes beyond those normally provided in the regular curriculum of the local educational agency;

2. Instructional strategies which accommodate the unique learning styles of the gifted and talented; and

3. Flexible administrative arrangement for instruction both in and out of school, such as special classes, seminars, resource rooms, independent study, student internships, mentorships, research field trips, library media research centers and other appropriate arrangements. (pp. 81-82)

Looking at the above descriptions, the definition presented by the Office of the Gifted and Talented has similarities with the three characteristics developed earlier in the Marland Report (1972):

Finally, Tomlinson (2004) offers Passow's definition of differentiation: Differentiating curricula for the gifted/talented is essentially a process of individualizing curricula to better match individual and group learning needs, abilities, and styles. For the gifted/talented, "differentiated curriculum" denotes sets of specialized learning experiences, which develop the unique abilities of students identified as "gifted/talented." A differentiated curriculum embodies recognition of differing learning rates, styles, interests, and abilities. Curriculum differentiation aims at eliciting learner responses commensurate with gifts or talents. (p. 83)

Passow's definition (as cited in Tomlinson, 2004) comes from collaborative work with the Curriculum Council, whose mission was to clarify the questions raised by the 
Marland Report (Marland, 1972), and is based on his seven guiding principles of differentiation to be discussed later in this section.

While all of these definitions of differentiation are focused on the gifted, as is this paper, differentiation can take place and look similar with other groups of learners when the unique learning styles and content needs of the group are taken into consideration. There are a variety of models that incorporate differentiation of curriculum and learning experiences.

Tomlinson's Parallel Curriculum (Tomlinson et al., 2002) includes four paralleling curriculums: a) The Core Curriculum, b) The Curriculum of Connections, c) The Curriculum of Practice, and d) The Curriculum of Identity. The Core Curriculum constitutes the national, state or district learning goals and lays the framework for building the other curricula areas. Discovering the interconnectedness of knowledge is found in The Curriculum of Connections. This is the parallel curricula where students explore and describe connections in an effort to develop a deeper or broader understanding of a discipline. The Curriculum of Practice is built off The Core Curriculum, but offers students the opportunity to put into practice what they are learning in situations similar to actual professionals. Students are encouraged to use their knowledge to further contribute to the knowledge base rather than keep their learning to themselves. Finally, The Curriculum of Identity encourages students to explore disciplines that are of interest to them and their surroundings. The Curriculum of Identity focuses on students' goals, concepts of self, and what their contribution to society is currently and what it will be in the future. This model of curriculum incorporates students' learning differences and interests; therefore the experience for each individual 
is differentiated in some way. The parallel curriculum model is extensive and incorporates the entire learning experience for students. Such a model could prove difficult in implementing unless entire schools were willing to take on this philosophy of curriculum delivery. A more manageable approach to differentiation might be found in Passow's guiding principles to differentiation.

Passow (1982), in collaboration with the National/State Leadership Training Institute on the Gifted/Talented, developed the following seven guiding principles to differentiation:

1. The content of curricula for the gifted/talented should focus on and be organized to include more elaborate, complex, and in-depth study of major ideas, problems, and themes that integrate knowledge with and across systems of thought;

2. Curricula for the gifted should allow for the development and application of productive thinking skills to enable students to reconceptualize existing knowledge and/or generate new knowledge;

3. Curricula for the gifted/talented should enable them to explore constantly changing knowledge and information and develop the attitude that knowledge is worth pursuing in an open world;

4. Curricula for the gifted/talented should encourage exposure to, selection, and use of appropriate and specialized resources;

5. Curricula for the gifted/talented should promote self-initiated and self-directed learning and growth; 
6. Curricula for the gifted/talented should provide for the development of selfunderstandings and the understanding of one's relationship to persons, societal institutions, nature, and culture; and

7. Evaluations of curricula for the gifted/talented should be conducted in accordance with prior stated principles, stressing higher-level thinking skills, creativity, and excellence in performance and products (pp. 7-10)

While Passow's guiding principles are similar to characteristics found in Tomlinson's (Tomlinson et al., 2002) curriculum model, they seem to be more practical to implement in schools and classrooms. However, they are only guiding principles and the actual carrying out of these principles is found in practical classroom applications using a variety of differentiation tools.

Winebrenner (2001) offers the following six practical tools for implementing a differentiated curriculum:

1. most difficult first

2. compacting or streamlining curriculum

3. learning stations or centers

4. tiered assignments

5. flexible grouping

6. open-ended lessons

Having students do the most difficult problems first is not only a way to easily pre-assess students, it is also an effective way to move them through material at an accelerated pace if they can prove mastery of the given content. Compacting or streamlining curriculum provides extension activities for students who have mastered content without having to 
complete the regular assignments. Children are provided a choice of how they want to learn and at what level they want to learn about content when learning stations or centers are offered. Tiered assignments, where students work at varied degrees of difficulty on their tasks, offer students the ability to complete products that are appropriate to their knowledge level while the entire class studies the same topic or content goal. The term ability grouping has become politically incorrect (Tieso, 2003); however, grouping students by skill, interest, or learning styles is an effective tool for differentiating curriculum and can be offered in a flexible model so that children have the option or ability to move freely between the different groups being offered in the classroom. Finally, open-ended lessons and activities that have multiple solutions, or no prescribed correct answer, are very effective ways to differentiate learning for all students.

Two frameworks that have proven helpful in creating differentiated activities are Bloom's Taxonomy and Gardner's Multiple Intelligences theory. Bloom's Taxonomy (1994) portrays human thought from the least to the most complex and allows teachers to examine their curriculum to see if the six traits are included in their lessons. The six traits include: knowledge, comprehension, application, analysis, synthesis and evaluation. For gifted children in the classroom it is helpful to incorporate activities that go beyond knowledge and comprehension so they are forced to grapple with synthesizing, evaluating and analyzing material at a higher level. Howard Gardner's (1991) theory of Multiple Intelligences (MI) observes people’s learning through eight lenses: linguistic, logical-mathematical, spatial, musical, bodily-kinesthetic, interpersonal, intrapersonal, and naturalist. Understanding the learning styles of students allows for flexibility in what product they produce to show knowledge, as well as what journey they should take to 
attain that knowledge. Gardner's MI theory is referred to quite often in the area of differentiating curriculum.

The compacting of curriculum, as discussed earlier in the paper under differentiation models, has proven to be not only a viable tool for differentiating curriculum, but also a positive classroom practice leading to lesser frustration for gifted students as well as less work for teachers in the long run. Curriculum compacting is defined by Reis et al. (1998) as: “...a strategy for eliminating curricular material that students have already mastered and replacing it with more appropriate learning activities" (p.105). According to Reis et al. (1998), in a quantitative experimental study, students who were subject to compacting of up to 40 to 50 percent of their curriculum, in the areas of spelling, social studies, science, math and language arts, scored the same as students who completed the entire curriculum. The results of this study help to corroborate that compacting is a realistic tool for differentiation and that the elimination or streamlining of curriculum does not negatively impact assessment results in the long run.

Open-ended activities are another tool often mentioned for differentiating curriculum. Open-ended activities are defined by Hertzog (1998) as ...the potential to differentiate the curriculum through learner responses. Differentiating learner experiences through learner responses...means to differentiate instruction by allowing students to work at their own rates, use their preferred learning styles, investigate their own interests, and produce work commensurate with their abilities. (p. 78)

Hertzog (1998) conducted a qualitative study, using interviews and observations, to investigate the impact of open ended activities on differentiation because she wondered if 
it was a viable tool or not. Interestingly she found that it is a successful tool that leads to higher level thinking, often because the students can guide their own learning experience, and not because the teacher has posed a more difficult learning task. In this study the conclusion would lead to an argument that differentiating curriculum really does not take more time from a teacher. In fact, it could lead to less time spent in preparation and only require the role of facilitator as the student progresses through the activity.

Finally, a study about language arts shows the efficiencies of accelerated and enriched curriculum. According to VanTassel-Baska et al. (2002), accelerated and enriched curriculum are defined as: moving through the curriculum at a faster pace than the typical delivery rate and incorporating higher cognitive questioning and reasoning opportunities above what are offered in the typical curriculum. VanTassel-Baska et al. (2002), using a quasi-experimental design, investigated the impact of differentiated curriculum through the use of accelerated and enriched language arts units with identified gifted students. The researchers discovered that there was a statistically significant difference between their control group and treatment groups, particularly in the demonstration of high-level thinking. Across gender, culture and economical strata, those receiving the accelerated and enriched language arts lessons performed better on the post assessments given to both groups. This study was conducted over a five-year time frame with consistent results, concluding that gifted students performed better on performancebased assessment measures after receiving the advanced and enriched language arts units. While differentiation has been researched for many years in a variety of forms, there is still a need for further study in both the qualitative and quantitative paradigms. As Hertzog (1998) points out, the application of curricular differentiation is one of the least 
understood topics among practitioners in gifted education; however, it is one of the most talked about among all educators as classrooms are becoming more diverse. The need for further research is definitely there, but the dissemination of the findings to practitioners is also critical, so that appropriate curricular and classroom practice evolution can occur.

\section{Social/Emotional Needs and Affective Characteristics}

Social/emotional needs of the gifted: background and characteristics. In the

early $20^{\text {th }}$ century several researchers were beginning to investigate the social and emotional dynamics of gifted children and adults. Delisle (1992) compiled a list of the most influential contributors who laid the foundation for the evolution of understanding the unique social and emotional needs of gifted children. Lewis M. Terman, according to Delisle (1992), is well known in the educational field as the person who revised the Binet test, which led to the Stanford-Binet Intelligence Test—a measurement tool still used widely today. In Delisle's opinion, Terman conducted the most famous longitudinal study of gifted individuals in 1921 (Delisle, 1992). Terman's study found that while the group as a whole was very successful in their life endeavors, there was still a great deal of discrepancy in the degree of success achieved within the group. Through more investigating he found that the most successful individuals were those who were more socially and emotionally well adjusted and, overall, well balanced people (Terman, 1954).

According to Delisle (1992), Leta S. Hollingworth was another individual who began the investigation of social and emotional needs in gifted students in New York in 1922. Delisle (1992) contends that Hollingworth believed in the "emotional education" of students, specifically in four areas: problems of play and friendship, problems 
associated with a lackluster school curriculum, the problem of becoming negative toward authority figures, and the problem of using the intellect to take advantage of others. She believed that precociousness led to vulnerability for children who had an adult's intellect and a child's emotions, so she worked very diligently with her students on the emotionality of being gifted (Hollingworth, 1942). Her work is still widely respected today.

Strang (1951) worked to continue the progress that Hollingworth had made and she focused particularly on the family and home environment adding the following concerns: parental pressure and exploitation, parental indifference and neglect, financial limitations, perfectionism, and parental boasting and possessiveness. Strang's work contributed to the field through "a combination of empirical and anecdotal research of the highest quality" (Delisle, 1992, p. 8).

Virgil S. Ward served as more of a philosopher than a researcher or practitioner to the field of gifted education (Delisle, 1992). However, Ward (1961) believed the schools did not efficiently enhance the students' emotional lives stating, "It is perhaps truer in the area of character development than in any other significant undertaking by the school that the theoretical bases are not understood, the goals are not clarified and the methodology is not explicitly developed" (p. 194). Hollingworth's work was the source that Ward reflected on regularly as he "...stressed the importance of recognizing that gifted children's intellects may outstrip their emotional maturity—so teaching materials and methods must be chosen with this in mind" (Delisle, 1992, p. 9). Ward's book, Educating the Gifted: An Axiomatic Approach, was reissued in 1980 with a different 
title, but very little was updated as Ward believed the content was still applicable and still underutilized in the profession.

The above authors were instrumental in laying the groundwork in understanding the social and emotional needs of gifted children and adults; however, their work has been criticized as having socioeconomic, racial and cultural bias (Delisle, 1992). Other researchers (Barbe \& Renzulli, 1981; Cauley, Linder \& McMillan, 2006; Delisle, 1992; Moon, 2004; Newland, 1976; and Schmitz \& Galbraith, 1985) have taken a critical look at the work of Terman, Hollingworth and Strang. Out of that we now have some clearer understanding and definitions of affective characteristics in gifted students as outlined below.

Affective characteristics. Neihart, Reis, Robinson and Moon (2002) worked to create a chart that lists affective characteristics often found to be associated with gifted children. Not every gifted child possess all of these characteristics, but they may struggle with some listed on the chart. Table 1 is adapted from the chart presented by Neihart et al., (2002) of social and emotional characteristics:

Table 1.

Social and Emotional Characteristics of Gifted Children That May Pose Challenges

- Perceptiveness

- High involvement and preoccupation: need to understand

- Heightened sensitivity

- Perfectionism and need for precision

- Uneven intellectual abilities, even above-average abilities experienced as deficits

- Asynchronous development of physical, intellectual, social and emotional aspects 
- Emotional intensity

- Feelings and early awareness of being different

- Anxiety caused by advanced knowledge

- Need for mental stimulation

- Entelechy - a desire to become all one is capable of becoming

- Nonconformity and questioning of authority

- Excitability and overexcitability

- Tendency toward introversion and internalized locus of control

- Multipotentiality - the ability to succeed in any of several domains, requiring difficult choices

- Tendency toward self-doubt

Note: Adapted from Neihart, Reis, Robinson, \& Moon, The Social and Emotional Development of Gifted Children: What Do We Know?, Waco, TX. Copyright 2002. Prufrock Press, Inc.

All these characteristics have their strengths and drawbacks - the strengths lead to successful citizens, while the drawbacks can lead to isolation, fear of failure and, in extreme cases, dropping out or suicide (Neihart et al., 2002).

Other authors offer further insight into the social and emotional areas that gifted students are associated with, such as: sensitivity to themselves, others and their environment; preference to be with adults or older children; intensity; perfectionism; leadership ability; moralistic views; resourcefulness; and an advanced sense of humor.

Gifted students are often very aware of their environment and the people and happenings within it. Because of their heightened awareness or sensitivity, many gifted students are concerned with the feelings of others as well as the events that transpire 
within their environments. Schmitz and Galbraith (1985) speak of the concomitant problems that arise from gifted students' unusual sensitivity to their environments and others, such as, the vulnerability that comes from the criticisms from their peers, as well as frustration as others fail to maintain the high standards imposed by the gifted student. This vulnerability can lead to self imposed isolation resulting in feeling rejected by others, which can then lead to further inhibited social and emotional growth, and discouragement to develop peer relationships. This sensitivity also impacts students as they care for the feelings of others. In Delisle (1984) a girl writes the following answer to a question when asked if schools should have gifted programs, "Gifted Programs? Yes and no. Yes because it is a good idea for us to understand more and better things. No because the other kids feel like they're completely stupid because they aren't in the gifted class" (p. 21). In this case the young girl is concerned about the others' feelings of being left out and she is willing to compromise her needs and not have a program that she believes truly benefits her learning. That is a pretty tough situation to be put in, particularly in this case, since the child is only 12 years old.

Another affective characteristic of gifted students is that of preferring to be with adults or older children versus their same age peers. A 13 year old girl (in Delisle, 1984) writes, "I feel that I relate to adults relatively better than others my own age. I also feel that I have more ambition than most people my age. On the outside, though, I'm pretty much the same.” (p. 14). This characteristic can contribute to further isolation for gifted students, as they don't fit in with their peers so they tend to migrate towards the attention of adults. In an observation conducted by Kennedy (1995) a student is observed within the context of a heterogeneous classroom filled with 28 students of varying ability levels. 
Kennedy reports on the interactions this young child has with all the people in his environment. As the child proceeds to alienate himself from all the other children through inappropriate classroom behavior, the child then seeks the intellectual companionship of his teacher. Kennedy (1995) points out that this is not an abnormal reaction, as people in general tend to gravitate toward their mental-age peers; however, in this child's case his only success has been with adults, and the underlying issue is that he has no same mental age peers to understand what being a "kid" is really like. While adult interaction is important to fostering curiosity, without the skills to understand like age peers and those peers' perceptions of the gifted child, the gifted child can fall further into isolation and feelings of loneliness (Hollingworth, 1942).

Gifted students are often observed displaying intense efforts when engaged in a project or topic of interest. This intensity comes from goal directed behavior, eagerness, persistence, and concentration and most often is observed when students exhibit a long attention span to an area of interest (Heller, Monks \& Passow, 1993). While this attention span is desirable when a teacher would like a child to complete a task, it can be taken to the extremes in many gifted children. Examples of these extremes are: a resistance to being interrupted, a tendency to neglect duties or other people when their attention is desired, and an increase in isolation from peers when the peers move onto recess and the gifted child chooses to continue working instead of socializing.

Perfectionism is a trait common to gifted individuals that can lead to high performance levels, or to a total inability to perform because of a fear of failure. Schmitz and Galbraith (1985) explain the latter as, "immobilization of action due to high levels of frustration resulting from situations that do not meet expectations of excellence” (p. 40). 
A 12 year old boy writes (in Delisle, 1984), “I'm disappointed when I fail to accomplish something but I try to accept it and try again and again until I get it right. I'm proud of high achievement—who wouldn't be, may I ask? But still, I yearn for higher ones” (p. 41). Expectations by society, school, parents and the child him or herself are often extremely high when the child is labeled gifted, but expecting peak performance is unreasonable (Delisle, 1992) and can lead to, as Schmitz and Galbraith (1985) describe, complete immobilization of the child's ability to perform at any task.

Organizing people and things in a structured and ordered fashion is something many gifted students enjoy. They often like to take the leadership role in their quest to systematize things. This is a characteristic that can prove to be very useful for adults, but in childhood may be difficult for others to swallow (Hollingworth, 1930). Gifted students may be seen as bossy, rude or domineering in their efforts to construct complicated rules or systems (Heller et al., 1993). A delicate balance needs to be maintained when helping gifted students develop this particular strength.

Many gifted students have a strong sense of right and wrong, leading them to become highly moralistic. This conviction can lead gifted students to fight for what they believe in and to defend those who they consider have been mistreated or harmed. However, their moralistic ways can also lead to attempting unrealistic reforms and goals as well as intolerance and lack of understanding from their peer groups (Schmitz \& Galbraith, 1985). These things can lead to further isolation and rejection from their peers and intense frustration that Schmitz and Galbraith say can possibly lead to suicide in extreme cases where frustration has lead to intense depression. 
Resourcefulness and the ability to bring a variety of resources to a problem or situation are characteristics of the gifted. Gifted students often possess an inquisitive attitude and intellectual curiosity, as well as an affinity to search for significance and a willingness to consider the unusual (Heller et al., 1993). Because of these traits, gifted students may question teaching practices and leave out important details as well as resist directions and appear strong-willed (Olenchak, 1999).

Many gifted students have a keen sense of humor, which they can use to amuse others, or in some cases, do harm. In most cases gifted children use their advanced sense of humor to understand teachers' jokes, use puns or create jokes and riddles of their own. A gifted child's sense of humor is often far more sophisticated and insightful than their peers, and due to this advanced level of humor, it is necessary to allow time spent with other gifted children, so this sense of humor can be developed and appreciated. Delisle (1992) and Kennedy (1995) both reflected on Hollingworth's concern with gifted children's sense of humor; Hollingworth spoke of the harmful sense of humor as a form of "extreme or benign chicanery" (1931, p. 13). Her concern was that in some regards this chicanery or trickery is useful in adulthood and in adult pursuits; however, it is both damaging to the gifted child and peers when doled out from children who don't understand the hurt it can wield (Hollingworth, 1931). Hollingworth (1931) recommended that children be taught to understand the impact of their intellectual sense of humor.

The affective characteristics of gifted children have the power to both help and diminish the effectiveness of their cognitive characteristics and strengths (Neihart et al., 2002). It is assumed that all children have a desire to be successful in society and this is 
no different for gifted children (Cross, 2005). In fact this desire may be heightened for gifted students due to the characteristics listed above. Taking this into account, we must figure out how to nurture not only the cognitive intellect of gifted children, but also the social and emotional needs of gifted children as well.

Bronfenbrenner's ecological systems theory. In addition to the gifted students themselves, teachers, parents, peers, and society play important roles in the lived experiences of elementary school students.

Bronfenbrenner presents an accurate picture of how all individuals play a part in the psychological development of children with his ecological systems theory. Bronfenbrenner's (1976) theory focuses on the environment in which the child interacts and the influence of the settings and institutions on the child. He breaks down the environment into four systems - see figure 3. The child is in the center of Bronfenbrenner's concentric circles surrounded first by the microsystem, which is surrounded by, and interacts with, the mesosystem, then surrounded by, and interacting with, the exosystem, and finally the macrosystem encapsulates all the systems and the child (Trawick-Smith, 2006). With this child-centered model, Bronfenbrenner (1976) contends that the larger society has a direct impact on an individual's psychological development. In the microsystem layer of the model, the child interacts with their immediate environment such as school, family, neighborhood or social services. The mesosystem is made up of interactions among the persons or organizations within the microsystem. The exosystem includes influences on the child that may not come into direct contact with the child. Examples of the exosystem could include the school board, mass media, extended family, or community social services. The exosystem may interact 
FINDING THE GIFTED CHILD'S VOICE

through the mesosystem and microsystem to influence the child's development. Finally, the macrosystem encompasses the attitudes and ideologies of the culture. While the macrosystem may seem far removed from the child, its influence through the other systems can have a dramatic impact on a child's life and development (Trawick-Smith, 2006).

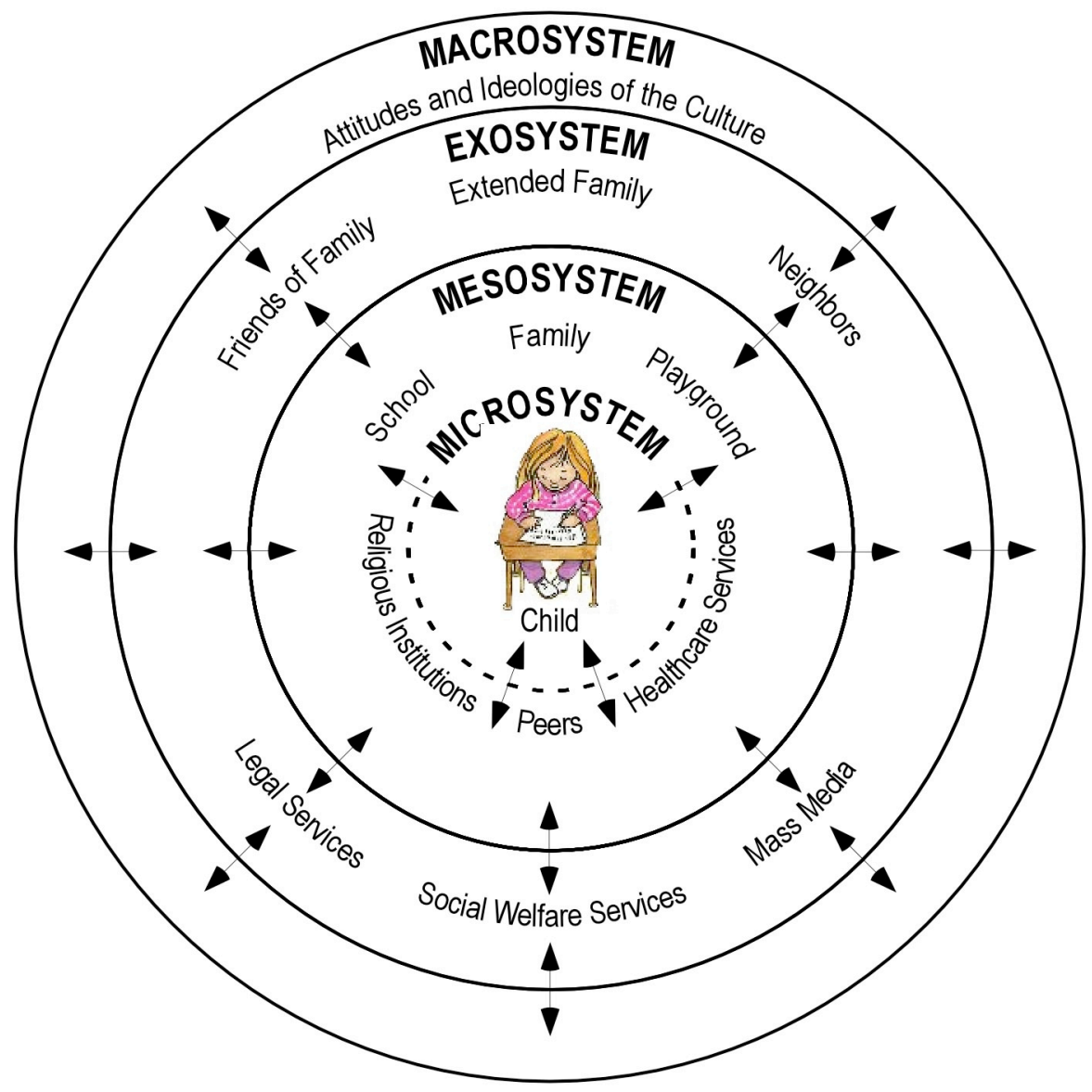

Figure 3. Bronfenbrenner's Ecological Systems Theory. This figure shows the interaction amongst the different systems and how they influence the child at the center. Adapted from Trawick-Smith, J. (2006). Early childhood development: A multicultural perspective. Upper Saddle River: NJ. Copyright 2006 by Pearson Education, Inc. 
Bronfenbrenner's model of ecological systems theory shows the direct impact teachers, parents and peers may have on the social development of a child.

Gifted developmental theories. A Polish psychologist and psychiatrist, Dabrowski (1964), introduced his theory of positive disintegration as an explanation of the emotional development of humans. Dabrowski's (1972) work discovered a phenomenon he called "superstimulatability" which has been further translated into “overexcitability." According to Silverman (1994), "The overexcitabilities (OEs) may be thought of as an abundance of physical energy, heightened acuity of the senses, vivid imagination, intellectual curiosity and drive, and a deep capacity to care" (p. 110). Grant and Piechowski (1999) believe that Dabrowski's theory is based on his belief that the most important dimension of human life is emotional development.

Dabrowski's (1964) theory is broken down into five levels: primary integration, unilevel disintegration, spontaneous multilevel disintegration, organized multilevel disintegration, and secondary integration. Dabrowski's levels are not stages of development, but are more of a continuum beginning with the egocentric (low level) to the altruistic (high level) (O’Connor, 2002).

Piechowski (1997) has done a good job in condensing and organizing Dabrowski's levels into more manageable descriptions:

Level I: Primary Integration. Egocentrism prevails. A person at this level lacks the capacity for empathy and self-examination. When things go wrong, someone else is always to blame; self responsibility is not encountered here....

Level II: Unilevel disintegration. Individuals are influenced primarily by their social group and by mainstream values... They often exhibit ambivalent feelings 
and indecisive flip-flop behavior because they have no clear-cut set of selfdetermined internal values. Inner conflicts are horizontal, a contest between equal, competing values....

Level III: Spontaneous Multilevel Disintegration. The person develops a hierarchical sense of values. Inner conflict is vertical, a struggle to bring up one's behavior to higher standards. There is dissatisfaction with what one is, because of a competing sense of what one could and ought to be (personality ideal)....

Level IV: Organized Multilevel Disintegration. Individuals are well on the way to self-actualization. They have found a way to reach their own ideals, and they are effective leaders in society. They show high levels of responsibility, authenticity, reflective judgment, empathy for others, autonomy of thought and action, self-awareness....

Level V: Secondary Integration. The struggle for self-mastery has been won. Inner conflicts regarding the self have been resolved through actualization of the personality ideal. Disintegration has been transcended by the integration of one's values into one's living and being. (p. 374)

The breaking down of the current level personality attributes with the replacement of a more desirable or higher-level personality attribute is what Dabrowski called positive disintegration (O’Connor, 2002). Moving from one level to the next is not guaranteed and advancement to higher levels “is contingent upon one's original endowment of intelligence, special talents and abilities, will to develop, and five forms of experiencing [what Dabrowski] called overexcitabilities" (O'Connor in Neihart, Reis \& Moon, 2002, 
pp. 53-54). Piechowski and Cunningham (1985) explain Dabrowski's overexcitabilities as he broke them down into five forms:

Psychomotor overexcitability. Is an organic excess of energy or heightened excitability of the neuromuscular system. It may manifest itself as a love of movement for its own sake, rapid speech, violent or impulsive activity, restlessness, pressure for action, and drivenness. It may be viewed as a capacity for being active and energetic....

Sensual overexcitability. Is expressed in the heightened experience of sensual pleasure, the seeking of sensual outlets for inner tension. Beyond desires for comfort, luxury, stereotyped or refined beauty, the pleasure in being admired and being in the limelight, sensual overexcitability may be expressed in the simple pleasure derived from touching things...or the pleasure of taste and smell....In short, it is a capacity for sensual enjoyment....

Intellectual overexcitability. Is to be distinguished from intelligence. It manifests itself as persistence in asking probing questions, avidity for knowledge and analysis, preoccupation with theoretical problems. Other expressions are: a sharp sense of observation, independence of thought (often expressed in criticism), symbolic thinking, development of new concepts, striving for synthesis of knowledge, and searching for truth.... Imaginational overexcitability. Is recognized through rich association of images and impressions, inventiveness, vivid and often animated visualization, use of image and metaphor in verbal expression.... Intense living in the world of fantasy, 
FINDING THE GIFTED CHILD'S VOICE

predilection for fairy and magic tales, poetic creations and dramatizing to escape boredom are also observed....

Emotional excitability. Is recognized in the way emotional relationships are experienced, and in the great intensity of feeling and awareness of its whole range. Characteristic expressions are: inhibition (timidity and shyness) and excitation (enthusiasm), strong affective recall of past experiences or concern with death, fears, anxieties, or depression. There may be intense loneliness, an intense desire to offer love, a concern for others. There is a high degree of differentiation of interpersonal feeling. (pp. 154-156)

According to O'Connor (2002), mainstream psychology finds Dabrowski's theory to be controversial because he refers to neurotic symptoms as signs of emotional development and suggests that overexcitabilities may be a positive attribute. Nelson (1989), however, believes that Dabrowski's theory may very well be a "framework for understanding and explaining the developmental patterns and challenges that occur for those of high ability" (p. 11).

According to many in the field (Lewis, Kitano, and Lynch, 1992; Lovecky, 1992; Piechowski, 1997; and Silverman, 1993), overexcitabilities can go beyond the positives of the personality characteristics and can make individuals feel more alienated by those who don't understand their unique personality traits. In an effort to conform, Lewis et al. (1992) say that those who experience overexcitabilities often attempt to control or hide their intensities and sensitivities. Additionally, Silverman (1993) suggests that those who feel deeper than others often feel frightened and are painfully aware of their emotional 
differences. Finding the gifted child's voice in the elementary setting can further inform this debate.

Asynchronous development. The framework of asynchronous development offers insight into the unique developmental patterns of gifted children. According to Silverman (1997), Leta Hollingworth was a pioneer in trying to understand the inner gifted child and the incongruent developmental path between intellect and emotions. She studied the psychology of being gifted and found that many gifted children struggle in social situations often leading to isolation (Silverman, 1997). In one study Hollingworth (1939) found that children with high IQs (above 160) rarely played with other children "because the difficulties of social contact are almost insurmountable" (p. 588). Hollingworth's (1931) concern with the contrasting development between a child's intelligence and their emotions led to this statement:

To have the intelligence of an adult and the emotions of a child combined in a childish body is to encounter certain difficulties. It follows that after babyhood the younger the child, the greater the difficulties, and that adjustment becomes easier with every additional year of age. The years between four and nine are probably the most likely to be beset with the problems mentioned. (p. 13) Terman (1931) adds:

Precocity unavoidably complicates the problem of social adjustment. The child of eight years with the mentality of twelve or fourteen is faced with a situation almost inconceivably difficult. In order to adjust normally such a child has to have an exceptionally well-balanced personality and to be well nigh a social genius. The higher the IQ, the more acute the problem. (p. 579) 
Hollingworth (1942) also added, "The more intelligent a person is, regardless of age, the less often can he find a truly congenial companion" (p. 253).

Silverman (1994) agrees that children who have the emotions of a child and the intellect of an adult are likely to have difficulties socially and academically. The term to explain the disparities between a child's chronological age, their intellectual age and their emotional age is asynchrony. In 1991, The Columbus Group, a group of practitioners, parents and theorists built upon the theory of Dabrowski and added a new definition of gifted:

Giftedness is asynchronous development in which advanced cognitive abilities and heightened intensity combine to create inner experiences and awareness that are qualitatively different from the norm. This asynchrony increases with higher intellectual capacity. The uniqueness of the gifted renders them particularly vulnerable and requires modification in parenting, teaching and counseling in order for them to develop optimally. (The Columbus Group, 1991)

They believed that asynchrony is a universal characteristic of the gifted. Asynchronous development is a conceptual framework that helps to explain or rationalize the out of synch feelings of gifted children. Tolan (1989) explains asynchrony as:

In terms of development chronological age may be the least relevant piece of information to consider. Kate, with an IQ score of 170, may be six, but she has a "mental age" of ten and a half. ...Unfortunately, Kate is an amalgam of many developmental ages. She may be six while riding a bike, thirteen while playing the piano or chess, nine while debating rules, eight while choosing hobbies and 
FINDING THE GIFTED CHILD'S VOICE

books, five (or three) when asked to sit still. How can a child be expected to fit into a classroom designed around norms for six year olds? (p. 7)

According to Morelock (1996), Vygotsky addressed asynchrony through his Zone of Proximal Development framework, adding:

Vygotsky saw emotional and cognitive development as interrelated, with children's ability to respond emotionally to abstractions intimately linked with the gradual course of cognitive development spanning the childhood years. This is a developmental progression that takes place precociously and at an accelerated rate in gifted children. (p. 11).

Taking a look back at the literature addressing asynchrony and realizing the social and emotional impact the environment has on a child, it is helpful to revisit the work of Bronfenbrenner. According to Cross $(2001,2005)$, schools have two common goals: acculturation into the mold preferred by policy makers and fulfilling the hopes of parents who believe a good education will improve their child's lives. If we take a look at a gifted child's life using Bronfenbrenner's (1976) ecological systems theory, we see that the gifted child's elementary school experience is bigger than just education. Cross (2005) writes:

... a gifted adolescent who lives with his or her family and attends a local school (microsystem), may see his or her school friends in church or in the neighborhood (mesosystem), learns from mass media about stereotypes he or she should hold (exosystem), all within the framework of Christian capitalism, the dominant ideology of our country (macrosystem). The public schools in the United States have been described as anti-intellectual environments (Howley, Howley, \& 
Pendarvis, 1995), an attitude promoted in the exosystem, dealt with directly in the mesosystem and perhaps causing conflict daily in the microsystem. (pp. 122-123) When gifted students are conflicted between these different layers of their environment, due to their unique characteristics, it makes it difficult to "understand" what experience exactly is appropriate.

According to Silverman (1994), asynchrony is a term without a great deal of empirical research behind it; however, it does provide a meaningful framework to help explain and understand the many social and emotional issues faced by gifted children. While the previous section illustrates a helpful framework, the participants in this study will only be sharing their lived experiences versus an in-depth measurement or comparison of their intellectual and chronological ages; therefore, asynchronous development will not be an area that is explored. This information was only provided for a thorough context in which to understand giftedness.

\section{Gifted Programming/Curriculum Delivery}

Providing an “emotional education.” Delisle (1992) speaks of Hollingworth's dedication to providing an "emotional education" to her gifted students as one of her biggest assets. Delisle (1992) recounts a study conducted by Renzulli and White (1987) where Hollingworth's students were contacted and as 60 year olds, they told stories of how Hollingworth's instruction provided them with attitudes about learning that they could have never gotten in a regular classroom. What can teachers do in their classrooms to provide the same support that these 60 year olds felt so long ago?

In Delisle's (1984) book, Gifted Children Speak Out, an eleven year old boy writes, "Teachers encourage originality and creativity, stimulate your imagination and 
care about you personally as well as schoolwise. They understand you're not perfect. They are friendly; they smile and make you feel good and happy. Teachers can help" (p. 55). The words of children have a great deal of wisdom and impact when you truly look deep into the meaning of their statements. This 11 year old has given us the recipe to what makes him feel safe in school, emotionally and intellectually.

Educational personnel serve a variety of roles in gifted students' lives, such as advocate/ombudsperson, consultant, diagnostician, listener, adviser, instructor, facilitator and role model (Van Tassel-Baska, 1983). Van Tassel-Baska (1983) says one of the most important things a teacher can do is help gifted students understand themselves and this is possible by using teaching methods that enable students to engage in activities that help them deal with problem solving, interpersonal relationships and value judgments.

According to Johnson (2000), there are five recommendations for teachers in meeting the social and emotional needs of gifted children: teachers must motivate their gifted students; schools must create an atmosphere of excellence, not perfection, to help gifted students be realistic in their outlook on accomplishments; communication between the adults who work with gifted students must be open, frequent and encouraged; teachers must take the time to know the gifted child's personality, interests and needs; and teachers need to design curriculum that specializes in enhancing self-concept.

The underlying common message from a variety of researchers (Cauley, et al., 2006; Cross, 1997; Delisle, 1992; Gust, 1996; Johnson, 2000; Kennedy, 1995; Moon, 2004; Van Tassel-Baska, 1983) is that teachers will be most successful in helping gifted students reach their fullest potential and meeting their social and emotional needs if they take the time to know their students. Teachers must make the effort to go beyond talking 
to the student and understand the entire life experience the child is having, including communicating with the child's family and any other adults who interact with the child on a regular basis. Without this extra effort, it is possible that teachers can miss hidden information that the gifted students are withholding in an effort to fit in at school and home, therefore leading to feelings of isolation and loneliness.

Story (1985) characterizes the role of the teacher as a facilitator of learning and Silverman (1983) states that successful teachers of the gifted provide for student involvement and do less talking; therefore, allowing students to think for themselves.

Delivery of TAG services. There is a debate around the identification of gifted students and what programming is most beneficial for gifted children. According to Renzulli (2004), the debate begins with two different paradigms of measuring and servicing gifted students. The positivist or conservative paradigm believes that giftedness is an absolute and can be measured. Conservatives have the appearance of objectivity on their side; they also appeal to regulation writers and those who like the administrative "tidiness" of cut-off test score approaches. In contrast, in the post modern or developmentalist paradigm it is believed that giftedness is something that is developing and changing at all times, therefore not a constant that can be easily measured. Renzulli (2004) states, "Developmentalists... believe that giftedness is not fixed in an individual, but rather is developed in certain people (not all people), at certain times (not all the time), and under certain circumstances (not all circumstances)" (p. xxvii).

Both the conservative and developmentalist paradigms imply a variety of gifted programs and service delivery models. However, the funding crises in education has had 
more of an impact on what TAG programming schools can provide as budget cuts have eliminated many TAG Specialists in school buildings.

Defining inclusive and exclusive TAG programming. Inclusive programming became more prominent with the passage of the Individuals with Disabilities Education Act (IDEA) in 1975. According to IDEA, talented and gifted students are afforded the same protection as all children classified as special education students. IDEA's passage required that:

All children with disabilities must be referred, evaluated, and determined to be eligible or not; all eligible students must have IEPs [Individualized Education Program]; and all must be provided with a free, appropriate public education, meaning they must be served in the least restrictive environment. (Smith, 2005, p.

Including special education students in the public school system, as well as the mainstream classroom, included an integration of TAG students, because in most states and districts, administratively, TAG falls under the special education umbrella. In cases where no previous TAG programming was provided, IDEA brought attention to gifted students' educational needs and addressed their inclusion in the regular classroom. An inclusive programming model consists of two service delivery methodsfully inclusive programming or pull-out programming (Maker \& Nielson, 1995). For students being serviced in a fully inclusive model, the classroom teacher assumes the responsibility for delivery of curriculum at the students' appropriate rate and level. The rate represents the speed that a child progresses through the curriculum. The level represents a grade level equivalency where learning occurs, for instance they may be 
learning Social Studies material at the $3^{\text {rd }}$ grade level, but their reading level is at the $10^{\text {th }}$ grade level. In both instances, the classroom teacher is responsible for accommodating the gifted child's specific academic needs.

Students who are receiving services through a pull-out model are similarly taught as those in a fully inclusive model with a few minor changes. Students are offered enrichment activities to complement regular classroom curriculum (material that extends or enriches the curriculum being taught in the regular classroom), and acceleration (moving students through material faster than their peers in the regular classroom) is also a possibility in small group pull-outs. The term pull-out refers to the students being removed from the regular classroom to work with like peers or individually. The pullouts are usually facilitated by a TAG specialist or coordinator in the building and may involve transporting students to a different building. With this model, pull-out programming can be delivered as either a full day pull-out or sporadic pull-out model, which happens throughout the school day. This form of programming is becoming less frequent as budget cuts eliminate TAG Specialists and coordinators from buildings (Cloud, 2007).

An exclusive programming model consists of students who are taught with only alike peers and accelerated through curriculum or offered an entirely different curriculum than what is offered in the regular classroom. Currently, the most likely exclusive programming environments are found in magnet, charter, or private schools (Cloud, 2007).

Whether a school district is using an inclusive or exclusive TAG programming model is dependent on a variety of factors; however, it is important to note that in either 
delivery model, according to Cloud (2007) and Cleaver (2008), the use of differentiated and affective curriculum is a necessity.

John Dewey, many years ago, made the following statement that sums up the delivery of curriculum quite nicely:

...the educator cannot start with knowledge already organized and proceed to ladle it out in doses.... No experience is educative that does not tend both to knowledge of more facts and entertaining of more ideas and to a better, a more orderly, arrangement of them. (Dewey, 1938, p. 82)

Dewey's challenge of not ladling out education is the perfect foundation in which to build an understanding of the lived experiences of gifted elementary school children. Are gifted students experiencing differentiation and affective curriculum delivery in their current model of gifted programming? This is an important question.

\section{Phenomenology}

Gifted studies using phenomenology. When using a phenomenological research method, it is possible to extract and analyze the lived experiences of the participants. In the following studies phenomenology allowed the researchers the ability to understand a phenomena, in these cases giftedness, and discover how this phenomena plays a role in the experiences of the participants.

Schultz (2002a) conducted a study on underachievement in gifted students. His argument was that most research around underachievement sought to find a solution to how to mold the underachieving gifted student into a program that is already in place versus molding a program to fit the needs of the gifted student. He states, "In most instances, research is done on the researched, rather than with them" (p. 193). After a 
thorough analysis of the literature surrounding underachievement, Schultz (2002a) suggests that a broader perspective of research methods could help to understand underachievement in gifted students. One of his suggestions is to use a phenomenological approach. According to Schultz, "This approach contributes a 'voice' to the literature base in gifted education that historically has been methodologically ignored...” (2002a, p. 200). While this study is interested in the underachievement of the gifted child and the documented tendency to try to fix their underachievement by changing the child versus the approach, the focus is on finding a research method that goes from measuring the child's performance to giving the child a voice in what works for them. Therefore, while Schultz suggests phenomenology as one of the alternative research methods, he does suggest others as well, in the qualitative study of gifted students. He adds,

"The breadth and depth of understanding to be gained from qualitative designs far outweigh the eloquence and clarity of statistical analysis and provide context when considering whether or not the statistics from one study mean anything in other educational settings.” (Schultz, 2002a, p. 205).

Finally, Schultz (2002a) shares his hope to move from fixing the underachieving gifted child or conforming them into a set system and, instead, opening a dialogue between the gifted student and those who are trying to meet their unique needs.

After advocating for phenomenology as a research method, Schultz (2002b) used this methodology to study two underachieving gifted learners. While the participants are in high school not elementary, the methodology and outcomes of the students are pertinent to this study. In the phenomenological case study that Schultz conducted, it was 
concluded, from the students' perspectives, that they were not underachieving, rather the school was under serving them. After defining underachievement and gifted underachievement, Schultz (2002b) describes his use of a phenomenological study as a method of allowing for the students' voices and the documenting of the students' lived experiences. After developing themes from the data collected from the students, such as fitting in, the classroom experience and teachers; he concluded that what the students wanted and/or needed was to be heard in regards to feeling that their unique needs were not being met in the educational setting. Or, as Schultz put it, "School should be a reflection of life - with all the stakeholders involved as a community of learners; rather than the common hierarchical structure pervading much of the system that ignores the individuals engaged in the education process" $(2002 \mathrm{~b}, 210)$. In an effort to change the educational environment they were in, these two students shared their lived experiences and offered their voice to the discussion. This is a perfect example of the impact phenomenology can have for both researchers and participants.

Huff, Houskamp, Watkins, Stanton, and Tavegia (2005) conducted a phenomenological study with parents of gifted African American children in an effort to collect data regarding the experiences their children had both academically and socially at school. While this study takes the parents' perspective of the lived experiences of gifted African American students, it illustrates the dynamic of phenomenology and this research method's ability to collect voices from its participants. The participants were given a demographic questionnaire and met with the interviewer for one interview that lasted 6090 minutes. After outlining the specific needs of this population, Huff et al. found that themes of lack of adequate support, parental factors, social isolation and racism emerged. 
This data was collected through interviews, usually conducted at the family's home. The data concluded that parents felt frustrated with a lack of rigor in their child's classes and the inability of teachers to understand the special needs of the gifted child; adding that the teacher often has to spend most of their time with children with significant behavior or learning problems. The parents also felt the gifted programming was lacking in both funding and in the amount of pull-out programming as well as overall options available to gifted students. Additionally, parents felt their child's teachers were not prepared with the knowledge and understanding of a gifted child and their unique needs as well as the African American culture; therefore, the teachers often misunderstood their child's behavior or interest level. Parents also reported a tendency towards social isolation as their children tried to assimilate both culturally and academically and did not fit in because they were smart. This isolation was both self and culturally imposed. Huff et al. (2005) concluded that parents expect teachers to understand the unique needs of their gifted children and "If they [school districts] continue to overlook the gifted children in their classrooms and give scant attention to the needs of these children and their families, these families will look for alternative schooling options for their children" (p. 221).

Cross, Stewart and Coleman (2003) conducted a phenomenological investigation with students in an elementary magnet school. Cross et al. used phenomenological interviews with gifted children in grades 1-6 to try to capture their lived experience in an elementary magnet school.

The interviews were conducted at the participants' magnet school and varied in length from 20 minutes with 6 year olds to 60 minutes with 12 year olds. The goal of the research was to gather actual lived experiences from the participants, not what they 
thought about the experiences; therefore, they began their interviews with "When you think of your experience of being a student in the [name of program], what stands out in your mind?" This question began a dialogue between the researchers and participants that informed the following research questions:

- "What is the lived experience of attending an elementary magnet school for academically gifted students?”

- "Are there beneficial components to the magnet school experience that could inform practice in other settings?"

- "How does the magnet school experience compare with the experiences in traditional school settings?” (Cross et al., 2003, p. 205).

Through the phenomenological interviews, four themes developed from the data: others, role, personal development, and time.

In regards to others, the gifted students quickly articulated the awareness of other people and this included students, parents and teachers. This awareness was comprised of both positive and negative examples, such as other students sharing common interests and the feelings of being rejected by a clique; in both areas the perspectives fluctuated depending on the age of the participant. Younger students found more positives in their interactions with others, while older students were more aware of other's expectations, fitting in and academic competition.

The second theme that emerged was that of the gifted child's role. The participants had an awareness of being gifted and what that might mean in regards to expectations and a sense of responsibility in being gifted. These participants attend a gifted magnet school, but many of the students spoke of the negative stigma associated 
with being gifted when they attended previous heterogeneous schools. The social stigma of being gifted resonated amongst the participants less if they had attended the magnet school their entire academic career, stating they didn't feel as different as their peers who described feeling different from others while attending a heterogeneous school.

The participants expressed awareness of personal development throughout the interviews; therefore the third theme of personal development emerged. The students were aware of their abilities, liked to learn new things, and understood that not all students are alike. They set goals and expressed concern or stress related to the elevated expectations they, or others, had for them.

Finally, the theme of time developed as the participants brought up conceptual examples of time flying by or preparing for future goals or experiences as part of their experiences as a student in the school. While time was a theme that emerged and seemed to impact how the participants described their goals, the researchers listed it last as they thought it was possible that all students experience time similarly and it may not be unique to these participants.

Overall, Cross et al. (2003) concluded, "The experience of Others was the most figural aspect of attending the magnet school for academically gifted elementary students" (p.214). Gifted students attending the magnet school exhibited characteristics that are listed in the above literature review and those characteristics play a role in the social schema within the school. They have fears of feeling different, fitting in and meeting other's expectations; however, they also have a homogenous environment of gifted students and feel the support of understanding from their peers as they develop socially and academically. 
In all the phenomenological studies detailed above, the common thread is the gathering of lived experiences through bringing forth participants' voices. The researchers took the shared experiences, developed themes to create understanding and allowed for the participant's voice to tell the story. Finding the gifted child's voice in the public elementary school setting will allow those interested to compare their lived experience to what literature suggests they should experience and this will expose all of us to a better understanding.

\section{Conclusion}

As the literature review shows, since the early $20^{\text {th }}$ century researchers and authors have debated over the definition of giftedness, have discovered gifted children have unique and defining characteristics, and have developed many ideas on how to best meet the unique needs of gifted children. However, research that focuses on the gifted elementary aged child's lived experience is underrepresented, with the exception of the study conducted by Cross et al. (2003) in which they interviewed elementary aged gifted children attending a magnet school. Therefore, there is a need to hear the gifted child's stories of their lived experiences in the public elementary school to further inform, educate and influence the body of knowledge. 


\section{Chapter 3-Methodology}

As mentioned in the introduction, there are many perceptions regarding gifted education and gifted children. The underrepresented perspective or voice of the gifted child is the one that is missing from the literature. The literature review focuses on adult perceptions that indicate gifted student's unique needs are not being adequately met in public elementary schools and, as the researcher for this study, I must disclose that was also my initial perception. However, there are some people out there who believe that gifted education is not needed because a smart student will do fine in school without any additional help. In other words, their perception is the gifted have the advantage of being smart, so no other programming advantage is needed. I am curious as to what the gifted child's perception is; therefore, I want to know, "What are the lived experiences of gifted children in the public elementary school setting?"

In an effort to answer the above question, the following chapter includes these sections:

- An introduction to phenomenological methodology;

- The purpose of the study and rationale for type of research;

- The study participants and participating school;

- Data collection: including the Epoch process, interviews, data collection timeline, data analysis, and ethical considerations.

\section{Phenomenological Methodology}

I would argue, as would Sokolowski (2000), that perceptions are multifaceted. Sokolowski uses the example of a cube to make his point. When looking at a cube, there 
are the sides or faces we can see and those are the sides or faces we may be perceiving; however there are other sides or faces that make up the entire cube and those are important to understanding the fullness of the cube. While the cube is only showing us certain sides, we, as observers, will often use the absent sides to create a full perception of the cube using our self-imposed intentions of what the absent sides look like.

If the same analogy is used for gifted students, it illustrates how important it is to find their voice in helping us to understand the many facets of a gifted student and their lived experiences. They may show their math side in class, but there are also the sides of their cube that struggles with perfectionism or friendships and all these facets can influence that math experience in the classroom. To the outside observer, the struggles with friendship or perfectionism are not factored into the gifted child's school experience if our imposed intentions state that the gifted child has an easier school experience than the typical student. Therefore, Sokolowski (2000), says, "Perception...involves layers of synthesis, layers of manifolds of presentation, both actual and potential" (p. 20). That is why phenomenological research methods are the best choice for answering the research question posed in this paper.

According to Sokolowski (2000), "Phenomenology is the study of human experience and of the way things present themselves to us in and through such experiences" (p. 2). He adds, "Phenomenology is a significant philosophical movement because it deals so well with the problem of appearances. The issue of appearances has been part of the human question from the beginning of philosophy" (p. 3). By finding the gifted child's voice through their lived experiences, we can begin to appreciate the many facets that are unseen to the uninformed observer. Chapter Four shares findings that 
illustrated this point for me as I felt I was an informed observer; however, I really didn't fully understand the participants in this study. I was closest to knowing Wilma and Theo, but there was a lot more to Finn and Trudy (all names are pseudonyms) than I had imagined. This will be discussed further in the following chapters.

Descriptive versus Interpretive approach. Before further discussion continues, however, it is important to point out that phenomenology is a complex method that encompasses multiple approaches. The two most common approaches are descriptive or eidetic phenomenology and interpretive or hermeneutic phenomenology (Cohen \& Omery, 1994). Both approaches are derived from the field of philosophy and the work of Edmund Husserl who was a German philosopher and mathematician in the late 1800's through the early 1900's. Husserl is credited as being the founder of phenomenology as a descriptive approach for studying lived experiences (Wojnar \& Swanson, 2007). According to Lopez and Willis (2004), a student of Husserl challenged some of the assumptions put forth by Husserl and made a movement towards a more interpretive research tradition. Heidegger was this student and his phenomenological approach is also known as hermeneutic.

Both approaches rely on the qualitative, in-depth interview to generate data (Lopez \& Willis, 2004) and both approaches emphasize the importance of understanding lived experiences (Wojnar \& Swanson, 2007). However, Wojnar and Swanson (2007) offer the following key distinctions:

...in the emphasis on describing universal essences (descriptive) versus understanding the phenomena in context (interpretive); viewing a person as one 
representative of the world in which he or she lives (descriptive) versus a selfinterpretive being (interpretive); and an assumption that self-reflection, and conscious stripping of previous knowledge, help to present an investigator-free description of the phenomenon (descriptive) versus the assumption that as prereflexive beings, researchers actively co-create interpretations of the phenomenon (interpretive). (p. 175)

These differences are important to note for this paper, so that the reader is made aware of the researcher's use of a descriptive approach and can move toward the following discussion using the descriptive phenomenological lens.

\section{Purpose/Rationale}

Purpose of study. From the survey of the literature in the previous chapter, there appears to be a continued need to qualitatively investigate the social, emotional and intellectual experiences gifted children are having in today's elementary schools. While several researchers and practitioners have grappled with this topic, very little researchbased information is available to thoroughly understand the gifted child's school experience particularly in the realm of social and emotional needs and from the gifted child's personal perspective. If the literature search is narrowed to qualitative research, the number of studies is even smaller.

To assert that more research is needed in this area, Coleman, Guo, and Dabbs (2007) discuss a 2002 computer search and later a manual search of journals where only 124 articles were found to truly be qualitative studies in gifted education. Qualitative research helps us to understand the "because of" and "in order to" of the subjects being 
studied versus the "if...then" predictability of quantitative methods (Coleman, et al., 2007).

I believe that the gifted child's elementary school experience lacks an appreciation by TAG Specialists, regular classroom teachers, parents and TAG students themselves, not to mention society at large and those in position of making political and programming decisions. Therefore, utilizing descriptive phenomenological methods will inform the "because of" and "in order to" attitudes, perceptions and understanding of the lived experiences of the research participants.

In an effort to assimilate the information above, the following research question is posed:

- What are the lived experiences of gifted children in the public elementary school setting?

As mentioned before, the rationale for this study is in adding to the limited body of knowledge regarding the experience of gifted children in elementary school. However, according to Van Manen (1990), a more appropriate purpose of this study may be, As educators we must act responsibly and responsively in all our relations with children, with youth, or with those to whom we stand in a pedagogical relationship. So for us the theoretical practice of phenomenological research stands in the service of the mundane practice of pedagogy: it is a ministering of thoughtfulness. (p. 12)

It is through this thoughtful approach that insight into the gifted child's lived experience in public elementary school will be illuminated. 
FINDING THE GIFTED CHILD'S VOICE

Rationale for type of research. To find the answers to my research question above, I used a descriptive phenomenological design. For purposes of this study, I was not looking to find a measurable answer to a question, but more of an exploration of the phenomenon of being gifted and a deeper understanding of their unique experiences in elementary school. According to Levering (2006) "No method so consistently identifies the ordinary human being as a subject with the epistemological subject as phenomenology does" (p.451). Therefore a qualitative (descriptive phenomenological) approach will be the best method in finding the gifted child's voice in the elementary school setting.

Qualitative research is more of a naturalistic way of investigating a question or problem. Bogdan and Biklen (1982) articulate five characteristics of qualitative research: ...the term naturalistic is used because the researcher observes and gathers data where the behavior under study is likely to occur, it happens naturally; qualitative research is descriptive; qualitative researchers are concerned with process as well as product; qualitative researchers tend to analyze their data inductively; and "meaning" is of essential concern to the qualitative approach. (p.25) Additionally, Farber (1943) offered the following list of five functions of phenomenology:

1. It is the first method of knowledge because it begins with the things themselves, which are the final court of appeal for all we know. It is a logical approach because it seeks to identify presuppositions and "put them out of play."

2. It is not concerned with matters of fact but seeks to determine meanings. 
3. It deals both with real essences and with "possible" essences.

4. It offers direct insight into the essence of things, growing out of the selfgivenness of objects and reflective description.

5. It seeks to obtain knowledge through a state of pure subjectivity, while retaining the values of thinking and reflecting. (p.568)

Using this approach and design, the participants' attitudes, perceptions and experiences were gathered, analyzed and interpreted in an effort to bring forth the gifted child's voice in elementary school.

\section{Research Setting}

Study participants. As this study's primary focus is to understand a central phenomenon, being gifted in public elementary school, I chose purposeful sampling as a means of choosing participants. Purposeful sampling is defined as intentionally selecting individuals or sites that have the information necessary to understand a central phenomenon (Mugo, 2008). According to Mugo (2008), this means of selection is common to qualitative research because of its flexibility of incorporating a variety of participants from individuals to different sites or any combination thereof.

Additionally, through purposeful sampling the students in this study were a homogenous sample in that they are members of "a subgroup that has defining characteristics" (Creswell, 2002, p. 196).

The purposeful sampling was done as TAG families, with children enrolled in fifth grade in this selected school, were invited to have their child participate in the research. To aid in narrowing the sample size to a manageable number, further selection criteria was administered in the following order: participant must have participated in 
TAG for at least 3 years, the sample needed to represent all TAG identifications (Intellectually Gifted, Academically Talented in Reading, Academically Talented in Math, or any combination of these three), and the sample would equally balance for gender if necessary. The desired sample included a minimum of four participants, but no more than eight. Participation was solely on a voluntary basis and only after expressed written permission was granted by all participants as well as permission granted by all students' parents or guardians. All fifth grade TAG students' families were invited to participate and 14 families expressed interest in the study. After applying the selection criteria mentioned above, nine participants were eligible and four of those participants were willing and able to commit the time necessary to the study. Five students, who were not able to participate in the full study, were invited to participate in a pilot study to help further develop the narrative/art work session and two participated in this study.

When the four children were confirmed as study participants, I asked them to write a brief statement about themselves that I could use to describe them without giving away their identity. Each participant was assigned a pseudonym per the requirements of the Human Subjects Review Committee, therefore, not even the participants knew the names they would be called throughout the study. Table 2 represents the children behind the pseudonyms as well as their TAG identification.

Table 2 .

Participant self-descriptions

\begin{tabular}{|l|l|}
\hline Participant: & Description: \\
\hline Wilma & $\begin{array}{l}\text { [Wilma] swims on the local swim team. Her favorite stroke is } \\
\text { the breaststroke. She also enjoys dancing and acting and is not }\end{array}$ \\
\hline
\end{tabular}




\begin{tabular}{|c|c|}
\hline $\begin{array}{l}\text { ACADEMIC } \\
\text { MATH }\end{array}$ & $\begin{array}{l}\text { shy on stage. She plays the alto saxophone and enjoys } \\
\text { performing whenever possible. Math is her favorite subject in } \\
\text { school. She loves spending time with her siblings whenever } \\
\text { they are around and loves giving hugs to her family. }\end{array}$ \\
\hline $\begin{array}{l}\text { Trudy } \\
\text { ACADEMIC } \\
\text { READING }\end{array}$ & $\begin{array}{l}\text { [Trudy] is } 11 \text { years old, enjoys school and is never without a } \\
\text { book by her side. She loves music, watching movies and } \\
\text { hanging out with her sister. She looks forward to family } \\
\text { vacations. Math and writing are her favorite subjects. Her } \\
\text { favorite hobby is any type of art. }\end{array}$ \\
\hline $\begin{array}{l}\text { Theo } \\
\text { INTELLECTUALLY } \\
\text { GIFTED }\end{array}$ & $\begin{array}{l}\text { [Theo] loves science, physics, engineering, outdoors and } \\
\text { creating ideas, concepts and "Rube Goldberg" projects, marble } \\
\text { runs, and anything that moves, twirls, flows, crashes, explodes } \\
\text { and more. He is a boy scout who enjoys camping, swimming } \\
\text { and having fun with friends. He has a sense of humor and } \\
\text { enjoys good pranks that don't harm anyone. He hates bullying } \\
\text { and mean people or kids that make fun of him or puts him } \\
\text { down. [Theo] is kind and fun, and likes to think of new ideas } \\
\text { to try out-his only limitations are when his parents disapprove } \\
\text { of how far it can go or the cost. }\end{array}$ \\
\hline $\begin{array}{l}\text { Finn } \\
\text { ACADEMIC } \\
\text { READING \& } \\
\text { SPECIAL } \\
\text { EDUCATION }\end{array}$ & $\begin{array}{l}\text { [Finn] is smart, funny and creative. He loves to write and } \\
\text { enjoys foods such as bacon and hamburgers. He also is very } \\
\text { enthralled in computers and Legos. He takes class on } \\
\text { computer technology. He likes to read a good book. Some of } \\
\text { his favorite series are the Bartimaeus Trilogy, the Hitchhiker's } \\
\text { Guide to the Galaxy and the Hunger Games. [researcher's note: } \\
\text { he also was hoping his pseudonym could have been Bacon } \\
\text { Overlord] }\end{array}$ \\
\hline
\end{tabular}

The study focused on the lived experiences of gifted public elementary students. The study began in June 2012 and concluded at the end of August. Participants engaged in interviews and work sessions that generated participant narratives and/or drawings. Interviews and work sessions took place after school and during the summer break. After all the interviews and work sessions were completed the participants were given the opportunity to have either a bowling or miniature golf outing with friends.

Participating school. This study was conducted in a large suburban school district where gifted students spend the majority of the academic day in their regular 
classroom with occasional small group pull-outs and after school activities with a schoolbased gifted specialist.

In this location, arrangements were made with a gatekeeper who granted the researcher access to students, faculty and parents. A gatekeeper, according to Bolman and Deal (2003), is a person who will grant access to an area otherwise closely guarded to protect its integrity and reputation. The gatekeeper in this study was the principal of the suburban elementary school being studied. He is, as LeCompte and Schensul (1999), put it, the individual who controls access to a group of people to be studied. However, this school is working towards better differentiation practices, so access was given without reservation. Additionally, the administration is looking for help in better understanding the unique needs of gifted children; therefore, they were willing to allow access to participants in hopes that the data collected will offer insight into their actual school experiences.

The participating school has almost 600 students in grades k-5. When compared to districts from the same geographical area, this school received the lowest ESD support per student and had the lowest percent of teachers with a Master's Degree or higher. However, this school, as did all the other schools in this area, had greater than $95 \%$ of their TAG students exceed state benchmarks in reading, math and science. There were approximately 80 TAG students identified in this elementary school at the time of this study.

TAG students are identified in the areas of Intellectual Giftedness and Academic Talent in Reading and/or Math. The statewide assessment is used to screen candidates for TAG evaluation and students who score in the $97^{\text {th }}$ percentile are further evaluated for 
the program as Academically Talented, while students scoring in the $96^{\text {th }}$ percentile or those with environmental disadvantage such as: special education, poverty, homelessness, language or extenuating circumstances; are evaluated as Potential to PerformAcademically Talented. The children are serviced the same as those in the $97^{\text {th }}$ percentile, but their identification journey is a little different.

When a child is chosen for further TAG evaluation, they are then given a nationally normed achievement test in the area they are being evaluated-reading or math or both. The tests currently being used are the TerraNova Online Assessment, Kaufmann Test of Educational Achievement-Second Edition (KTEA-II), and Weschler Individual Achievement Test-Second Edition (WIAT-II). Students scoring in the $96^{\text {th }}$ percentile or higher on these nationally normed tests meet the criteria of showing a pattern of giftedness and are further evaluated with behavioral checklists from parents and classroom teachers. A classroom observation may also be completed. After all the data is collected a building committee meets for final approval of the candidate.

Children are given the Naglieri Nonverbal Abilities Test (NNAT) when being evaluated for Intellectual Giftedness. This test is given to all second grade students in the district. Students scoring in the $96^{\text {th }}$ percentile or higher on this test are further evaluated with behavioral checklists from parents and classroom teachers. Similarly to the students being evaluated for Academic Giftedness, students being considered for Intellectual Giftedness may have a classroom observation completed. After all the data is collected a building committee meets for final approval of the candidate.

This suburban elementary school is located in the Pacific Northwest. According to 2010 Census data, when compared to the surrounding communities, the community in 
which this elementary school is found has the largest non-Caucasian population; however, all the communities are over $70 \%$ Caucasian. It falls in the middle for median age, population and home values, and has the lowest median income. While this community may be an outlier in a couple of areas, it is very similar in all measured areas with the surrounding communities.

\section{Data Collection}

The study used three interviews with participants to collect and analyze their stories of their lived elementary school experiences.

The first interviews with participants collected baseline data in the area of attitudes, perceptions and their overall lived experience in elementary school. All the participants were interviewed with a protocol containing six questions. See Appendix A for an example of interview protocol $\# 1$.

The second interview with participants engaged them in the research as they created and then shared a narrative and/or drawing that captures their school experience. Van Manen (1990) and Moustakas (1994) say that, particularly with children, the act of writing and/or drawing may elicit memories or experiences that are not normally shared during an interview. Before any of the work sessions took place with the participants, a pilot study was conducted to help develop and guide the process. It became clear immediately that the participants needed to know how the product would be used, as this actually helped them get started on the project. The students in the pilot study had not had the first interview, but they were given the protocol, so they could understand the questions the others had been given. Because of this difference, the pilot study products seemed to more closely reflect those specific questions; whereas, the participants were 
able to delve deeper into the previous shared experiences as well as generate new stories and this was the goal of the work sessions. The pilot study was a useful tool in understanding how to help the participants fully engage in this process.

The drawing/writing activity and second interview engaged the participants in a more precise exploration of their individual experiences. After analyzing the narratives and/or art, a protocol was developed to elicit more details about their stories and pictures. It is through this further delving into stories of experiences that themes emerged, helping to develop the common themes that describe the phenomenon of being gifted in the elementary school setting.

The third interview engaged participants in verifying the development of themes and the valid capturing of essences that represented their lived experiences. After given a summary of the first two interviews and work session, the participants were able to add to, subtract from or correct the essences captured. Additionally, the participants were offered an opportunity to add any data that may have come to them throughout the process, but was not originally collected.

The Epoch. Before collecting data I engaged in a process, as the researcher, to develop my Epoch. According to Moustakas (1994), "Epoch is a Greek word meaning to refrain from judgment, to abstain from or stay away from the everyday, ordinary way of perceiving things...[it] requires a new way of looking at things...” (p. 33). Through this process I made my best effort to put my preconceptions aside and look at the children's stories with a naïve perspective.

I have worked with gifted children for several years and was a gifted student myself in middle school and high school; therefore, it was critical that I engage in a 
process to develop my Epoch before interviewing participants. While there is no way to fully remove my thoughts and feelings from the research, I was able to understand my preconceptions and put them aside, so I could see the experiences being shared by the participants with a new consciousness and fresh perspective. Even though it was possible that I was not engaged in the experiences being shared by the participants, it is important this process was carried out as I might have had similar experiences with previous students or myself in the past. Despite that I was only borrowing the experiences shared by the participants, according to Van Manen (1997), this was a necessary and beneficial process in the research. It was also an important tool during the actual research as it was referred back to throughout the entire process.

Using the interview questions that I developed for the participants, I wrote my epoch. It was important that my prejudgments surrounding these interview questions be fully vetted. Moustakas (1994) explains that through the process of creating an epoch, we bracket the outside world and only concentrate on the bracketed world we are studying. Adding: “...the world in the bracket has been cleared of ordinary thought and is present before us as a phenomenon to be gazed upon, to be known naïvely and freshly through a 'purified' consciousness" (p. 85). It is through this process that the participants' lived experiences move to the forefront and take on the voice needed to tell their stories. Borrowing experiences from the participants allows the researcher to keep the subjects within the brackets for the purpose of describing the experiences and finding common themes or outcomes, versus interpreting them for meaning that might not be readily disclosed. 
Interviews. Each interview took between 20 and 30 minutes and was conducted after school was out for the year. The interviews took place at the school where the participants attend. Due to construction at the school, the first interview, pilot study and work sessions were conducted in the Literacy Specialist's office. This unfamiliar room didn't seem to make the participants less comfortable, I think they were comfortable just being in their school. The second and third interviews were at the public library and local church due to continued construction at the school. Again, this did not seem to negatively influence the participants, as they all are regular visitors to the library. My role as interviewer offered further comfort, which gave the students the opportunity to be forthright in the interviews, as we had established a trustworthy relationship over the past three years.

A total of three interviews and one work session were conducted with each participant. Using open-ended questions to stir discussion, participants had the opportunity to explain their experiences at school in depth. According to Van Manen (1990), a common mistake in the phenomenological interview is not staying focused on the research question being studied; therefore, the interviews were guided by the researcher using a protocol. All interviews were documented with both interview notes as well as audiotaping. The audiotaped interviews were transcribed using Dragon Naturally Speaking 9 for Mac.

The purpose of the first interview was to elicit responses from students regarding their general lived school experiences, such as; the overall feelings they have about school, favorite school activities and what they would change about school if they could. 
Comparisons of the data looked for correlations and differences between the experiences of the TAG students.

All participants were also asked, "What is gifted?" in an effort to find similarities or themes surrounding the overall concept of giftedness in elementary TAG students. Before the second interview the students were asked to participate in a work session so they could develop a narrative and/or pictorial description of their school experience. Reflecting on the questions they were asked in the first interview and the experiences they already shared, the participants were prompted to use either narrative writing or drawing or both to further capture the details of their lived experiences. The hope was that this exercise would validate previous answers and elicit details not shared during the first interview. The purpose of holding a separate work session was to ensure it was the participant's work and not work influenced by parents, peers or teachers.

In the second interviews, fact checking and additional questions were developed for participants with guidance from the information gathered from the first interview. Additionally, the participants were asked to share their narrative and/or drawing that captures their lived experiences in elementary school. To help align this process, and focusing on the research question, a protocol was created for each participant and was specifically tied to the experiences shared in their work session products. See Appendix A for a copy of the protocols.

The third, and final, interview was not done to gather additional data, but was used to verify with the participants the accuracy of the data that had been collected and that the ideas that had been captured during the previous interviews are what the 
participant wanted to communicate and were an accurate reflection of their lived experience. Each participant was provided a summary of the essences of the experiences the researcher gathered and each participant was able to confirm, correct or add to the summary. Additionally, the participants were asked to choose one word to capture their experience as a gifted child and another word to describe their elementary experience. This activity was similar to the first interview, in that it was more for understanding commonalities and differences between the participants versus generating data for analysis; however, this activity was used and is discussed later in the findings.

As a way to try to make the research process enjoyable, I met with each participant for one hour. After their 20-30 minute interview or work session time, we would spend the remaining time playing some of their favorite games, often times including family members. At the end of the study all of the participants were disappointed we weren't going to meet anymore. They enjoyed all aspects of the interviewing process and looked forward to the games they were going to play after our work time.

Data collection timeline. The following was the timeline for completing the research:

May 2012

- Obtained approval from PSU Human Subjects Committee-5/15/2012

- Notified families of study-5/20/2012

- $\quad$ Selected participants-5/20-31/2012

\section{June 2012}


- Consent received from participants and parents-6/1-12/2012

- Consent received from building principal-6/14/2012

- $\quad$ First interview (Interview protocol \#1)—6/15/2012

- Pilot study for work session-6/18/2012

- Analyzed first set of data—ongoing

- Work session for narratives/artwork-6/20-21/2012

- Analyze narratives/artwork and create protocols for second interviewongoing

July 2012

- Second interview (Interview protocol \#2) - 7/12-19/2012

- Analyze second set of data-ongoing

August 2012

- Third interview (interview protocol \#3) -8/7-20/2012

- Participant celebrations-8/20-30/2012

\section{September-November 2012}

- Final analysis of data, determine and communicate findings—ongoing

Data analysis. Data analysis was an ongoing and developing process throughout the entire study. While a process may have been in place there was a fluidity within the steps that allowed for more of a cyclical approach (Lundsteen, 1987). In the case of this study, open-ended interview data was gathered to help inform or establish future interview questions. The data was then analyzed in an attempt to narrow and develop 
certain themes and answers to the research question. The cyclical approach, as mentioned by Lundsteen (1987) manifested through transcribing the raw data and analyzing the transcriptions looking for meaning units. Then the meaning units were assigned keywords or essences in an effort to narrow the data to relevant meaning units that were pertinent to answering the research question. These essences and relevant meaning units were then clustered to develop themes in an effort to understand the phenomenon of being gifted in elementary school. After that process was completed, however, there was a constant revisiting of the transcribed data and meaning units to verify and capture experiences from the participants that would further support the essences being reported and themes developed.

Furthermore, the data gathered was analyzed using an established process of: preparing and organizing the data for analysis, exploring the data, describing and developing themes from the data, reporting and representing findings, interpreting findings, and, finally, validating the accuracy of findings. According to Moustakas (1994):

The aim is to determine what an experience means for the persons who have had the experience and are able to provide a comprehensive description of it. From the individual descriptions general or universal meanings are derived, in other words the essences or structures of the experience. (p.13)

It is important to note that during this process of borrowing the participant's experience, the researcher is sharing the experiences and finding common themes among the data versus trying to interpret the experience and assigning meaning to this interpretation. This is why it was important to have the third interview, so the participants could verify 
that their experiences had been captured accurately. Additionally, it was important to revisit the researcher's epoch to ensure I was appropriately capturing the participant's experience without any prejudgments of my own understanding of similar experiences.

Using a descriptive phenomenological data analysis process suggested by Giorgi (1979), the data was thoroughly read to get a sense of the whole, meaning units were developed, redundancies were eliminated, essences of the situations/experiences were developed, and finally, the insights gained were integrated into a description of the experience.

For the beginning descriptive phenomenologist, it can be difficult to process interview data without a concrete or step-by-step guide. Hycner (1985) recognized this challenge for researchers and created the following fifteen guidelines to help "sensitize the researcher to a number of issues that need to be addressed in analyzing interview data..." (p. 280).

1. Transcription.

2. Bracketing and the phenomenological reduction.

3. Listening to the interview for a sense of the whole.

4. Delineating units of general meaning.

5. Delineating units of meaning relevant to the research question.

6. Training independent judges to verify the units of relevant meaning.

7. Eliminating redundancies.

8. Clustering units of relevant meaning.

9. Determining themes from clusters of meaning. 
10. Writing a summary for each individual interview.

11. Return to participant with the summary and themes: Conducting a second interview

12. Modifying themes and summaries.

13. Identifying general and unique themes for all the interviews.

14. Contextualization of themes.

15. Composite summary. (Hycner, 1985, pp. 280-294)

In steps 1-3, Hycner (1985) points out that transcription is an obvious step, but also argues that it is important because it brings you back to the data one more time. Bracketing is important because it allows the researcher to approach the data "...with an openness to whatever meanings emerged. This is an essential step in following the phenomenological reduction necessary to elicit the units of general meaning" (Hycner, 1985, p. 280). After the data has been transcribed and the researcher has, as much as possible, bracketed their preconceptions, it is critical to listen to (and read) the interview to get a sense of the whole. As Hycner says, "This will provide a context for the emergence of specific units of meaning and themes later on" (1985, p. 281).

According to Hycner delineating units of general meaning or step four in his guidelines is done:

...in order to elicit the participant's meanings. This is done with as much openness as possible and at this point does not yet address the research question to the data. This is a process of getting at the essence of meaning expressed in a word, phrase, sentence, paragraph or significant non-verbal 
communication...Also at this point all general meanings are included, even redundant ones. $(1985$, p. 282)

Once the researcher has noted units of general meaning it is time to address the research question through delineating relevant meaning units. Hycner points out that, “...the researcher addresses the research question to the units of general meaning to determine whether what the participant has said responds to and illuminates the research question" (Hycner, 1985, p. 284).

Steps 6-9 address reliability, redundancies and clustering data to determine themes. Training an independent judge to evaluate the data is a good reliability check to see if the researcher's interpretations are accurate and their presuppositions have been bracketed. Additionally, independent verification will add rigor to a study and should be considered. Before clustering units of relevant meaning to determine themes, it is important to review the units for redundancies. However, it is important when investigating for redundancies that the researcher look at how the unit is mentioned, not just that it is mentioned more than once as a unit that is used many times reflects the importance of that unit to the participant and they can use the same literal words to express very different things. After the redundancies are eliminated, Hycner recommends looking at the units to determine natural clustering or "... whether there seems to be some common theme or essence that unites several discrete units of relevant meaning" (1985, p. 287). Finally, the researcher looks for central themes from the clusters of relevant meaning units.

Summarizing is the focus of steps 10-15 in Hycner's (1985) guidelines. First, Hycner recommends that a researcher write a summary of each individual interview and 
then take that summary back to the participant along with the developing themes and conduct an additional interview. He adds that these two steps are a great validity check and serve two important purposes: to check on whether "... the essence of the first interview has been accurately and fully captured." and "If the participant is in essential agreement with the summary and themes..." (Hycner, 1985, p. 291). Additionally, conducting a second interview also allows for the participant to add information that was missed in the first interview. After additional interviews, it may be necessary to modify themes or summaries and this would happen in step twelve.

After all the interviews are conducted and individual summaries are completed, Hycner (1985) recommends looking for common themes of most or all the interviews as well as any themes that might be unique to one interview. This previous step leads into the final evaluation of the data by writing a composite summary. Hycner says a composite summary "...describes the "world" in general, as experienced by the participants" (1985, p. 294). It would be at this time that significant differences between the individuals might be noted.

The fifteen steps that Hycner (1985) recommends as a guide were influenced by the work of Giorgi and are the specific guidelines used in the final analysis of the data in this paper.

Finally, Moustakas (1994) would add that reflection is one of the key tools to phenomenological data analysis, saying, "The method of reflection that occurs throughout the phenomenological approach provides a logical, systematic, and coherent resource for carrying out the analysis and synthesis needed to arrive at essential descriptions of 
experience" (p. 47). This is also important in the epoch to make sure the researcher is staying informed of preconceived ideas and influences.

By bringing the data back to the participants for verification of ideas, concepts and experiences derived from transcribing the data; there is increased validity and accuracy. Additionally, Moustakas (1994) would say that bringing the data back to the "community" of participants also increases validity. He said, "A continuing alteration of validity occurs as people articulate and describe their experiences. Reciprocal correcting of reality takes place in social conversations and dialogues" (p.57). I see this process as sharing the big picture ideas I have gathered with participants to see if I have authentically captured the accurate big picture-the essence of the experiences the participants have shared.

As the data was analyzed and interpreted through the coding process, I believe this study offers a deep insight into the gifted students' experience within schools. It will inform the phenomenological question of: "What are the lived experiences of gifted children in the public elementary school setting?"

Ethical considerations. In an effort to protect all research participants, the following ethical considerations were made:

Human Subjects approval of research process/methods were obtained; consent from participants and their parents or guardians was obtained; every effort to protect the privacy and confidentiality for the participants was made; and participants were given multiple opportunities to verify their data for accuracy. 
In an effort to gather their most honest feelings about the school environment including instruction, learning and social interactions, students were assured that every safeguard to protect their confidentiality was put in place. Each participant has a unique pseudonym, known only to the researcher, to protect their confidentiality; however, by signing an informed consent both participants and their parents/guardians understood there is no guarantee of confidentiality of the findings due to the publishing of the completed dissertation.

Additionally, the Human Subjects Research Review Committee (HSRRC) approved the informed consent forms created for participants and their parents/guardians as well as the selection of participants and their role in the overall proposed project.

\section{Conclusion}

In conclusion, the researcher hopes this descriptive phenomenological study will move beyond the literature to a living picture narrative of the TAG student's elementary school experience; therefore, allowing their voices to be recognized as an influential partner in their educational experience. 


\section{Chapter 4-Findings}

The goal of this study was to use a descriptive phenomenological approach to answer the question: What are the lived experiences of gifted children in the public elementary school setting? The following findings include excerpts of the transcripts from four participants and are shared in an effort to answer the above question as well as allow the participants to contribute a voice that is missing from the body of knowledge in gifted education.

The participants' lived experiences are shared in this chapter in the following manner:

- Findings: including identification implications, what is gifted, and different students and different experiences;

- Analysis: including delineating units of general meaning, delineating units of meaning relevant to the research question, clustering units of relevant meaning and determining themes from clusters of meaning;

- Summarizing: including interview summaries, the composite summary, the Epoch and its role, and the summary of findings.

Delisle (2012) says that we must engage and listen to students if we are to improve education and educators. Jessiman (2001) says that school reform is difficult; however, phenomenology can help in informing and instigating necessary change. Bergmark (2008) talks about how powerful the student voice can be in building relationships with educators and influencing school improvement. All of these scholars recognize the importance of capturing, understanding and sharing the lived experience of students if we are going to improve education for children. Using the analysis guidelines 
of Giorgi (1979) and Hycner (1985), the following borrowed experiences show that gifted children have a great deal to share about their school experience.

\section{Findings and Analysis}

Findings. The most prominent finding in this study was that while these children share the phenomenon of experiencing elementary school as gifted children, the way in which they individually experience elementary school is very different. Some of them experience school with a high awareness of themselves, others and what is happening around them; while others are experiencing a more academically based journey that is full of a desire to be challenged and enriched in the regular classroom. For some children the TAG Program at the school was what they relied on for intellectual and social support and for others it didn't seem to be as important. Some of the children seemed to experience a variety of feelings and emotions that were connected with many aspects of their school experience; whereas others weren't as emotionally expressive. The one commonality amongst all the participants, and their stories, was the importance of having and spending time with friends.

Data collection. The data was collected from the four participants through three interviews and one work session. The first interview, referred to throughout the analysis as Interview \#1, included a protocol with six identical questions that each participant answered.

The second interview and work session were unique in that they were used in tandem in an effort to stir up more memories and get more details from experiences the children had. The children first were asked to capture their overall elementary school experience in writing, art or both. Two participants chose to only write and two 
participants chose to draw pictures and then use writing to explain their pictures. After the participants completed their work sample, I generated questions that focused on delving deeper into either their drawings or narratives. Using questions like, "Can you tell me more about...?" and "How did...make you feel?" as well as giving the participant time to add or explain anything that I might not have asked them, more data was collected and more meaning units were selected from these transcripts. The relevant meaning units that were generated out of this process are referred to as Interview \#2 throughout the analysis.

The final interview, referred to as Interview \#3 throughout the analysis, included a culminating activity of having the participants choose words to describe their elementary school experience and themselves as a gifted child. This was done for more of a fun activity with the children and wasn't really intended to be used in the study; however, the words they chose illuminated some of the findings and offered a bit of validation to the research process, therefore, they were added to the paper. The third interview was primarily focused on bringing a summary to the participants to verify that the essence of their experiences had been captured appropriately and in the manner in which they wanted them presented. After sharing the summary with the children, they were able to change, add or subtract anything they wanted from the summary. The final interaction in the interview allowed the children to add any last words and all four participants had something to say. Many of those last words are shared in the analysis that follows.

Participants. The four participants just finished fifth grade at a suburban elementary school and they have all participated in the Talented and Gifted (TAG) Program at their school for the past three years. Wilma is identified as Academically 
Talented in Math and she appreciates a challenge. Trudy is identified as Academically Talented in Reading and she describes herself as creative. Science and Engineering are Theo's passion and he is identified as Intellectually Gifted. Finally, Finn relishes in his newfound ability to make people laugh and he is identified as Academically Talented in reading. Finn also has an IEP for speech and help with social skills. The following analysis shares the participants' experiences.

Identification implications. When the participants for this research were chosen, the process of purposeful sampling was used so that there would be representation from all the areas of giftedness that are identified and served in the school district being studied. One of the most significant findings in this study was how differently the participants experienced elementary school and others might suggest that the participant's different identifications influenced their experience. However, the important thing to point out is the students are not being given different opportunities because of their particular area of identification. When the students are pulled out of the classroom it is for interest based learning opportunities and they are grouped only as gifted students not by specific labels. Additionally, when they are skill grouped for reading or math classes, their gifted and non-identified peers are also in those same skill groups; therefore, they are not experiencing a unique gifted learning opportunity.

The participants had some tendencies to share stories that could be influenced by their differing identifications, because these are areas of strength or particular interest for them. However, I did not bring up their specific identifications at any time during the study. 
Wilma is identified as Academically Talented in Math and many of her stories were focused on being challenged and not bored in math. She is competitive in math games and other things she is good at, but shies away from activities, such as art and certain games, where she feels her work or performance may not be deemed the best.

Trudy is identified as Academically Talented in Reading, but the areas she talked about as fun and academically challenging were in her advanced math class. She didn't share any stories about reading.

Theo talked about how he approaches things differently particularly in the area of science and his identification is Intellectually Gifted. He talked about how sometimes his giftedness will create problems because he over-thinks even the simplest things and he has had to develop strategies to help him when he gets into an over-thinking situation.

Finn's identification is unique in that he is twice exceptional, meaning that he is identified as Academically Talented in Reading and also receives services from Special Education in the areas of speech and the autism spectrum. Being twice exceptional does create a different lens through which Finn looks at his experiences in school; however, his stories only referred to the Special Education piece when he felt it was a positive to get to go to speech and skip the monotony of grammar work in the mornings. He feels like the help he has received on social skills may have helped him, but he doesn't feel like he needs that anymore and will not need it in middle school.

As you can see, the participants are very different and their identification may very well be one of the factors that causes them to experience school differently. The surprising aspect, to me, of these very different experiences was the degree to which it was so extremely different. I really thought that their experiences and stories would be 
more similar. The following description of the data further confirms how different being gifted can be.

What is gifted? Before I asked the participants to share any stories or experiences with me, I asked them to explain to me what gifted is. This was done during our first interview session and I asked the question mostly to help break the ice, but I also wanted to know what their understanding of gifted was.

I stated in my Epoch that I thought the children would probably say that being gifted means to be different because this is what I teach my students. I start the year off by telling them that being gifted means you think differently and it does not mean that you are better or worse than anyone else. In fact, when Trudy was asked during the final interview if there was anything missing from the data that we needed to add, she shared the following story:

The story I want to share is...I was actually thinking about this yesterday, I thought about the first thing you actually say at the first TAG meeting every year with all the people there, all the grades, it's when they hand out the candy bag with the Smarties, the Dum Dums and the Jolly Ranchers. They always say that just because people are not in TAG doesn't make them Dum Dums, and just because we are in TAG doesn't make us Smarties, we all just want to be Jolly Ranchers. And I had a Dum Dum yesterday and I thought of that, so I want that to be in the paper because I think that's cool and I bet I am going to remember that forever. (Trudy, Interview \#3).

In the following figure the participants do, indeed, define gifted as being different, but they also articulate what that difference looks like to them individually. 


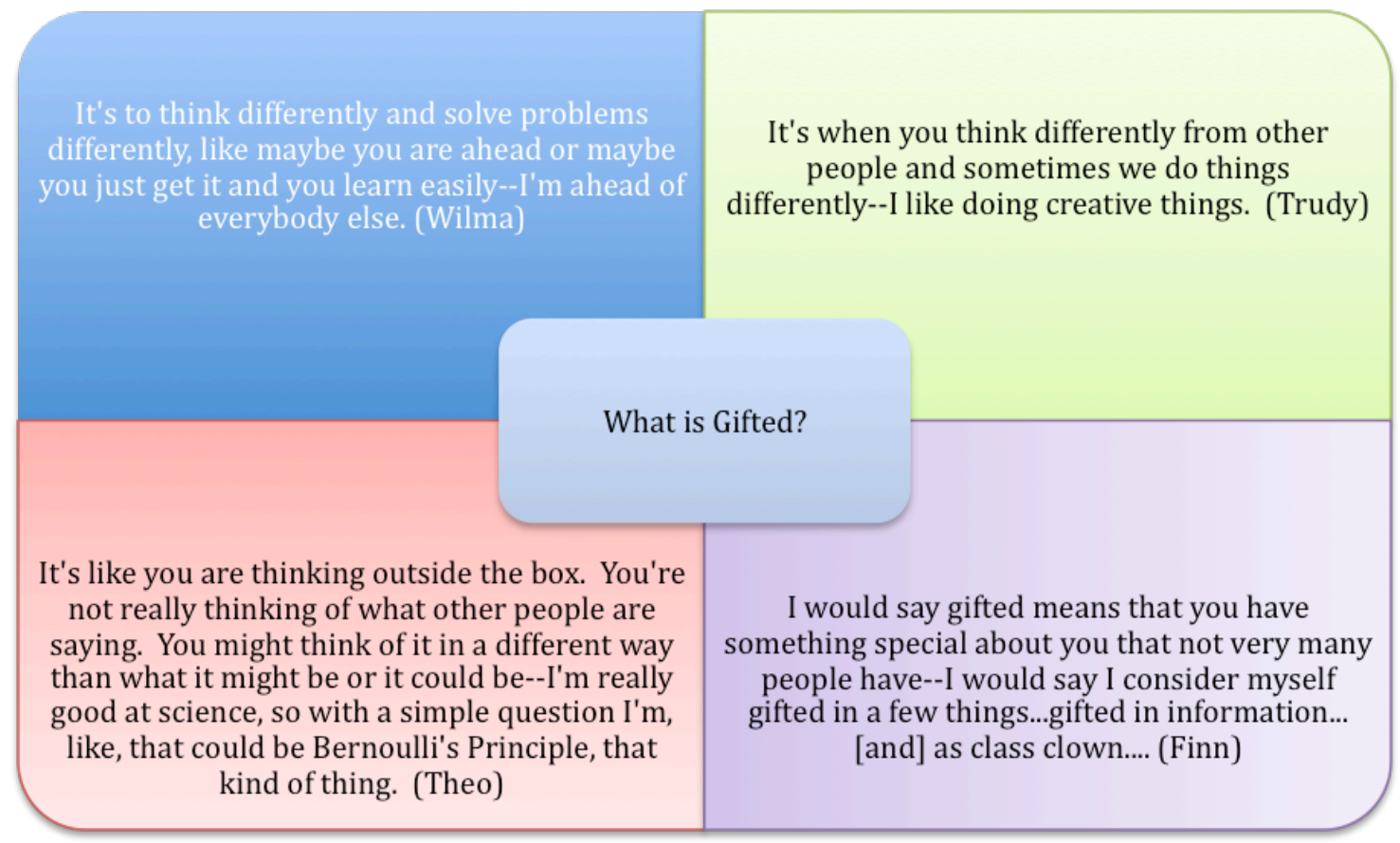

Figure 4. What is gifted? This figure represents the participants' descriptions of what gifted is and how you would explain it to a stranger.

From Wilma's interpretation that it means you may be ahead or learn easily to Trudy saying it could mean you are creative to Theo's Bernoulli's Principle to Finn as the class clown, all of them are articulate in describing how different being gifted can be from their perspective.

Different students and different experiences. During the third and final interview, I was trying to gain an additional perspective from the participants regarding their experience in elementary school and as a gifted student. I asked them if they were to choose one word to describe their overall elementary school experience, what would it be and why? While this question was not phenomenological in nature, I found an interesting connection between their statements and the findings in this study. 


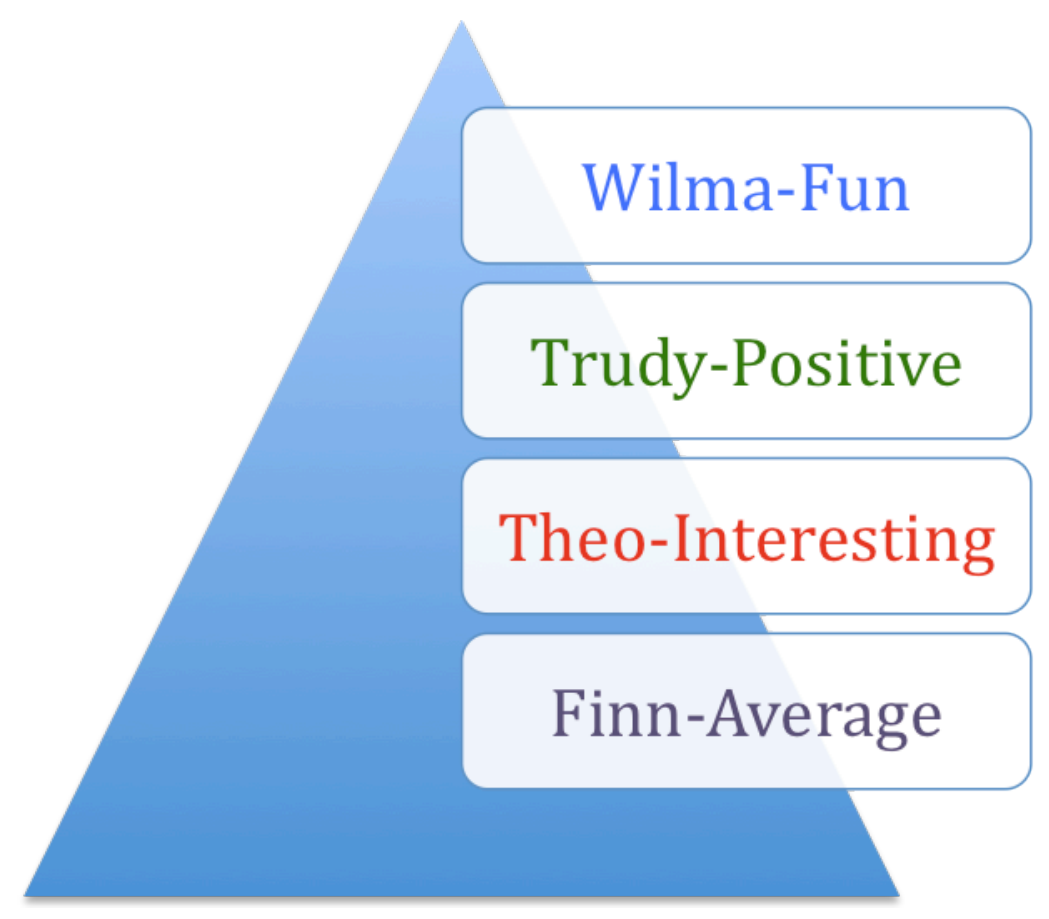

Figure 5. Elementary school in one word. This figure represents the one word each participant chose to describe their overall elementary school experience.

After the participants chose one word to describe their overall elementary school experience, I asked them to elaborate on their word choice. Wilma said she chose "fun" because: "You have recess, meet new friends and you get to do different activities. And even though you leave each year, you come back to the same people and you have a lot of fun" (Interview \#3). Trudy gave examples of her "positive” experience, "Everyone was nice and helpful and kind and understanding. I made new friends in kindergarten and I've had the same friends all the way through" (Interview \#3). Theo elaborated on “interesting” by giving the following statement: "Every day brings something new. It's always interesting because you never know what's going to happen and even when you do know what's going to happen, there's still some unknown about it" (Interview \#3). Finn added this explanation for choosing "average" to describe his school experience: 
Normally I would say mediocre, but I figured that since elementary school is the only reason that I have friends...I figure the amount of friends I made in elementary school...I figured they make up for a lot of the things I don't like about elementary school, but I would still not want to say good, so I just say average. (Interview \#3)

The participants were also asked to choose one word to describe themselves as a gifted child and Figure 6 depicts their answers.

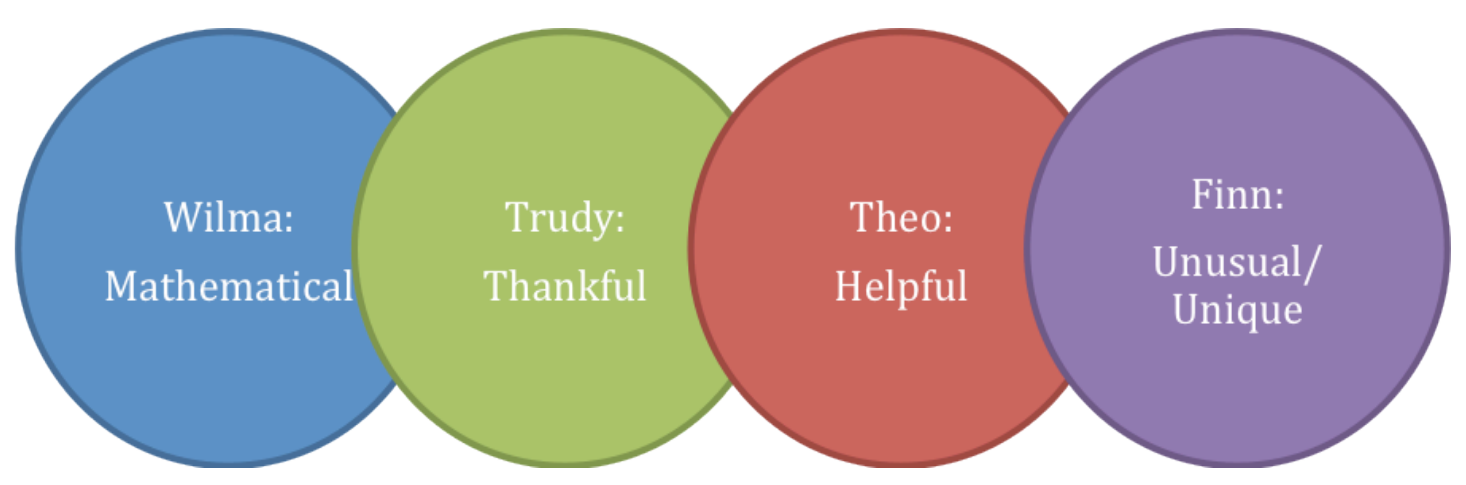

Figure 6. Gifted children in one word. This figure represents the one word each participant chose to describe their experience as a gifted child.

Again, the participants were asked to elaborate on why they chose those particular words and these were their responses. Wilma said:

When you're mathematical you could do more stuff when you complete the first stuff, that way you can keep going, keeping it challenging. And it's fun because math can be very, very fun and it can be challenging. (Interview \#3) 
Trudy shared:

I am thankful that I got the opportunity to participate in all of the TAG activities and work. My opinions will probably change a couple of times, but I think I will always come back to thankful because I will be a gifted teenager and a gifted adult. (Interview \#3)

Theo chose helpful because:

I'm kind of helpful because I have that talent or that gift in engineering stuff that might help later on during a project...I'm one of those people who loves science, builds things every day, has everything fail every day, having things succeed, having thousands of ideas and only a couple of them work, having things actually get built, so for doing something, then I might have already built it and I could just bring it in. (Interview \#3)

Finn described unusual/unique in this way:

There are not a lot of people like me. There are some people that I think might be sort of similar to me, but there are none that really have the same firestorm of traits that I have. I'm smart and funny and I can be creative, I'm also appreciative of weirdness....I'm sure that there are a lot of people that also have those traits but none of them have all of them, the very same traits, in the various intensities that I have them and in the various ways and forms that I have them. (Interview \#3) When I take the above information generated from the participants and compare it to the findings in this study, I feel it validates the phenomenological process and the discussion in the following analysis. 
Analysis. Giorgi (1979) proposes a process for descriptive phenomenological data analysis that focuses on a thorough understanding of the data by getting a sense of the whole and paring it down until you can get an understanding that allows you to insightfully describe the experience. Using Giorgi's method of analysis will allow a researcher to attain their final conclusions; however, if you are a novice descriptive phenomenologist, the steps can seem a bit blurred and undefined. This is where Hycner (1985) steps in with his guidelines for descriptive phenomenological analysis of interview data. He proposes fifteen steps, as mentioned in the methods section of this paper, that were used as a guide throughout the analysis process described below.

Incorporating Hycner's (1985) steps 1-3, the interviews were listened to multiple times to get a sense of the whole as well as focusing on pauses, enthusiastic responses and intonations from the participants. I also referred back to notes taken during the interviews to capture any physical gestures the participants may have exhibited while sharing their stories. After I felt I had an indepth grasp on what the participants were sharing, I transcribed the recordings. I then again listened to the recorded interviews to make sure I had correctly transcribed the stories and captured the relevant intonations.

Before, during and after the above process, I revisited my Epoch to make sure that the essences that I was capturing were those intended by the participant and not essences that were based on my own understanding or presuppositions. This was a very important part of the process as many of the findings surprised me and I had to be careful to not insert questions during the interviews or choose excerpts during the analysis that I felt were important, based on my own experiences or understanding. I had to keep myself in check so I did not impose on their stories. At times, this was difficult and at others it was 
easy because their stories were so vivid and the participants were so engaged in sharing their experiences.

Using Hycner's analysis guidelines, the following sections outline the findings of this study and the amazing stories shared by the four very unique participants.

Delineating units of general meaning. According to Hycner, "This is a process of getting at the essence of the meaning expressed in a word, phrase, sentence, paragraph or significant non-verbal communication.... I define a unit of general meaning as those words, phrases, non-verbal or para-linguistic communications which express a unique and coherent meaning....Also at this point all general meanings are included, even redundant ones." (p. 282).

There were 224 general meaning units (paragraphs) that were chosen from the transcribed data. In an effort to parse down the general meaning units, keywords were used to capture the essence of the general meaning units and these keywords were eventually used in the next stages of analysis to cluster meaning and develop themes. Four participants generated 375 keywords with many that were repeated (both by the participants and within the same theme), yet were not redundant in nature and described different individual experiences. When placed into a frequency chart, the keywords then represented 63 individual essences plus 20 additional essences that were either used by more than one participant or were representative of more than one unique experience. In other words, these 20 same essences were captured multiple times in reference to different experiences or different participants. These keywords were used to turn paragraphs into excerpts that represented relative meaning units. In the following section, an example from Finn will illustrate this process. 
Delineating units of meaning relevant to the research question. According to Hycner, “...the researcher addresses the research question to the units of general meaning to determine whether what the participant has said responds to and illuminates the research question. If it appears to do so, then it is noted as a unit of relevant meaning in a manner similar to the process in step number four." (p. 284).

The research question is: What are the lived experiences of gifted children in the public elementary school setting? However, after conducting this research and delving deeper into the experiences with the participants, it seems like the question is not answered by stories alone, but it begins to be answered when the essences of their stories are captured and shared. Policy makers, teachers, administrators and parents may find the stories informative or maybe even interesting, but for them to engage in what they are reading it is important that the essence, or "the basic, real and invariable nature" (Braham, 2001), of the experience be shared.

An example of the delineation process is illustrated in the following excerpt. One of the participants, Finn, shows he has a heightened awareness of his giftedness in that he is aware it has an impact on how he experiences elementary school; however, he doesn't completely understand where his insight comes from.

I think being gifted is instrumental in my personality as well as problematic. It is instrumental because it shapes me and also I think, but I'm not sure about this, but I have a rough estimation, based on no facts whatsoever, that being gifted might be one of the reasons I am funny, it might influence my style of humor. And it is also problematic because I figure, another guess made on no facts whatsoever, the reason why people were annoyed by me and my excessive factuality that, you 
know, led to the collapse of my social life, it was brought on, partially, by being gifted. (Finn, Interview \#2).

When the data from Finn's second interview was being analyzed, the paragraph that this excerpt came from was labeled with the keywords of awareness and gifted to capture the essence of awareness and giftedness as something Finn was attuned with and this was conveyed in the excerpt that was pulled from the paragraph and shared here. This excerpt became a unit of relevant meaning because it addresses his lived elementary school experience in a variety of ways, but most importantly in the area of his awareness of being gifted and that being both a positive and negative experience for him.

Clustering units of relevant meaning. Prior to clustering units of relevant meaning, Hycner (1985) recommends that you train an independent judge to verify your findings up to this point in your analysis. I did not do this for two reasons, first, because I had not included it in my Human Subjects application and felt that this process may expose the participants to possible risk in their confidentiality and, second, I also felt confident in my use of the Epoch to make sure my presuppositions were in check.

Once the verification of units of relevant meaning is complete, Hycner instructs the researcher to eliminate redundancies. After revisiting the transcripts, very few units of relevant meaning were redundant in nature. This is not to say that throughout the three interviews and work session the participants didn't repeat stories, because they did; however, the repetition of the stories added to or highlighted another unit of meaning in the process. As Hycner says, "If there is ambiguity or uncertainty as to whether a statement constitutes a discrete unit of general meaning, it is best to include it." (1985, p. 282). 
Clustering units of relevant meaning is the predecessor to determining themes, and Colaizzi (1978) states, "Particularly in this step is the phenomenological researcher engaged in something which cannot be precisely delineated, for here he is involved in that ineffable thing known as creative insight." (p. 59).

Hycner (1985) says that this step in the analysis is where relevant meaning units are evaluated for natural clustering. In other words, it involves looking for an essence or common theme that "unites several discrete units of relevant meaning." (p. 287).

Through this process the relevant meaning units seemed to naturally fall into the participants':

- awareness of others and themselves, including compassion, rules and social justice;

- feelings/emotions from a variety of experiences including feelings of frustration, awkwardness, concern about change and pleasure;

- learning experiences including being challenged (or not), having choice (or not), having fun (or not), getting to work on projects or different activities (or not) and the influence (positive or negative) of a teacher on their learning experience;

- perspective on TAG Programming, including its role in providing challenging and differentiated experiences as well as more opportunities to have fun in school and make friends.

It is impossible to share every detail of every story the participants shared; therefore, from the complete transcripts meaning units were selected and in this form they came with a lot of context, so that context would be available during the analysis phase and help capture the essence of the experience. Once that essence was noted, then a relevant 
meaning unit could be pulled from the original meaning unit. In some instances, the stories were so rich that the entire meaning unit transformed into the relevant meaning unit. However, in most cases the meaning unit was parsed down into a phrase or two that captured the story's essence. Eventually this process led to finding themes and those are reflected in these tables as well, but a discussion of determining themes doesn't come until after this section. To illustrate how the participants shared stories and how essences from their stories were captured to find relevant meaning units, the following tables use transcript excerpts to exemplify the findings.

Awareness. The excerpts from Table 3 reflect essences and relevant meaning units that were clustered to represent awareness.

Wilma's segments reflect the compassion she shows for the other students at school who need the regular math curriculum to meet their academic needs.

Trudy shares stories that reflect the compassion she feels for the students who don't get special academic opportunities like she gets when she leaves the regular classroom to attend TAG activities, but she is also aware that some of it might be jealousy, so there may be some awareness of social justice at play.

Concern for the students who are going to follow him through the TAG program illustrates how Theo is compassionate about the feelings of others and how he wonders about students getting the same opportunities as others; therefore showing his awareness of social justice for others in the coming years.

Having to follow rules that seem to hamper the experience for Finn is not something he enjoys; however, he has a heightened awareness of rules and why they are 
in place, even if he sees the effectiveness and importance of the rule differently than

those in authority.

Table 3.

Transcript Segment: Awareness-compassion/social justice/rules

\begin{tabular}{|c|c|c|}
\hline Participant: & Relevant Meaning Unit: & Essence/THEME: \\
\hline Wilma & $\begin{array}{l}\text { "I felt fine about it [getting the regular math } \\
\text { curriculum] because some of those kids are } \\
\text { really learning it and I already know how to do } \\
\text { all that stuff." (Interview \#1) } \\
\text { "I was fine and the other kids were challenged } \\
\text { with the math they had and that was okay for } \\
\text { them. It was good they had a challenge." } \\
\text { (Interview \#2) }\end{array}$ & $\begin{array}{l}\text { Compassion } \\
\text { Social Justice } \\
\text { AWARENESS }\end{array}$ \\
\hline Trudy & $\begin{array}{l}\text { "Sometimes they [other students] think it is } \\
\text { sort of weird that we leave, but I think some of } \\
\text { it may be jealousy, but I really don't know." } \\
\text { (Interview \#3) } \\
\text { "I didn't necessarily feel bad for them [the } \\
\text { students left behind], but sort of, like, I wish } \\
\text { they were in TAG so that they could have fun } \\
\text { too." (Interview \#2) }\end{array}$ & $\begin{array}{l}\text { Compassion } \\
\text { Social Justice } \\
\text { AWARENESS }\end{array}$ \\
\hline Theo & $\begin{array}{l}\text { "When I am at school, I kind of wonder, like, } \\
\text { what will happen to the TAG Program... will } \\
\text { they [the students left at the school] be able to } \\
\text { do something that might have to do with } \\
\text { critical thinking, kind of like the activities we } \\
\text { used to do. I am always waiting for those } \\
\text { kinds of questions and always trying to find } \\
\text { ways to answer them." (Interview \#1) }\end{array}$ & $\begin{array}{l}\text { Compassion } \\
\text { Social Justice } \\
\text { AWARENESS }\end{array}$ \\
\hline Finn & $\begin{array}{l}\text { "Having troubles with rules is kind of an } \\
\text { experience I've been having...there were some } \\
\text { rules that I've really thought there's no point } \\
\text { in, but had to follow them anyway. I just } \\
\text { thought the rules were unreasonable and they } \\
\text { usually didn't make much sense and, in my } \\
\text { opinion, they weren't really fixing anything." } \\
\text { (Interview \#1) } \\
\text { "I think that because I was gifted I had a } \\
\text { greater tendency to break the rules because I } \\
\text { don't see the rules the way other people do." } \\
\text { (Interview \#3) }\end{array}$ & $\begin{array}{l}\text { Rules } \\
\text { AWARENESS }\end{array}$ \\
\hline
\end{tabular}


Feelings. The transcript segments in Table 4 represent relevant meaning units that capture feelings the participants shared while telling stories of their experiences. Wilma shares feelings of frustration when she tells a story of getting a different math packet to work on in $3^{\text {rd }}$ grade. Her feelings of frustration manifest from not understanding the math in the packet and having to wait for help or instruction while the teacher helps the other children with the regular math assignment.

Feeling awkward was something that Trudy expressed in multiple stories. She expressed feeling "weird" (awkward) when students in the classroom were given one assignment and the advanced students were given something different. While she wasn't embarrassed and felt that leaving the classroom for TAG opportunities was worth it, she also felt awkward being pulled out of her class. The feeling of awkwardness was less when multiple children left with her at the same time.

Theo expressed feelings of concern regarding change, both current change and possible change in the future. His feelings of concern seem to revolve around him not knowing the reason for the change and not understanding how that change will make things better than they currently are.

Finally, Finn expresses stories where he talks about something making him feel good or taking pleasure in an activity. It is important to note that Finn's feeling good and taking pleasure encompasses some negative behavior. Finn has found his humorous side and this has helped his social standing with friends. His humor makes him feel good and he is motivated to find opportunities to use humor in his daily experiences. In the situation referred to in this table his humor was not appreciated by the teacher as much as 
his peers; therefore, the laughs he generated for his peers got him a referral to the office from his teacher. Finn also shares stories of experiences in earlier grades, when he took pleasure in annoying people and how annoying people made him feel good. Reflecting on the experience as he tells it now, he doesn't understand why he felt good about this behavior and he realizes that the underlying reason, correcting other people's mistakes, is still something that he feels compelled to do, but now understands the social ramifications of these actions.

Table 4.

Transcript Segment: Feelings—frustration/awkwardness/change/pleasure

\begin{tabular}{|c|c|c|}
\hline Participant: & Relevant Meaning Unit: & Essence/THEME: \\
\hline Wilma & $\begin{array}{l}\text { "I was in my own packet and I was really } \\
\text { confused on what to do...I was just stuck and } \\
\text { no one was there to help me. I was frustrated, } \\
\text { I was really frustrated!" (Interview \#1) } \\
\text { "I don't just want to be stuck there } \\
\text { forever...I'll be frustrated as long as there's } \\
\text { someone there to help me understand and I'm } \\
\text { not just frustrated and confused all the time." } \\
\text { (Interview \#3) }\end{array}$ & $\begin{array}{l}\text { Frustration } \\
\text { FEELINGS }\end{array}$ \\
\hline Trudy & $\begin{array}{l}\text { "And that felt sort of weird because everyone } \\
\text { else had the regular work and we had the } \\
\text { advanced work." (Interview \#1) } \\
\text { "Being pulled out of class was a bit awkward, } \\
\text { but it always paid off. It was awkward, but not } \\
\text { to the point where I was embarrassed." } \\
\text { (Interview \#2) }\end{array}$ & $\begin{array}{l}\text { Awkward } \\
\text { FEELINGS }\end{array}$ \\
\hline Theo & $\begin{array}{l}\text { "I am concerned about how the behavior } \\
\text { system will change, like it did this year, or how } \\
\text { the playground will change and I won't know } \\
\text { why they changed what they did. Kind of like } \\
\text { right now how they are making changes on the } \\
\text { building, they say it is for energy efficiency, } \\
\text { but it added an extra } 4 \text { feet of room to the } \\
\text { classrooms." (Interview \#1) }\end{array}$ & $\begin{array}{l}\text { Change } \\
\text { Concern } \\
\text { FEELINGS }\end{array}$ \\
\hline Finn & $\begin{array}{l}\text { "My motivation was to make people laugh...It } \\
\text { makes me feel good, that's sort of what keeps }\end{array}$ & $\begin{array}{l}\text { Felt Good } \\
\text { Pleasure }\end{array}$ \\
\hline
\end{tabular}




\begin{tabular}{|l|l|l|}
\hline $\begin{array}{l}\text { me going." (Interview \#1) } \\
\text { "I felt good when I was annoying people back } \\
\text { then-it felt good until much later. In a way I } \\
\text { took pleasure in annoying people." (Interview } \\
\# 2 \text { ) } \\
\text { “...it used to be that whenever something was } \\
\text { not factual it made me, I don't know, angry and } \\
\text { frustrated and correcting it would make me } \\
\text { feel better. I felt like I was stopping mistakes } \\
\text { but now I figure that no matter how old people } \\
\text { get there are probably always going to be } \\
\text { people who are always one step behind me, } \\
\text { who are still going to make mistakes, they may } \\
\text { not be the same mistakes but they still are } \\
\text { going to be making a lot of mistakes and I } \\
\text { figure it's kind of pointless to try to prevent } \\
\text { them if I am not going to be able to do it } \\
\text { because of the cost of losing friends." } \\
\text { (Interview \#3) }\end{array}$ & \\
& \\
\hline
\end{tabular}

Learning. The largest cluster of essences was found in the area of learning and some of those are shared below in Table 5. Out of the four participants, three had this as their largest representation of essences; therefore, illustrating that this is a very important part of their lived elementary school experience. All four of the excerpts below relate to having fun learning in school.

Trudy and Wilma refer to the challenges they received in their advanced (skill grouped) math class as fun. Wilma talks about how being challenged means she isn't bored and Trudy shares that even though the advanced math class is hard, she is in there with friends who are being challenged also, so she doesn't feel alone.

Theo exudes enthusiasm when you get him talking about critical thinking activities and games. In the excerpt referred to below, in his excitement talking about 
critical thinking opportunities in the classroom, he throws in an animated fist pump to show just how much he loves these experiences.

Having fun while learning is important to Finn and he credits teachers and different projects or activities for making that possible. Finn likes having the opportunities to do different things while learning instead of always having to learn out of a workbook or textbook. He also appreciates teachers who work at keeping things interesting, funny and entertaining.

Table 5.

Transcription Segment: Learning_challenge, choice, fun, activities, teachers

\begin{tabular}{|c|c|c|}
\hline Participant: & Relevant Meaning Unit: & Essence/THEME: \\
\hline Wilma & $\begin{array}{l}\text { "In } 5^{\text {th }} \text { grade our teacher would give us a page } \\
\text { or two of } 6^{\text {th }} \text { grade standards, that way we } \\
\text { didn't have to be bored, so we were challenged } \\
\text { because we were high... if we [all students, not } \\
\text { skill grouped] were all in the same class, we } \\
\text { would've never gotten all those same sheets } \\
\text { because some of the kids just wouldn't be } \\
\text { ready for that." (Interview \#1) } \\
\text { "I felt it was much better that we had a high } \\
\text { math class because then everybody who was in } \\
\text { the class could be more challenged and didn't } \\
\text { have to just go with the other kids and be } \\
\text { bored. When you are bored, that doesn't make } \\
\text { school fun!" (Interview } \# 2 \text { ) }\end{array}$ & $\begin{array}{l}\text { Challenge } \\
\text { Teachers } \\
\text { Activities } \\
\text { Fun } \\
\text { LEARNING }\end{array}$ \\
\hline Trudy & $\begin{array}{l}\text { "In } 5^{\text {th }} \text { grade I was in the advanced math class } \\
\text { and it is really, really hard and it's fun, so it is } \\
\text { my favorite part of my day. It's challenging } \\
\text { and I'm with a group of people, who I'm } \\
\text { friends with most of the people, but they are as } \\
\text { challenged as I am. I liked it because I wasn't } \\
\text { falling behind and I didn't feel alone." } \\
\text { (Interview \#1) }\end{array}$ & $\begin{array}{l}\text { Challenge } \\
\text { Fun } \\
\text { Friends } \\
\text { LEARNING }\end{array}$ \\
\hline Theo & $\begin{array}{l}\text { "Those things just really get me thinking. } \\
\text { They are things to stretch your mind a little bit } \\
\text { and when you play one of those games, you } \\
\text { are thinking of those same things but on }\end{array}$ & $\begin{array}{l}\text { Choice } \\
\text { Fun } \\
\text { Activities }\end{array}$ \\
\hline
\end{tabular}




\begin{tabular}{|l|l|l|}
\hline \multirow{7}{*}{ Finn } & $\begin{array}{l}\text { completely different level-a MUCH higher } \\
\text { level. And it makes me, like, just, YES!! [with } \\
\text { a fist pump] Because those games are quite } \\
\text { fun!" (Interview \#2) }\end{array}$ & LEARNING \\
$\begin{array}{l}\text { "Sometimes we do some really fun things in } \\
\text { reading and there have been multiple moments } \\
\text { where we've worked on projects that I've } \\
\text { really enjoyed and then there are other days } \\
\text { where we do really boring stuff like } \\
\text { worksheets and textbooks." (Interview \#1) } \\
\text { [in reference to one of his favorite teachers] } \\
\text { "She was fun and had us do fun assignments } \\
\text { and she was nice. I never saw her lose her } \\
\text { temper and she was pretty interesting and fun." } \\
\text { (Interview \#2) } \\
\text { "Being a teacher is kind of a tough job and it's } \\
\text { kind of hard to be humorous when you are a } \\
\text { teacher today and, in my opinion, it's even } \\
\text { harder than it was before. Thankfully there are } \\
\text { a few teachers out there who have maintained } \\
\text { their sense of humor and I do appreciate that } \\
\text { because it does make everything more fun and } \\
\text { not only do I have the chance to laugh at } \\
\text { somebody else, the classroom is more } \\
\text { relaxed." (Interview \#3) }\end{array}$ & LEARNING \\
\hline
\end{tabular}

TAG programming. Table 6 represents the relevant meaning units clustered under TAG Programming. It was noted, when discussing the previous table, that 3 of the 4 participants had their highest frequencies in learning and that is because TAG Programming was Trudy's highest frequency cluster. Trudy's stories are similar to those in the learning cluster; however, she actually credits the TAG Program and TAG label as to what makes these experiences relevant, so that is why they are clustered here.

On multiple occasions Trudy talks about how school was good, but how TAG has been instrumental in making it better. She credits having challenging learning opportunities, as well as another arena for making friends, to her TAG identification and inclusion in the TAG Program. Later in this analysis she does share some drawbacks to 
being identified as a TAG student; however, the majority of all her stories referring to

TAG are very positive.

Wilma also credits the TAG Program for providing her the challenging and differentiated learning experiences she likes so much. In the excerpt shared in Table 4 she is referring to TAG activities (worksheets) that were out and available on a daily basis for students to pick up at their leisure. She would take these activities to enrich her regular classroom experience and to keep her occupied if she finished her assigned work quickly.

Here, again, Theo is talking about those critical thinking opportunities and in this excerpt he is specifically talking about those that happen in the TAG room.

While the other participants shared experiences that were positive about being a TAG student, Finn shared an observation in which his giftedness was not so positive in his regular classroom setting.

Table 6.

Transcript Segment: TAG Programming—challenge/differentiation/friends/fun

\begin{tabular}{|l|l|l|}
\hline Participant: & Relevant Meaning Unit: & Essence/THEME: \\
\hline Wilma & $\begin{array}{l}\text { [referring to positives of TAG Programming] } \\
\text { "During math I could get really bored, so after } \\
\text { I got done or if I was bored, I was able to do } \\
\text { the TAG activities and the challenges that were } \\
\text { available...I got to have my own math packet } \\
\text { in } 3^{\text {rd }} \text { grade and I don't think that would have } \\
\text { happened if I wasn't in TAG." (Interview \#2) }\end{array}$ & $\begin{array}{l}\text { Challenge } \\
\text { Differentiation }\end{array}$ \\
TAG \\
"When I got into TAG things just got better. \\
Trudy \\
$\begin{array}{l}\text { There were more activities to do and things } \\
\text { that were on my level and things that would } \\
\text { challenge me a lot....Another thing that is } \\
\text { really fun about TAG is you can talk about } \\
\text { things in depth that would be boring to other } \\
\text { people...TAG helped me blossom....I was }\end{array}$ & $\begin{array}{l}\text { Challenge } \\
\text { Friends } \\
\text { Fun }\end{array}$ \\
\hline
\end{tabular}




\begin{tabular}{|l|l|l|}
\hline & $\begin{array}{l}\text { happy and I was good and then in TAG I } \\
\text { started growing more, like putting myself out } \\
\text { there a lot-I said hello to new people and I } \\
\text { challenged myself in new things." }\end{array}$ & \\
\hline Theo & $\begin{array}{l}\text { "In TAG we do activities to really get us } \\
\text { thinking." (Interview \#2) } \\
\text { "...sometimes TAG students do miss out on } \\
\text { fun things in the regular classroom, but at the } \\
\text { same time you don't want to miss out on the } \\
\text { TAG activity." (Interview \#3) }\end{array}$ & $\begin{array}{l}\text { Thinking } \\
\text { Fun }\end{array}$ \\
\hline Finn & $\begin{array}{l}\text { Preferring to issue of shouting out in class] "I } \\
\text { think that was mainly because I was gifted in } \\
\text { information, so it was kind of hard not to share } \\
\text { that information." (Interview \#1) }\end{array}$ & \begin{tabular}{l} 
Difficult \\
TAG \\
\hline
\end{tabular} \\
\hline
\end{tabular}

Friends. There was also another natural clustering of relevant meaning units, but this one was unique in that it also was represented throughout all the other clusters and this cluster referred to friends. In the areas of awareness, feelings, learning and TAG Programming, there were relevant meaning units that referred to friends. However, what is unique about the cluster of friends is that there are separate relevant meaning units that tie solely to the essence of experiencing with friends and have their own relationship. So, while friends is included in the next step as a central theme, it not only stands alone as a theme but it also weaves itself throughout the other clusters in an effort to capture how important friends are to gifted children in elementary school.

Table 7 represents relevant meaning units that are not found in the other clusters because their essence is captured in phrases that make general reference to experiencing with friends. Wilma and Trudy refer to their friendships being inclusive of many children; however, Wilma points out that her close circle of friends consists of TAG students and Trudy is thankful to have friends in TAG because she feels extra support and encouragement. 
Theo's statement in Table 7 is just a general statement about how he spends his recess and lunchtime hanging out with friends and others. He speaks of a particular friend, who he considers his best friend, but he also talks about a variety of others who are both close friends and people in general.

In Finn's excerpts, in Table 7, he further articulates his struggle with being socially accepted by the other students, outside of his close circle of friends. He understands how important friends can be in the future and he feels the ramifications of his earlier actions; however a great deal of his understanding came later in fifth grade so he has had to work hard on repairing old damage. Additionally, he appreciates how his newly developed sense of humor has helped him in repairing his social standing.

Table 7.

Transcript Segment: Friends-fun/general reference to...

\begin{tabular}{|l|l|l|}
\hline Participant: & Relevant Meaning Unit: & Essence/THEME: \\
\hline Wilma & $\begin{array}{l}\text { "I have a small group of close friends, but I let } \\
\text { a ton of other kids play if they want....Most of } \\
\text { my friends are not in TAG, but my close circle } \\
\text { of friends are." (Interview \#1) }\end{array}$ & Feneral Reference to \\
\hline Trudy & $\begin{array}{l}\text { [in reference to friendship circle] "I don't } \\
\text { really think about are you in TAG or not, I } \\
\text { don't really remember. I don't treat them } \\
\text { differently and they don't treat me differently." } \\
\text { (Interview \#1) } \\
\text { [my TAG friends] "They encouraged me and I } \\
\text { made new friendships, they're just really there } \\
\text { for me. It makes me feel happy that they are } \\
\text { there for me, in fact, I'm jubilant!! I'm happy } \\
\text { they are there for me and I will be there for } \\
\text { them. I'm very relieved they are there for me. } \\
\text { When I get to middle school, I will know a lot } \\
\text { of people and that will help a lot. I will have } \\
\text { friends who will encourage me." (Interview } \\
\text { \#2) }\end{array}$ & FRIENDS \\
\hline "At recess I play with a group of people and & General Reference to \\
\hline
\end{tabular}




\begin{tabular}{|c|c|c|}
\hline & $\begin{array}{l}\text { my friend "X", we do all kinds of fun activities } \\
\text { running around a lot....At lunch I pretty much } \\
\text { sit in the same spot and with the usual group of } \\
\text { people or my close friends and some others } \\
\text { and we just talk a lot about things." (Interview } \\
\# 1 \text { ) }\end{array}$ & $\begin{array}{l}\text { Fun } \\
\text { FRIENDS }\end{array}$ \\
\hline Finn & $\begin{array}{l}\text { "I really like recess!" (Interview \#1) } \\
{\left[\text { in } 3^{\text {rd }} \text { grade] "I pretty much alienated myself }\right.} \\
\text { from pretty much just about everyone....I } \\
\text { would sit around and make historical and } \\
\text { grammatical corrections to what they were } \\
\text { saying, you know, basically annoying } \\
\text { them....[in } 5^{\text {th }} \text { grade I noticed] All the people } \\
\text { that I had missed an opportunity to strike up a } \\
\text { friendship with were starting to strike up } \\
\text { friendships with each other and with other } \\
\text { people and I was the only person who wasn't. } \\
\text { So I started to realize that there were benefits } \\
\text { and that they were doing a lot cooler stuff." } \\
\text { (Interview \#2) } \\
\text { "In the middle and end of the [5 } 5^{\text {th }} \text { grade] } \\
\text { school year were sort of a salvation for me } \\
\text { because they kind of came over to my side. } \\
\text { People wanted to start being my friend because } \\
\text { they saw me as funny." (Interview \#1) } \\
\text { "Friends have always been kind of important, I } \\
\text { mean I have always had friends...my true } \\
\text { friends haven't changed....it's mostly about } \\
\text { loose ties which overall, generally, can be in } \\
\text { some categories more important than strong } \\
\text { ties. If you're looking for jobs especially." } \\
\text { (Interview \#3) }\end{array}$ & $\begin{array}{l}\text { General Reference to } \\
\text { Fun } \\
\text { FRIENDS }\end{array}$ \\
\hline
\end{tabular}

Determining themes from clusters of meaning. Friends seem to be the most integral part of the gifted child's elementary experience. While reading and listening to the data again and again, the central theme of Friends keeps entering into my analysis as truly the most important part of elementary school for these participants. As much as the participants talked about wanting to be challenged and choice in their projects or activities or about how their favorite teachers were the ones who made learning fun, the 
one thing they always came back to was friends - not always conveying positive stories about friends, but sharing stories that they clearly felt strongly about. Under this central theme of Friends there are four general themes that help to illuminate the essence of the elementary experience for gifted children: Awareness, Feelings, Learning and TAG Programming. And with all that said, I would wholeheartedly say that the only thing that I found or felt to be similar, common, and descriptive amongst all four participants is in the way they all experienced elementary school so differently. According to their stories they chose to share, each participant had a distinct experience and perception of their overall elementary school experience.

One common unit of relevant meaning that was expressed in each of the above themes was fun. Every participant, in some way, referred to wanting to have fun at school or with friends, and while a gifted child might define fun at school differently than the typical child, I don't believe the concept of wanting to have fun in school is relevant or unique to the understanding of the phenomenon of being gifted in elementary school. Where the concept of having fun is relevant is in how essences of fun were captured in the stories and experiences shared. In this study essences of fun were captured and were clustered into the general themes of: Awareness, Feelings, Learning and TAG Programming as well as the central theme of Friends and didn't emerge as a theme of its own.

Analysis of distinct experiences. Table 8 represents how the keywords that captured essences from the general meaning units were clustered to determine themes. As you can see, and as was stated earlier in the analysis, Learning had the highest 
FINDING THE GIFTED CHILD'S VOICE

frequency of keywords in total instances for Wilma, Theo and Finn. You can also see that Trudy's highest frequency fell under the theme of TAG Programming.

Table 8.

Frequency table of keywords representing essences from general meaning units

\begin{tabular}{|c|c|c|c|c|c|}
\hline Theme: & Wilma & Trudy & Theo & Finn & Total: \\
\hline Awareness & 5 & 10 & 12 & 23 & 50 \\
\hline Feelings & 9 & 13 & 7 & 27 & 56 \\
\hline Learning & 55 & 25 & 18 & 40 & 138 \\
\hline $\begin{array}{l}\text { TAG } \\
\text { Programming }\end{array}$ & 21 & 37 & 8 & 6 & 72 \\
\hline Friends & 10 & 15 & 7 & 27 & 59 \\
\hline
\end{tabular}

Additional analysis of Table 8 supports the finding that the four participants all experienced elementary school in a distinctive way. While 3 of the 4 participants had Learning as their highest frequency of keywords, the range of frequency was from 18 to 55; showing a difference in general meaning units that directly connected to Learning and a difference in the expressiveness of the participants regarding Learning.

To further support how the participants each described unique school experiences, the following figure represents how Table 8 would fall on a radar graph. Radar graphs are usually used in quantitative analysis of data and are often referred to as web or spider charts in that it is similar to how a spider creates a web. I thought, however, that the radar graph was illustrative of how differently TAG students navigate their environment when given the same structure or environment. 
According to Harris (2002), a spider builds a web by casting a single thread into the wind and when it catches onto something, the spider pulls it tight and then uses this bridge to release a loose thread that the spider then attaches to another axis. When that structure is in place the spider then fills in the middle of the spider web and waits to catch its prey. Using this analogy you could say that Wilma, Theo and Finn cast that first strand and it landed on Learning and after pulling it tight, they then attached the loose thread to another area in which they felt secure. Wilma attached hers to TAG Programming, Theo's was attached to Awareness and Finn attached his to Feelings. Trudy did the same thing and her bridging thread was attached tightly to TAG Programming and anchored in learning. After these participants anchored their "webs" you can see how differently they navigated their completed web in which they "caught" their elementary experiences. A detailed description of how they navigated their web is found immediately after Figure 7.

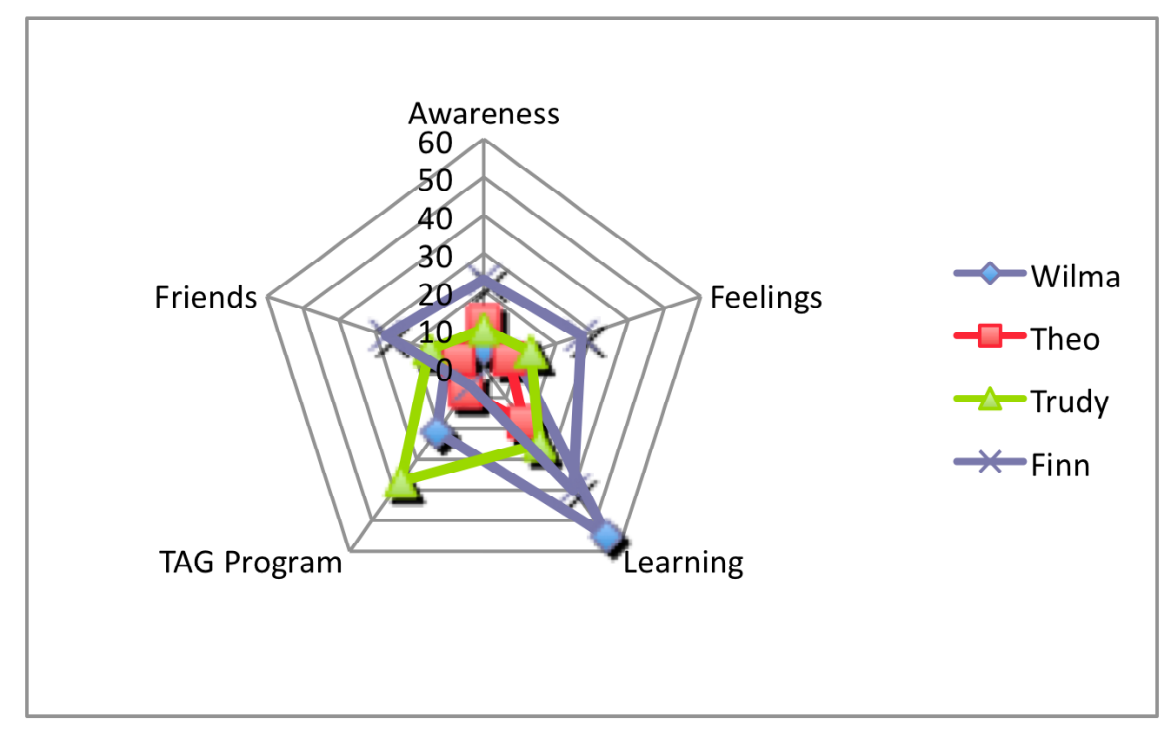

Figure 7. Radar graph of keywords. This figure is a graphic representation of keywords used to cluster relevant meaning units and the different ways in which the participants experienced these clusters. 
As you can see from Figure 7, there is not one thematic cluster in which any of the participants directly stack on top of one another. None of their peaks overlap and none of their lowest frequencies share a common space, nor do any of the points in between. This illustration shows how varied their experiences were.

While their experiences were varied, I also found it interesting in how two of the participants were high in frequency while the other two would be low; and that it wouldn't be the same two that were high or low in different areas. Or there would be one participant who would be high, one who would be low and the other two would be in the middle. Here is an analysis of what I am trying to describe:

In the cluster of Awareness Wilma has the lowest frequency and Finn has the highest frequency, while Trudy and Theo are only two frequencies apart in the middle; but 5-7 frequencies higher than Wilma and 12 lower than Finn.

In the Feelings cluster Finn has the highest frequency and Theo the lowest. Trudy and Wilma are in the middle; however, Wilma is closer to Theo (only 2 frequencies different) than Trudy (4 frequencies different) and Trudy is 14 frequencies less than Finn. That difference is greater than the actual frequencies Trudy has in this cluster.

As stated many times throughout the analysis and findings, Learning has the highest frequency, by far, of the other themes, but, again, it includes variation from Theo's 18 keywords compared to Wilma's 55. Trudy's 25 and Finn's 40 frequencies fall in the middle, but are still varied by quite a bit from each other and Wilma and Theo. 
In TAG Programming, Trudy and Wilma dwarf the frequencies of Theo and Finn. Trudy has 37 frequencies, Wilma has 21, Theo has 8 and Finn has 6. TAG Programming has the most polar division with two participants with high frequencies and two with low.

Finally, Friends, the central theme that also represents a cluster in itself, shows a difference of 20 from Finn with the most frequencies of 27 to Theo with only 7; Wilma and Trudy come in the middle with 10 and 15 frequencies, respectively.

This analysis confirms that these four participants had a varied elementary school experience or, at least, the stories they chose to share to represent their school experience were very different.

\section{Summary}

Interview summaries. In the final steps of the analytic process, Hycner (1985) suggests that the researcher write a summary for each individual interview, return to the participant with the summary and themes, conduct a second interview, modify themes accordingly, identify general and unique themes for all the interviews, contextualize themes and develop a composite summary.

I wrote a summary for each participant based on the first two interviews and work session and in a third and final interview, I reviewed the summary with the participants and allowed for corrections and additions to the data. After that process, no modifications to the themes were necessary.

In an effort to identify general and unique themes for all the interviews, I reviewed all the transcripts and all the data analysis charts. Looking at the data, 3 of 4 participants had the highest number of relevant meaning units in the area of learning, indicating that this is an important theme in their elementary experience. For the other 
participant, their highest number fell in TAG Programming. For the other themes there was a wide variety of representation of relevant meaning units from the participants, again reinforcing how differently they experience elementary school.

Wilma. One participant, Wilma, had a very high number of references to learning, particularly in the areas of differentiation, boredom, skill grouping and lack of challenge and choice in her day-to-day learning experiences. She had a clear understanding of the workings and benefits of skill grouping, often pointing out that the lack of skill grouping led to her boredom and frustration.

[speaking about the benefits of skill grouping] That way they're [the teachers] not really always focused on the kids that are needing help, because then one teacher is focusing on what the high kids need and one is focusing on the kids who need help. Like one is teaching a high group, one is teaching the on grade level group and one is focused on the kids who need help instead of just the kids who need help and leaving the high kids out there to do their own thing and it really doesn't work that way. It doesn't work because the high kids are, like, helping the kids who need help and the high kids already know that stuff so they're, like, bored and then they're not learning anything and then they soon will get behind because they're not learning anything. (Wilma, Interview \#1).

Trudy. Another participant, Trudy, attributed most of her stories to the positive impact of the TAG Program and the opportunities it gave her for making friends, building confidence and growing as a student and individual. She talked about the encouragement, support and challenge she found from her TAG teacher and TAG friends. However, she also talked about the misunderstanding others have of TAG. 
In relationships with teachers, those are affected a bit because some teachers don't like us being pulled out. Some teachers like TAG and some teachers like it but they don't like the things that come with it, so it feels like they have a vision of us that's not good because we're in TAG sort of. I think their expectations are a bit higher because we're in TAG and this isn't wrong, but it isn't right either, they think because we're in TAG we should be able to do things better than other kids so they raise their expectations higher and that's challenging in a fun way and that is sort of also challenging in a not so fun way because everybody else gets this [work] and we get this major project, but being in TAG is very fun. It's like, you are in TAG, so you should be able to do those things and do better things, so do it. (Trudy, Interview \#1).

Theo. Theo was the least expressive storyteller of the four participants and while he had the most relevant meaning units in the area of learning, they were sporadic in nature and not heavily concentrated in any particular area like fun, projects or relating to teachers. Theo's stories of learning were typical in nature and similar to the other participants in that he liked to stretch his brain and work with friends, but where Theo seemed to really become descriptive and more engaged was when he was telling stories about rules and his cognizance of social justice. Theo's second highest number of relevant meaning units fell in the Awareness theme and in this area he expressed an acute awareness of rules and social justice including everything from questioning the rules of how to write a proper paragraph to rules of playground games and the rules of not being in a classroom without a teacher present. He also shared stories that expressed concern of others not getting the same experiences or advantages he has received. Theo shared 
stories that had the essence of compassion and concern for friends and other students that highlighted his awareness of rules and social justice.

Kind of like that recess thing and my friends, we like to come up with games that involve running and because we have a rule of not really playing Tag, we would make exceptions to that by calling the game Madman so that would make it different but still have the same concepts as Tag and sometimes we get away with that, in fact, always. Sometimes there are problems with this game. When we use the entire play structure it is complicated and I, kind of, had this issue, but not really an issue, but I kind of always tried doing something and I didn't know if it was an actual rule until someone said, "you can't do that" and then I asked why and they said, "because we have a rule of this..." but sometimes we don't use it or evaluate the rules and all we do is just play, like okay, let's just do it and I always do it and then I just don't always know the rules, even though I just kind of learn them as I go. (Theo, Interview \#1).

Being Finn: An expanded summary. Finn was very unique in that he was, by far, the most expressive participant in the group. While his stories contained the most relevant meaning units in the area of learning, his number of relevant meaning units in the areas of awareness and feelings were more than double the other participants and almost double in the area of friends. As mentioned earlier, Finn has had quite the journey through elementary school and this journey has been full of both high points and low points that are illustrated the following snapshot of his elementary school experience. In the areas of Friends, Awareness and Feelings, Finn elaborated on a journey through elementary school that was riddled with feelings of isolation, frustration and 
rejection. He shares stories of not understanding why it didn't bother him at the time he was alienating himself from his peers, but is thankful that in his later elementary school years he was able to turn his social standing around through humor. When asked about how he felt during the earlier years, he shared this story:

It felt good while I was doing it and I don't know why I expected this, but I kind of expected them to sit and take it, instead of fighting back and I didn't like it when they fought back, even though I kind of deserved it. Eventually I got used to it and they said they didn't care and that is the least insulting thing I could think of someone saying and I don't know why it bothered me so much that they said they didn't care, but I guess it was because it was showing that they were becoming resistant to me or either that or they just didn't care about factuality which, back then, was the gravest insult to me because of my obsessiveness of being factual. (Interview \#2).

His keen awareness of rules and the interpretation of them as well as the impact giftedness has had on his elementary experience is portrayed through his intense description of feelings and friends/peers in his stories. While Finn tells his stories of his elementary experience, he also, on occasion, offers a contemporary observation (or what he calls a modern insight) in trying to explain the essence of some of his stories and I appreciated that, since he supplied the essence and I didn't have to derive it.

I believe 3rd grade was the beginning of what carried on into 4th grade and into early 5th grade years, but it's getting better, but there are still people that I haven't made up with yet....It wasn't until 5th grade that I was feeling the consequences and was starting to feel the weight of what I had done earlier....At first I really 
FINDING THE GIFTED CHILD'S VOICE

didn't care until I started to realize that it was a lot better to be popular, than to have a few friends and have everyone else not like me. I don't know, I just felt isolated later on. [When things started turning around for him] First it was because people were actually acknowledging that I existed and then when they were acknowledging that I existed, they were acknowledging me not for being the devil but for being funny. (Interview \#2).

Finn was very excited the last week of school when he had a tangible experience where he felt accepted by his peers.

At the end of the year our teacher very kindly said we could sit by anyone we wanted and make our own table groups...Several people actually invited me over to their table group and before that people were talking about how funny I was. People just started to acknowledge me more frequently and it was not for something negative. I figured that was a huge step from where it started at the beginning of the year, where they would have probably jumped out the window in an effort to avoid having me at their table group. But even if it only was 2 people, it was a sign of good things to come, like an omen. (Finn, Interview \#2).

Finn's references to Learning came in the form of not liking memorization and textbooks and his preference for teachers who make learning fun through projects and activities versus lectures and homework. He also appreciates a teacher who incorporates humor in the classroom and in activities.

I like learning about math but sometimes it can be hard to focus because all we do is work, work, work; review, review, review; teach, teach, teach; and listen, listen, listen.... I think people are more inclined, well I'm particularly more inclined to 
listen and pay attention in class if it's something fun and there's jokes thrown in there every time and then we do fun activities and not just the usual memorization. (Finn, Interview \#1).

Finn also appreciates time to socialize with his friends. His favorite part of the school day is recess and lunch because he can spend that time freely talking to his friends. $\mathrm{He}$ says:

In school they don't let us talk, I personally, don't think we get enough time to just talk and socialize. But it is kind of hard to have a decent amount of talk and socializing time in a place where we're supposed to be learning. So that's kind of a down side of going to school. (Interview \#3).

In fourth grade, Finn started a business called MegaMart that was a huge success with his classmates, even during a time when he says he was not liked by many of his peers. He sold small toys to other students using the school's behavior reward system coupons as currency. He experienced various emotions from worry to excitement and was devastated when it was closed down in fifth grade. He loved that he was able to learn about business and marketing. He was also excited about how wealthy he had become in the reward coupons, but became disenchanted when he realized the actual school rewards he could cash the coupons in for "weren't all that they were cracked up to be." (Interview \#2).

Throughout his interviews he talks about being the "oddball out" (Interview \#1) and that his main ambition in life was to be as smart as he could be (Interview \#2). He also has story after story where rules are an issue for him and he is clearly aware that he sees many things differently than others: 
I don't see things the way other people do, most people see that there are certain things or they see things in black and white and I am more imaginative. Other people see some things are possible and some things are impossible and there are some things that are difficult and I look at things as some things are possible and some things are difficult and some things are difficult but possible. (Interview \#3). Finn gives further insight into how he looks at rules differently:

I either follow the rules that are very basic and I follow the rules that I agree with and I follow the rules that are very serious....There are some minor rules that I like to break all of the time mainly because I see them as a hamper on something I'm doing and they're not all that important to me, so I just ignore them....there are other rules I simply follow because if people like me don't follow them then chaos will ensue. (Interview \#3).

Finn's data was incredibly rich, however, he would warn against just a study of him. He felt so strongly about this that he added this statement to the end of our final interview, when asked if there was anything we had missed:

I would like people to know that there are very few gifted kids exactly like me, it is a very wide spectrum and I could see a potential problem being created if people read my story and think wow I did not know this about gifted people and they would probably make decisions about that and they might not be accurate and they might not be the best decisions. So I just want to add that I am probably the only one like this even in the gifted community. (Interview \#3).

Composite summary. To develop a composite summary, Hycner (1978) advises researchers to write a summary to capture the essence of the phenomenon being studied. 
He says, "Such a composite summary describes the (world) in general, as experienced by the participants." (p. 294). The world, elementary school, that the participants in this study experienced is represented in over 115 pages of transcribed data from three interviews and one work session that included an exercise in capturing their elementary experience in art, writing or both. The findings show that friends are a very important part of elementary school and that the essence of being gifted in elementary school manifests itself in different ways for this group of participants. Wilma's giftedness is reflected in her desire to be challenged with appropriate curriculum and experiences. Trudy credits her giftedness for opening the door to the TAG Program; therefore, more opportunities for challenging activities and friends she can relate to and who support her. Finn says his giftedness is an integral part of him and has been both helpful and hurtful in his ability to make and keep friends. Theo thinks he is helpful when working on science projects in groups because he is gifted in this area of study and can come up with great ideas even though he thinks differently.

An important step in capturing the essence of the participant's experiences and describing the world in which their experiences took place was to continually bracket my preconceptions of what I expected their experiences to be. This was done by creating an Epoch and revisiting it throughout the entire data collection and analysis process.

Epoch and its role. According to Moustakas (1994), "Epoch is a Greek word meaning to refrain from judgment, to abstain from or stay away from the everyday, ordinary way of perceiving things...[it] requires a new way of looking at things..." (p. 33). Through this process I was able to vet my preconceptions in an effort to listen to and capture the children's stories with a naïve perspective. This process was very important 
because of my many years of working with gifted children as well as their teachers and parents. I, myself, was a gifted student; however, I attended a small rural school during my elementary years and do not remember any special opportunities until my middle and high school years. In middle school and high school I was advanced in math, science and business classes. Without special TAG programming or opportunities during my own elementary school experience, I completed the Epoch in both the capacity of a Talented and Gifted Specialist and as an elementary school student. For some of the questions I had answers from when I was a student and if I didn't have a story from that perspective, I completed the question reflecting on my perspective as a TAG Specialist. Using the same analysis process as I used for the participants' responses, I looked for the essence in the meaning units shared in the Epoch and created relevant meaning units. Table 9 reflects the relevant meaning units and essences found in the researcher's Epoch. Additionally, it shows which participants had similar essences captured as the researcher. Table 9.

Researcher's Epoch

\begin{tabular}{|l|l|l|}
\hline Question: & Relevant Meaning Unit: & $\begin{array}{l}\text { Essence/ } \\
\text { PARTICIPANT: }\end{array}$ \\
\hline What is gifted? & $\begin{array}{l}\text { I think that it is a child who } \\
\text { experiences their environment in a } \\
\text { way that is different from the } \\
\text { typical student. This difference } \\
\text { could be positive or negative and } \\
\text { could be recognizable by the } \\
\text { student and others or not. I think } \\
\text { giftedness is something that } \\
\text { shouldn't be held back for those } \\
\text { identified but should be shared with } \\
\text { all parents, students, and teachers, } \\
\text { so a better understanding could be } \\
\text { shared by the entire education }\end{array}$ & TRUDY \\
\hline
\end{tabular}




\begin{tabular}{|c|c|c|}
\hline & $\begin{array}{l}\text { community. This way everyone can } \\
\text { look for signs of giftedness in } \\
\text { children and we can also recognize } \\
\text { that being a great student, who is } \\
\text { well rounded, is a blessing. }\end{array}$ & \\
\hline $\begin{array}{l}\text { Tell me your favorite } \\
\text { stories. }\end{array}$ & $\begin{array}{l}\text { One of my favorite activities to do } \\
\text { with the kids is our annual } \\
\text { Invention Convention....It is so fun } \\
\text { to teach the kids about inventions } \\
\text { and how some inventions are really } \\
\text { mistakes from other ideas or } \\
\text { experiments that end up solving real } \\
\text { problems and becoming very } \\
\text { helpful. As the kids are attempting } \\
\text { their inventions it is so fun to see } \\
\text { the wheels turning, the dialogue that } \\
\text { is happening and the coping } \\
\text { strategies that are being tried and } \\
\text { developed as they learn to work } \\
\text { together and through failure....You } \\
\text { can really see their little } \\
\text { personalities come through in } \\
\text { anything from a satellite that is } \\
\text { going to improve communications } \\
\text { with Mars to the robot that is going } \\
\text { to help do your chores in a matter of } \\
\text { minutes to a security device that } \\
\text { bops little brothers on the head if } \\
\text { they try to sneak into an off limits } \\
\text { bedroom of an older sibling. } \\
\text { Giving the kids the opportunity to } \\
\text { fail in a safe environment opens the } \\
\text { door for so many great lessons. }\end{array}$ & $\begin{array}{l}\text { Exciting } \\
\text { Safe } \\
\text { Failure } \\
\text { Creative } \\
\text { Opportunities } \\
\text { TRUDY }\end{array}$ \\
\hline $\begin{array}{l}\text { Tell me about your school } \\
\text { day as a gifted child. }\end{array}$ & $\begin{array}{l}\text { My favorite part of the day was } \\
\text { recess in elementary school. I loved } \\
\text { playing with my friends and } \\
\text { because I lived in a rural } \\
\text { community, school was often the } \\
\text { only time I got to play with other } \\
\text { children my age.... The only thing I } \\
\text { didn't like about recess was being } \\
\text { teased because I wore glasses and } \\
\text { some kids could be very mean. I }\end{array}$ & $\begin{array}{l}\text { Friends } \\
\text { Different } \\
\text { WILMA } \\
\text { TRUDY } \\
\text { THEO } \\
\text { FINN }\end{array}$ \\
\hline
\end{tabular}




\begin{tabular}{|c|c|c|}
\hline & $\begin{array}{l}\text { didn't like being so noticeably } \\
\text { different than the other kids. }\end{array}$ & \\
\hline $\begin{array}{l}\text { Tell me about being gifted } \\
\text { in terms of your } \\
\text { relationships with friends } \\
\text { and teachers }\end{array}$ & $\begin{array}{l}\text { I was a very social kid and I don't } \\
\text { remember hanging out with other } \\
\text { smart kids as much as hanging out } \\
\text { with the jocks and, truly, we all } \\
\text { pretty much hung out together } \\
\text { because we were such a small } \\
\text { school district that all of us knew } \\
\text { each other really well. }\end{array}$ & $\begin{array}{l}\text { Social } \\
\text { Friends } \\
\text { WILMA } \\
\text { TRUDY } \\
\text { THEO } \\
\text { FINN }\end{array}$ \\
\hline Any other stories? & $\begin{array}{l}\text { I loved teachers who did things } \\
\text { differently, like Mrs. Graham, in } \\
\text { third grade, had us write a recipe for } \\
\text { a cookbook for our moms on } \\
\text { Mother's Day, it was a great lesson } \\
\text { in writing and math and we didn't } \\
\text { even know it. I like teaching kids } \\
\text { about descriptive writing by making } \\
\text { PB\&J sandwiches - nothing better } \\
\text { than their giggles when I smash the } \\
\text { bread with the peanut butter jar or } \\
\text { try to balance the jar on the knife. } \\
\text { Good stuff! }\end{array}$ & $\begin{array}{l}\text { Different } \\
\text { Teachers } \\
\text { Fun } \\
\text { TRUDY } \\
\text { FINN }\end{array}$ \\
\hline $\begin{array}{l}\text { What would you change } \\
\text { about school if you could? }\end{array}$ & $\begin{array}{l}\text { When I was a kid, I don't think I } \\
\text { would have changed anything } \\
\text { because I loved school. As an } \\
\text { adult, I would make the school year } \\
\text { and school day longer. I think we } \\
\text { try to jam too much into our current } \\
\text { time frame, which creates stress for } \\
\text { both teachers and students. I think } \\
\text { we need to create more "time" so } \\
\text { we can all enjoy the journey. } \\
\text { And, of course, reinstate TAG } \\
\text { Programming to a fully funded } \\
\text { position and program. }\end{array}$ & $\begin{array}{l}\text { Loved school-Kid } \\
\text { Time-Adult } \\
\text { TAG Program } \\
\text { WILMA } \\
\text { TRUDY } \\
\text { THEO }\end{array}$ \\
\hline $\begin{array}{l}\text { Choose one word to capture } \\
\text { your elementary school } \\
\text { experience. Why? }\end{array}$ & $\begin{array}{l}\text { Great! I really liked every part of it. } \\
\text { I liked to learn, I loved playing with } \\
\text { my friends and I thought my } \\
\text { teachers were nice, particularly my } \\
\text { primary grade teachers. I liked } \\
\text { being a strong student because I } \\
\text { liked getting my work done and } \\
\text { being able to help others and I loved }\end{array}$ & $\begin{array}{l}\text { Great } \\
\text { WILMA } \\
\text { TRUDY } \\
\text { THEO }\end{array}$ \\
\hline
\end{tabular}




\begin{tabular}{|l|l|l|}
\hline & $\begin{array}{l}\text { projects that used my imagination. } \\
\text { I was pretty creative and crafty. }\end{array}$ & \\
\hline $\begin{array}{l}\text { Choose one word to capture } \\
\text { your experience as a gifted } \\
\text { child. Why? }\end{array}$ & $\begin{array}{l}\text { Advantage. I appreciate, } \\
\text { particularly now, the advantage I } \\
\text { had by being gifted in math, science } \\
\text { and business. }\end{array}$ & $\begin{array}{l}\text { Advantage } \\
\text { WILMA } \\
\text { TRUDY } \\
\end{array}$ \\
& $\begin{array}{l}\text { THEO } \\
\text { FINN }\end{array}$ \\
\hline
\end{tabular}

It is important to note that I did not complete the Epoch with solely stories from being a gifted child as the participants did; however, after analyzing both the Epoch and participants' stories, it is evident that my experiences were most similar to Trudy's.

Trudy and I shared similar stories of giftedness being misunderstood by others. When asked to share our favorite stories both of us shared the invention convention. Trudy referred to it as one of her bright spots from her work session:

The Invention Convention was really fun because I got to work with two of my friends. I felt mostly nervousness because we didn't know what we were going to do, so I was nervous but it wasn't a bad thing as there wasn't any punishment or anything. (Interview \#2)

I shared it was one of my favorite experiences because:

As the kids are attempting their inventions it is so fun to see the wheels turning, the dialogue that is happening and the coping strategies that are being tried and developed as they learn to work together and through failure....You can really see their little personalities come through....Giving the kids the opportunity to fail in a safe environment opens the door for so many great lessons. (Epoch, p. 2)

Trudy and I both enjoyed friends and teachers who made learning fun and special. When you compare our choice of words that capture our elementary school experience, we both 
thought school was good. Trudy thought it was a positive experience and she appreciated the kindness and support she received. I liked every part of school including friends, teachers and learning. Both of us describe ourselves as being creative and we shared that we thought being gifted was an advantage we were thankful for.

When you compare the essences captured by my Epoch and the other participants, you can see, again, how individuals experience elementary school differently even when there are similarities.

All four participants and I appreciated friends and liked recess. We all thought that being gifted was advantageous. Wilma credited being gifted to her great math skills and Theo said it makes him helpful in class during science projects. Finn says that being gifted makes him unusual or unique, but also credits his giftedness for his newly discovered humorous side. Trudy is thankful that she was identified as gifted because it gave her more opportunities for activities and making friends. Finally, I credit my giftedness for the love I have of science and math and think that shows through in my lessons now that I am a teacher.

When the above analysis is then compared to the themes that emerged during the analysis of the participant data, it is difficult to exactly place my stories within the same themes due to the confusion of childhood stories and those that come from adult experiences. Below is an attempt at evaluating the Epoch with the same themes used with the participants.

In elementary school I wasn't aware of how differently kids were thinking, but I understand this in depth, as a teacher. As a child I loved school and other than feeling sad or angry when kids teased me about my glasses, I was a pretty happy student. As a 
gifted specialist, I have observed many feelings and emotions that surround a gifted child, so I could relate to those essences that emerged from the data.

With regards to friends, I appreciated and wanted them as a child and still do as an adult, but did not realize how important of a role, both positive and negative, friends play in the lives of gifted children in elementary school.

A love of learning has always been a part of my personality, so it is not surprising that this thematic cluster captured the highest number of essences. Additionally, if you look at my meaning units created in this area, they could fall in the same high areas as the participant's: challenge, choice, fun, projects/activities, and teachers.

In regards to TAG Programming, there wasn't one essence that was captured that I couldn't relate to or understand when it emerged from the participant's stories. Therefore, this theme was where the Epoch was critically important to making sure the outside influences were bracketed and the essences that were being captured came solely from the child sharing the story.

In comparing the experiences shared by the participants and myself, Figure 8 illustrates similarities and differences. 


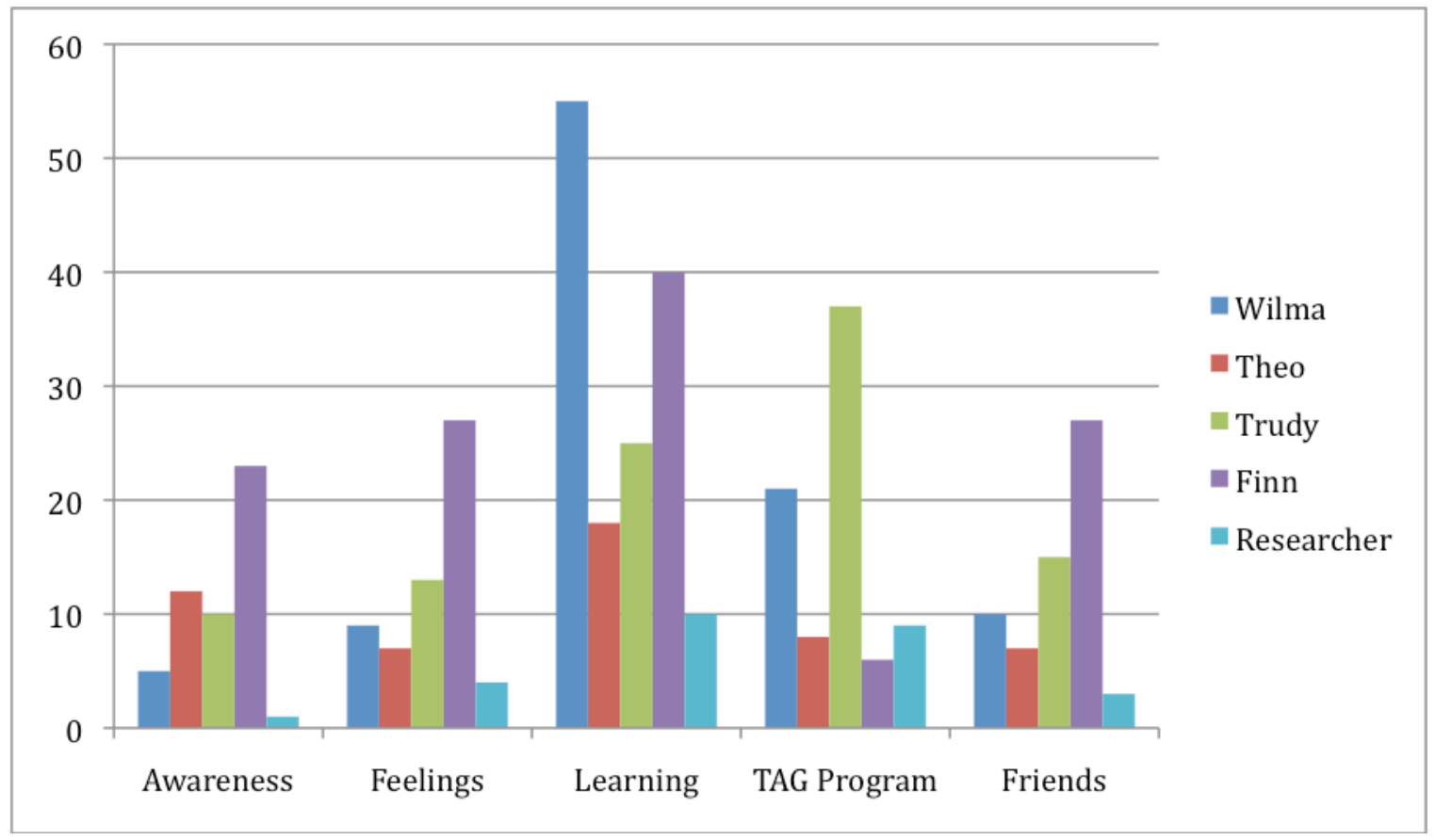

Figure 8. Researcher and participant thematic comparison. This figure compares the findings from the participants and the researcher's Epoch.

In Figure 8, similar to the participants, the researcher also scored highest in the thematic areas of Learning and TAG Programming. This would seem consistent to her role as a TAG Specialist and her focus on differentiated and enriched learning experiences with TAG students.

Summary of findings. I have to say the findings are different than I anticipated and the stories were richer than I could have hoped for, and that is what makes work like this so rewarding. The voices of the children were sincerely theirs. There was no parent or teacher influence in our sessions and when the participants knew they were helping to educate future teachers and leaders, they were honest and generous with their stories. They appeared to know that their mission was not to please me or others with the stories 
they chose to share, but to share stories that really captured the essence of their lived elementary school experience.

To further demonstrate the findings stated in this section and expand on the previous comment on the generosity of the participants with their stories, the following figure illustrates the expressiveness of the participants as defined by the number of keywords or essences attributed to each participant.

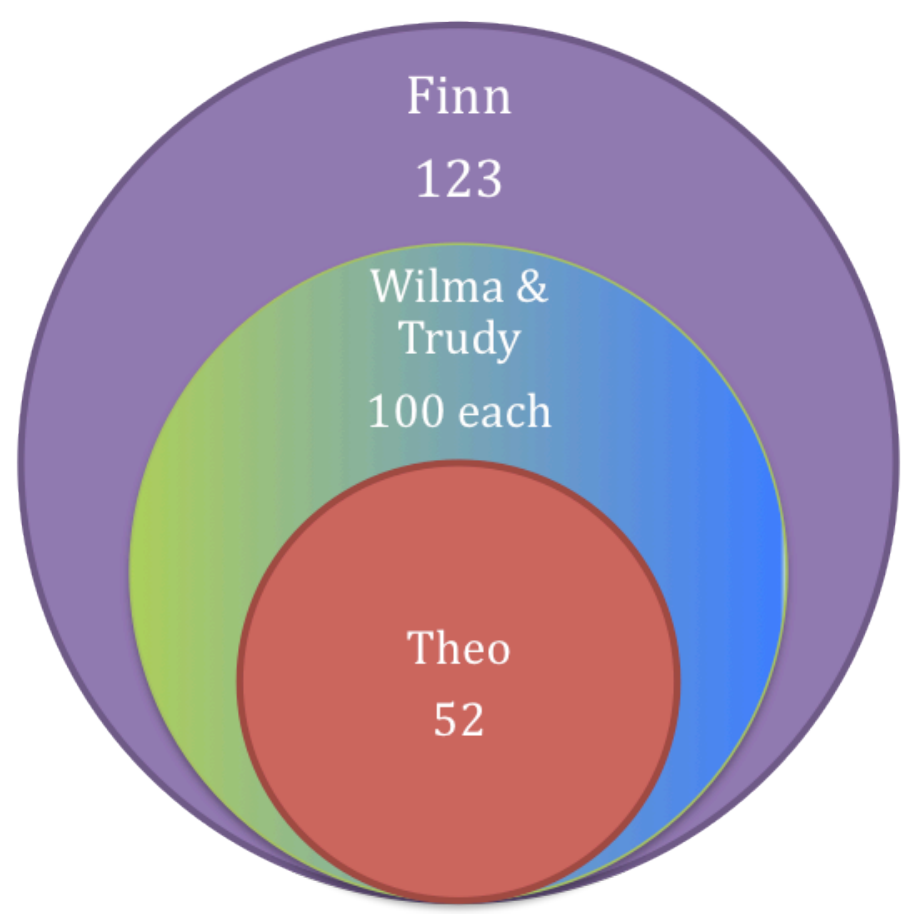

Figure 9. Expressiveness of participants. This figure illustrates the total number of keywords generated by each participant. Note that Wilma and Trudy each generated 100 keywords.

This figure represents the 375 keywords or essences captured from the original meaning units shared by the participants.

By clustering these essences the general themes of Awareness, Feelings, Learning and TAG Programming evolved. Additionally, a central theme of Friends evolved.

Figure 10 represents how Friends became a central theme by not only having its own 
frequencies of essences concerning experiences with friends, but the theme of Friends also touched all the general themes with essences that were directly tied to experiences with friends and those specific thematic clusters.

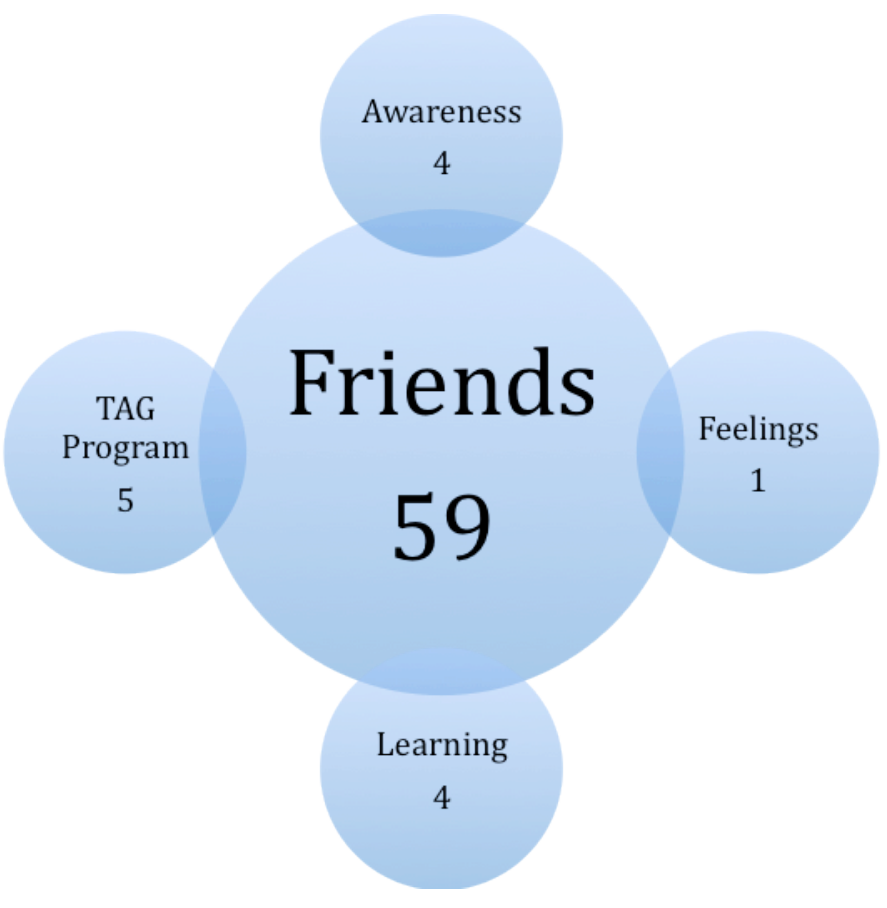

Figure 10. Central theme: Friends. This figure represents the connectedness with the other general themes.

As this figure shows, the essence of friends was captured 59 times from the participants' meaning units and out of those 59 instances, 14 of those essences were directly linked to the general themes of Awareness, Feelings, Learning and TAG Programming. This means that the essence of friends was captured another 45 times when the participants' stories made general reference to experiencing elementary school with friends. This clearly was an important part of their lived experience.

Finally, in an effort to condense all the above analysis and discussion of the findings into my understanding of the gifted child's lived elementary school experience, I offer this: While gifted children do appreciate the opportunity to be challenged in school, 
they really just want to have fun with their friends. How they define fun is most likely influenced by their heightened awareness of themselves and others and the very unique journey they navigate for themselves throughout the schooling process. 


\section{Chapter 5-Discussion}

The research question for this study was: What are the lived experiences of gifted children in the public elementary school setting? While findings were generated by this study that inform the research question, one study cannot describe the lived experiences of all gifted students in elementary school. These participants shared stories filled with references to friends, what they consider to be fun learning activities, and challenges they have encountered in school that may be attributable to being gifted.

The following sections guide the discussion and further illustrate how uniquely these students experienced school:

- A reflection on the research process;

- Implications for practice;

- Findings and their connection to the literature;

- Recommendations for further research and a conclusion.

\section{Reflection on the Research Process}

In the introduction to this paper, the struggle of the gifted student and the sacrifices their families make to support their unique needs is outlined with reference to articles in mainstream media and the scholarly literature, but one of the main reasons I chose this subject and this research question was because of my own experiences. This includes experiences with a reduction in funding for TAG programming that led to job frustration, experiences dealing with parents who were concerned and frustrated with their child's education, and experiences with teachers who were frustrated with having to add TAG and differentiation to their already overwhelming classroom responsibilities. 
Finally, and most of all, the reason I proposed this study is because of my experience working with gifted children and the joy their quirkiness brought to my life.

According to Schultz (2002a), phenomenology is a method that has been historically ignored in the study of gifted education. Shultz adds that this approach is important because it "contributes a "voice"" in the literature base. (2002a, p. 200). This study provides the depth and breadth needed to help understand the gifted child's elementary experience and it also addresses the need that Delisle (2012) speaks about when he says that we need to listen to our consumers if we are going to improve education. In this case our consumers are gifted children in elementary school and through this process their stories and experiences have become the missing voices that Schultz (2002a) speaks about.

Upon each participant's exit from the final interview, they were asked about the process and all of them felt special that their stories were going to be shared. Each participant said they wished the end of the interviews hadn't come because it was fun to tell their stories and they hoped we can do this again sometime in the future.

I, as the researcher, thoroughly enjoyed the research process with these participants. Having the opportunity to spend uninterrupted, one-on-one time with each student allowed me to learn more about gifted students and their experiences than I had encountered in twelve years of working with this population. The only drawback of this study was that I am not in a classroom this year to apply some of this newfound knowledge; however, I do know that this experience will positively impact my practice as I move forward in my career. It is also my hope that sharing this research will positively impact the work of others in the field and ultimately improve the lives of gifted students. 
Importance of the Epoch. Throughout the entire process I revisited my Epoch.

I wrote it before the participants were even chosen and I reflected on it post analysis and the statement of findings, as well as multiple times along the way when I would get concerned that maybe my thinking or perspectives were creeping in. Before each interview, I referred back to the Epoch in an effort to clear my preconceptions and prepare myself consciously for a new way of looking at things. It was a good check mechanism for me and in some instances it was hard to keep my preconceptions in check, so I was glad I had this tool to fall back on.

When I wrote my Epoch I disclosed how I was embarking on this project with a negative attitude regarding how TAG students were experiencing school, and while I still believe that they need advocates in the buildings to help them with some of the things they shared as negatives, all four of these participants seemed to come out of elementary school with positive things to say about their overall experience. This is not to say that they loved everything about school, but they were able to share many positive experiences. This experience has helped change my negative attitude into a hopeful attitude that after these findings are shared, we can create even more positive elementary experiences for gifted children.

\section{Implications for practice.}

This study has changed how I look at gifted children and gifted education in a positive way. I was really naïve to think that I was an expert when it came to gifted children and gifted education. I believe I understood, both in practice and in a scholarly manner, how gifted children "operated" in school, but the participants in this study really taught me how they "experience" elementary school. 
Giroux (1985) states that teachers must take active responsibility for raising questions about what they teach, how they teach, and what the larger goals are for which they are striving. Therefore, finding the gifted child's voice in the elementary school setting is critical in informing the need (or not) for change in TAG services to students. According to Delisle (2012):

...unless our nation's most capable students are consulted about their own suggestions for making our next generation of teachers competent, engaging, and caring, we will have omitted the most fundamental basic of all: listening to our consumers - our students — and then giving their ideas the legitimate consideration that they deserve. (p. 67)

According to Jessiman (2001), "Schools are stubborn" (p. 241). She continues with the notion that schools defy change, adding that most school reform efforts are abandoned just before they really discover something that might work. Jessiman argues that phenomenology is a tool to help bridge the gap between what is wrong in schools and the reforms necessary for thriving schools. She says, ...reformers should always think twice before deciding to throw away a lot of good in order to get rid of the bad. Reformers should work on restructuring schools to avoid perpetuation of ideologies that distort and oppress. They should do so, however, by making use of what is acknowledged to be desirable in schooling as a tool for working to eradicate the undesirable. In this way the very structures that make schooling inert can be used as powerful tools to make school reforms palatable to the public and to the people that work in schools. Inertia can produce momentum. (p. 249) 
Building off of Delisle's (2012) idea that we need to listen to our consumers and Jessiman's (2001) idea that phenomenology can bridge the gap between what is actually happening and desired change, Bergmark (2008) takes it to the next level by adding that if all members in a learning community are given a voice, they develop a collective responsibility that leads to a shared purpose and identity. Bergmark expands that idea by saying teachers really need to listen to students and by doing so the relationships and learning between students and teachers improves. Bergmark believes that "student voice is closely linked to school improvement" (p. 268). To sum it up, "The importance of student voice underlies inviting students to participate in their own education, as well as in educational research" (Bergmark, 2008, p. 268). Capturing the gifted child's lived experience and sharing it will allow for the voice Bergmark speaks of.

In interview \#1 I asked the participants what they would change about their school experience if they could. Two of the participants said they would like to have the TAG Program returned to what it was like when they were in third grade. One participant was concerned about change in general and the other participant wanted school to be less boring, with less homework. The following are their explanations and recommendations.

Wilma would like the TAG Program to go back to what it was, "because I was actually challenged and it was fun being challenged" (Interview \#1).

Trudy said she would do all that she could to bring the TAG Program back to what it was in earlier grades. She says:

...it probably wouldn't be the same as $3^{\text {rd }}$ or $4^{\text {th }}$ grade, but it would be better than what we currently have. Because of TAG I have made friends with more people 
and I have learned a lot about things. I didn't really like Scrabble before I came to TAG, but after going to all the Scrabble lunches and the competition with the other school, I play Scrabble a lot and it is really fun. (Interview \#1)

Finn says that sometimes school is just boring and there is too much homework.

Here are his suggestions for making school more enjoyable:

I would just say that there are a whole lot of things that I think are not really helping people learn, they're just giving people more of an incentive to not focus. I would suggest less memorization and textbook reading and working and have more fun activities. Things like projects and activities that you would do in class and stuff that, sort of, somebody might look forward to the class instead of dreading it. An example of a fun activity is like during the year we've read two novels in class with some sort of a wrap-up unit and we got to do some sort of a project. We had a bunch of different things we could do and we could do as many of them as we wanted to and we had several weeks to do them and it was really fun because we could do a whole lot of stuff. (Interview \#1)

Also adding:

Sometimes the load of homework even exceeds the limit that the advisory of schools, like the experts, have recommended. I would recommend loosening and lessening it and making it a little more fun--there are times, several times in math class when we've done fun things like that and I noticed it really helped people focus. Instead of us having do workbook work for reading and taking tests, if they let us write something adding little twists and quirks or just something that would be fun but also help you comprehend stuff other than tests. We could also 
get into groups of our own choice and we could reenact parts of the story.

Something similar to that would be great! (Finn, Interview \#1)

Theo has concerns about change in general and really wouldn't want to change anything about school other than how change occurs. He feels more comfortable when change comes in small doses; however, he does have some advice on how to improve the school day:

I would add a little bit of time per day for a little bit of critical thinking or even have it so if you are finished with all your work, you can do all of this stuff that's in the classroom to help you with critical thinking. With those critical thinking games you are, like, trying to figure it out while at the same time you are trying to work your brain. With those things you are having fun while you are learning. (Interview \#1)

According to Van Tassel-Baska (1983), one of the most important things a teacher can do is use teaching methods that enable students to engage in activities that help them deal with problem solving, interpersonal relationships and value judgments. In this study the data included stories that shared favorite experiences in the classroom revolving around opportunities engage in critical thinking activities. The participants also recounted how important friends were and the extra support or struggles they had in relationships. Finally, a heightened awareness of rules and social justice was evident in the data gathered. Looking at the findings in this study and the suggestion of Van TasselBaska (1983), it could be implied that an understanding of these unique needs is something that should be shared with educators. 
Additionally, Johnson (2000) offers five recommendations for teachers of gifted students. First, they need to motivate their gifted students. Second, teachers need to help gifted students understand the difference between excellence and perfection in an effort to help them have realistic expectations of their performance. Next, communication between the adults who work with gifted children must be encouraged. Then, teachers need to take the time to know the gifted child's personality; therefore, their interests and needs. Finally, teachers need to design curriculum that addresses the gifted child's selfconcept.

In this study, all the participants shared stories of not wanting to be bored and how they were more engaged if the curriculum was challenging, enriched and different. Wilma told stories of not wanting to do certain activities such as art, spelling bees or playing certain games because her expectations of her performance were higher than what she could achieve. She plays to win and wants her art to be the best, so she is hesitant to engage in activities in which she might not be the best. When given the opportunity to think differently about a project, Theo says, "I feel really interested in the subject, whereas before I'm not thinking that much, but when those opportunities do happen, then I really step up to the plate and go for it and try to get the answer." (Interview \#2).

Both Johnson (2000) and the participants share ideas in which to engage gifted students in school. Johnson states that teachers need to get to know gifted students to fully understand their interests and needs. The participants in this study share what makes for a good learning experience, so this is one step in helping teachers understand gifted students; however, offering opportunities for educators, both pre-service and those 
already in the classroom to learn more specifically about the gifted child is the only way to turn research into best practice.

Therefore, the implications for practice are multivariate in that it includes an informing of policy makers that gifted students experience school differently. This can be supported by allowing the power of the participants' voices to influence the level of understanding and direction of where monies are spent. There is also a need to enlighten administrators of the lived experiences of the gifted students in their buildings and this is possible by using this study to help illuminate areas for improvement as well as serve as a catalyst to help create a plan for gifted programming that includes the gifted child's voice.

One of the original reasons for conducting this study was to fill a void in the knowledge base of the field and I believe the participants in this study have done that by sharing their stories and allowing us to hear their voice. Publishing articles is just one more way to inform the field about these unique learners and using this study as a catalyst, I am hoping that other scholars will be encouraged to explore and research this area.

In an effort to help further understand the gifted child, I hope Finn will help me share his story. Finn's story is so important to me because I have known him for four years and had no idea of the depth of the experience he was having in school. I knew he was having a different experience, but not to the degree that he shared in this study. I am hoping a more complete body of knowledge will help another teacher do a better job than I did. 
Finally, this study made me miss working with these kids very much. I am not sure in what capacity or how it will happen, but I do know that I will be working my way back to interacting with these special children. My hope, also, is that when these findings are shared that other teachers will become inspired to learn more and embrace working with this population of students. How can you read about Finn's firestorm of traits or Trudy's jubilance about her TAG friends and not get intrigued or inspired?

Limitations of the study. Finn warned the readers of this study, in Chapter 4, that he is probably the only one like him in the gifted community and those people who are making decisions, shouldn't make decisions solely based on his story. While sample size is not technically a limitation in a phenomenological study, the findings in this study cannot and should not be generalized to describe all gifted children and their elementary school experience.

Another limitation to this study is that, due to purposeful sampling, there is not a clear understanding of one particular TAG identification, but more of a general study in giftedness. This is an area that can be addressed through further research and using purposeful sampling again, but in a particular area of interest, such as Academically Talented in Reading versus gifted in general.

This study was able to capture the lived experiences of gifted children in elementary school; however, an additional limitation is that this study only represents the stories of four participants in fifth grade from a public elementary school in the Pacific Northwest and is not representative of all gifted children attending elementary school.

Finally, even though I engaged in the Epoch process and referred to it throughout the entire study, it is irresponsible to portray an image of complete pure objectivity. 
Hycner says, "In fact, the phenomenological reduction teaches us the impossibility of a complete and absolute phenomenological reduction" (1985, p. 281). Therefore, no descriptive phenomenologist can stand in a totally presuppositionless or absolute space. My preconceptions and prior beliefs or experiences, even bracketed, are a limitation to this study.

\section{Findings and the Literature}

When the participants chose a word to describe their overall elementary school experience, all their words reflected positively on the experience. In their third interview, Wilma chose the word "fun" and Trudy said her experience was "positive". Theo added that his experience was "interesting" and while Finn said there were some things he didn't like about school, he did appreciate the friends he made in elementary school, so he chose the word "average". The participants' stories were filled with having fun with friends and liking lunch and recess. They also shared stories of favorite teachers and fun projects or activities and, in most cases, these positive stories were tied to teachers who differentiated the learning experience.

The following discussion explores the patterns between the findings in the study and the theories and best practices reviewed in the literature. These sections highlight the gifted theories shared in Chapter Two as well as the best practices that surround differentiation and affective characteristics, and are helpful in understanding the findings of this study. Not all the participants reported experiences that directly connected to all the theories and practices presented; therefore, some theories and best practices are more closely correlated to the findings than others. 
Differentiation. In the early 1960s differentiation was already being talked about as an opportunity for gifted children to engage in different processes, products and content when working in the classroom (Tomlinson, 2004). According to Marland (1972), gifted children should have the opportunity to work with their like-minded peers and at a level that promotes higher cognitive processes.

In this study, according to Wilma (Interview \#1) she was happiest when she was able to participate in a skill grouped math class in fifth grade. In third grade she had her own math packet and attended Kumon math classes outside of school for a challenge. She would get frustrated in her classroom when she would get to portions of the packet that she didn't understand and she would have to wait for help while the other children were getting the regular lessons from the teacher. In fourth grade Wilma pretty much spent the year helping other students with their math and she felt good about helping others learn at their appropriate level, but her appropriate level was primarily found in her Kumon classes and homework outside of school. She and other advanced mathematicians were even told that they were no longer allowed to answer any of the questions in the lessons because they needed to give other children an opportunity to answer. Finally, in fifth grade, she had her happiest math experience because she, and her advanced classmates, was given work at the appropriate rate and level. They moved quickly through some materials and supplemented the lessons with activities that came from a higher grade level and standards. Wilma's math experience shows an example of the inconsistencies that occurred in a three-year time span in regards to differentiation.

Passow (1982) would suggest that Wilma's teachers should have examined their curriculum to assure that it was focused on and organized around, “...more elaborate, 
complex, and in-depth study or major ideas, problems, and themes that integrate knowledge with and across systems of thought..." including:

...allow[ing] for the development and application of productive thinking skills to enable students to reconceptualize existing knowledge and/or generate new knowledge; enable[ing] them to explore constantly changing knowledge and information and develop the attitude that knowledge is worth pursuing in an open world; encourage[ing] exposure to, selection, and use of appropriate and specialized resources; promote[ing] self-initiated and self-directed learning and growth; and provide[ing[ for the development of self-understandings and the understanding of one's relationship to persons, societal institutions, nature, and culture. (pp. 7-10)

Winebrenner (2001) suggests six practical tools to help achieve Passow's goals for Wilma's experience. According to Winebrenner (2001) differentiated experiences are possible in the classroom by having the students do the most difficult problems first to show mastery of the subject matter and then compacting the curriculum, so the student has the opportunity to move on to extension or enrichment activities. Allowing choice through learning centers and tiered assignments is another way that Winebrenner suggests to differentiate curriculum and keep students engaged. Flexible skill grouping allows students to work with like-minded peers at the appropriate rate and level and, finally, open-ended lessons with multiple solutions or no prescribed answer help to differentiate learning for all students.

The above practical tools would have allowed Wilma to experience math in a different way in her earlier grades and validates why she enjoyed her fifth grade, skill 
grouped math experience. Additionally, the compacting of curriculum would allow Theo to get the critical thinking activities that he enjoys and Finn could benefit from the tiered assignments where he gets to choose the final product he produces to show his knowledge. Finally, Trudy could benefit from open-ended lessons because of her creativity, and skill grouping because of the support she feels from friends when they are challenged together.

Affective Characteristics. According to Schmitz and Galbraith (1985), gifted students often encounter problems due to their unusual sensitivity to their environments and others. Additionally they can develop a vulnerability that is fueled by criticism from their peers and a frustration that emerges when others fail to maintain the high standards that gifted students impose on others. The section dedicated to Finn, in the previous chapter, is filled with stories and experiences where he shares his struggles with exactly these things: vulnerability, criticism, frustration and unreasonable expectations of his peers' performance or understanding. Finn's stories illustrate how important it is that both educators and students understand these characteristics, so that, perhaps, we can better help students through the challenges associated with these characteristics.

Affective characteristics can be both positive and negative traits in the life of a gifted student. According to Cross (2005) it is assumed that all children have a desire to be successful; therefore, we need further research to figure out how to nurture all the unique characteristics of gifted children.

Ecological Systems Theory. According to Bronfenbrenner (1976), the social development of a child is influenced by parents, teachers and peers. In this study, the participants shared stories that were full of experiences with friends and peers, showing 
the importance of these relationships. Additionally, the participants shared stories about the impact teachers had on their enjoyment of school. Their favorite teachers were those who had a good sense of humor, made learning fun and understood the unique needs of gifted students. References to teachers and friends were very high throughout the data and each participant had stories that included experiences with friends and teachers, showing the influence and impact of these people on the participants' school experience.

Trudy specifically shares stories of how she felt supported by her family during the spelling bee when they would help her study every night after dinner and came to her school spelling bee instead of all the other things they could have be doing. She talks about how the TAG Program helped her blossom by providing her challenging activities and more friends that she felt she related to more than others. On multiple occasions she talks about the trust and support she felt from her classroom teachers and TAG teacher. Finally, she talks about how good she feels about going to middle school with a close group of friends that she is confident will support her when she needs it. Trudy's social development has been influenced by friends, family and teachers and she is confident that they will continue to help her develop and grow in the coming years.

According to Van Tassel-Baska (1983) teachers play many roles in gifted students' lives. Similar to Trudy's narrative, an 11 year old boy shares the impact a teacher can have on a child's school experience. "Teachers encourage originality and creativity, stimulate your imagination and care about you personally as well as schoolwise. They understand you're not perfect. They are friendly; they smile and make you feel good and happy. Teachers can help" (in Delisle, 1984, p. 55). The support of teachers is an important part of the gifted child's school experience. 
FINDING THE GIFTED CHILD'S VOICE

Theory of Overexcitabilities. Nelson (1989) said that Dabrowski's theory of overexcitabilities could be used as a "framework for understanding and explaining the developmental patterns and challenges that occur for those of high ability" (p.11). Dabrowski's (1964) work revolved around emotional development and Silverman (1994) used Dabrowski's work to help further articulate the overexcitabilities as, “...an abundance of physical energy, heightened acuity of the senses, vivid imagination, intellectual curiosity and drive, and a deep capacity to care." (p. 110). Two of the participants in this study showed signs of Dabrowski's overexcitabilities as they shared multiple stories that highlighted their acute awareness of themselves and others. Finn pointed out that he has intensities of traits that he believes others don't have, even other gifted children. When you look at the "firestorm of traits" that Finn (Interview \#3) speaks of and Theo's heightened awareness of rules and social justice, you can see how the theory of overexcitabilities is applicable and helps to explain some of the troubles these two experienced in school.

The findings in this study included relevant meaning units that captured experiences with friends. Additionally, the participants showed a propensity towards awareness, learning, feelings, and TAG Programming. In response to these findings and reflecting back on the above ties to the literature, The Columbus Group (1991) would suggest that modifications in parenting, teaching and counseling are necessary to address the vulnerability and uniqueness of gifted children and their development.

Dewey's (1938) wisdom illuminates the need for teachers to stop ladling out knowledge that is already organized and work towards more engaging experiences for children. In the stories of the participants they clearly speak of experiences where 
improvements in differentiating curriculum are needed and how they appreciate a teacher who makes learning fun. According to Story (1985) the role of the teacher is a facilitator of learning. Silverman (1983) adds that successful teachers of gifted children allow students to think for themselves, by involving them more and talking less. Trudy sums this up when describing her TAG teacher's approach to instruction:

Her help made me feel really good and she helped me a lot by teaching me new things and giving me encouragement. I got more confidence--she helped me with both social and intellectual things. And, she's really fun to listen to, she doesn't just talk and talk and talk and talk and talk--she let's us talk to our friends and she asks a lot of questions. She helped me with my determination on some of the projects we worked on, she just really made me want to work and carry the project through to the end. (Interview \#2)

Another modification that several authors (Cross, 1997; Johnson, 2000; Gust, 1996; Van Tassel-Baska, 1983; Delisle, 1992; Kennedy, 1995; Moon, 2004; Cauley, Linder \& McMillan, 2006) suggest is that teachers will be most successful in helping gifted students reach their fullest potential, and meeting their social and emotional needs, if they take the time to get to know their students. This study is just one step in getting to know gifted children and understanding their elementary school experience better.

\section{Recommendations for further research.}

When reviewing the literature for this study, there was clearly a void in the area of capturing the lived experiences of gifted children. Cross, Stewart and Coleman (2003) conducted a phenomenological study of a magnet elementary school for academically gifted students. Four themes developed from the analysis of their interview data: Others, 
Role, Personal Development and Time. They concluded that Others was the most descriptive of their experience in elementary school. The students articulated an awareness of others that included students, teachers and parents. The students' stories spoke of both positive and negative experiences and included fears of feeling different, not fitting in and the expectations that others place on them. What was unique to this study is that because they were in a magnet school for gifted only students, they also were aware of feelings of support and understanding that came from the other gifted students in the school.

In the study described in this paper, five themes emerged from the data including: Awareness, Feelings, Learning, TAG Programming and Friends. Taking the findings from this study and looking closely at them with the Cross et al. (2003) study, there are similarities in the findings regarding Others and Awareness. Being aware of being different and also being aware of what others may think about gifted students is an area that warrants further study. In Cross et al. (2003) the students felt supported because of the homogenous environment of a magnet school. In the study in this paper, the students felt support and understanding from other TAG students and while in the TAG classroom. Further study of how to meet the unique needs of TAG students should include a study of environments and what programming can be put into place to best meet their needs.

Another area that should be explored more is the area of the twice-exceptional child, which means children identified as both gifted and receiving services from the Special Education department in the school. Finn is a twice-exceptional child and after reviewing the data he generated, he clearly had a remarkably different experience in 
school than the other children. Finn's reflections of both the positive and negative experiences he had, in addition to him not understanding why some of the things happened in the manner that they did, affirm that further study is needed in this area.

Finally, Trudy shared in her final interview that she was thankful that she was gifted and "[her] opinions will probably change a couple of times, but [she] think[s] [she] will always come back to thankful because [she] will be a gifted teenager and a gifted adult." (Interview \#3). Are the school experiences different as the gifted student goes through middle school and high school? That is a question that should be investigated as it could inform practice for teachers as gifted students navigate their educational path.

\section{Conclusion.}

The data generated in this study clearly shows that gifted children can articulate the experiences they are having in elementary school. These participants shared stories that highlighted the enjoyment of learning experiences that included differentiated and enriched curriculum as well as teachers who were fun and made learning interesting. Additionally, the participants enjoyed spending time with their friends and expressed a desire to have more time to talk and work with friends in the classroom. Finally, the literature says that successful teachers of the gifted are those who involve the students more in the learning process, take the time necessary to get to know their gifted students and serve as facilitators in the classroom. After dialoging with the participants in this study, I believe the common thread through all these statements is time. If teachers take the time to listen to gifted children articulate their wants and needs, then the gifted child's voice develops a purpose and identity that allows them to become a partner in their education. I believe that all teachers want to do their best with all their students and I 
want to believe they have the skills necessary to help meet the unique needs of gifted students. It just comes down to taking and having the necessary time to get to know gifted students, to seek out help from colleagues regarding their gifted students if needed and collectively developing a plan for the gifted child's school experience.

The voice is such a powerful tool, and according to Bergmark "...student voice is closely linked to school improvement" (2008, p. 268). Even in the perfect educational environment there is always room for improvements and my hope is that this study is a catalyst for positive improvements in gifted education. I hope the lived elementary experience for gifted students is enhanced and I hope policy/decision makers are influenced to assign resources to gifted education. Additionally, I hope the preparation of elementary school teachers is enriched, so that they are equipped to engage the gifted learner in meaningful teaching and learning experiences in the future.

Finally, I hope to play a role in these improvements because I believe the voices captured in this study have the power to inform and influence the gifted and general education communities. 


\section{References}

Barbe, W. B. \& Renzulli, J. S. (Eds.) (1981). Psychology and education of the gifted. New York, NY: Irvington Publishers, Inc.

Bergmark, U. (2008). I want people to believe in me, listen when I say something and remember me--how students wish to be treated. Pastoral Care In Education. 26(4). 267-279.

Bloom, B. S. (1994). Excerpts from taxonomy of educational objectives, the classification of educational goals. In L. W. Anderson \& L. A. Sosniak (Eds.), Bloom's Taxonomy: A forty year retrospective. Chicago, IL: University of Chicago Press.

Bolman, L. G. \& Deal, T. E. (2003). Reframing organizations: Artistry, choice and leadership. San Francisco, CA: Jossey-Bass.

Braham, C. G., Ed. (2001). Random House Webster's dictionary. New York: Ballantine Books.

Bronfenbrenner, U. (1979). The ecology of human development: Experiments by nature and design. Cambridge, MA: Harvard University Press.

Cauley, K. M., McMillan, J. H., \& Linder, F., Eds. (2006). Annual editions: Educational psychology. Dubuque, IA: McGraw-Hill/Dushkin.

Cleaver, S. (2008). Smart \& Bored. Instructor, 117, 28-32.

Cloud, J. (2007). The genius problem. Time. 170, 40-47.

Cohen, M. Z. \& Omery, A. (1994). Schools of phenomenology. In J. M. Morse (Ed.), Critical issues in qualitative research (pp. 136-156). Thousand Oaks, CA: Sage.

Coleman, L. J., Dabbs, C. S. \& Guo, A. (2007). The state of qualitative research in gifted 
FINDING THE GIFTED CHILD'S VOICE

education as published by American journals: An analysis and critique. Gifted Child Quarterly 51(1): 51-63.

Columbus Group. (1991). Transcript of the meeting of the Columbus Group. Columbus, $\mathrm{OH}$.

Costley, K. C. (2012). Who are today's students in a diverse society? Russellville, Arkansas, Arkansas Tech University: 8.

Creswell, J. W. (2002). Educational research: Planning, conducting and evaluating quantitative and qualitative research. Upper Saddle River, NJ: Merril PrenticeHall.

Creswell, J. W. (2007). Qualitative inquiry \& research design: Choosing among five approaches. Thousand Oaks, CA: Sage Publications, Inc.

Cross, T. (1997). Guiding and supporting the development of gifted children. Gifted Child Today 20(September-October): 46-47.

Cross, T. (2005). The social and emotional lives of gifted kids: Understanding and guiding their development. Waco, TX: Prufrock Press, Inc.

Cross, T. L., Stewart, R. A., \& Coleman, L. J. (2003). Phenomenology and its implications for gifted studies research: Investingating the Lebenswelt of academically gifted students attending an elementary magent school. Journal for the Education of the Gifted 26(3): 201-220.

Dabrowski, K. (1964). Positive disintegration. Boston, MA: Little, Brown.

Dabrowski, K. (1972). Psychoneurosis is not an illness. London, England: Gryf.

Davidson Institute for Talent Development. (2006). Genius denied: How to stop wasting our brightest young minds. Retrieved February 6, 2006, from 
FINDING THE GIFTED CHILD'S VOICE

http://www.geniusdenied.com/Policies/StatePolicyDetails.aspx?StateCode=1003 $8 \& \mathrm{NavID}=$

Delisle, J. R. (1984). Gifted kids speak out. Minneapolis, MN: Free Spirit Publishing, Inc.

Delisle, J. R. (1992). Guiding the social and emotional development of gifted youth: A practical guide for educators and counselors. White Plains, NY: Longman Publising Group.

Delisle, J. R. (2003). To be or to do: Is a gifted child born or developed? Roeper Review 26(1): 12-13.

Delisle, J. R. (2012). Reaching those we teach: The five Cs of student engagement. Gifted Child Today 35(1): 63-67.

Dewey, J. (1938). Experience \& education. New York, NY: Touchstone.

Dweck, C. S. (2006). Mindset: The new psychology of success. New York: Ballantine Books.

Edwards, J. W. (1959). The gifted child in Portland: A report of five years experience in developing a program for children of exceptional endowment. Portland, OR: Portland Public Schools.

Farber, M. (1943). The foundation of phenomenology. Albany, NY: SUNY Press.

Gagne, F. (1993). Constructs and models pertaining to exceptional human abilities. In K.
A. Heller, F. J. Monks and A. H. Passow (Eds.), International Handbook of Research and Development of Giftedness and Talent (pp. 63-85). Oxford: Pergamon Press.

Gagne, F. (2000). A differentiated model of giftedness and talent: Year 2000 update. 
FINDING THE GIFTED CHILD'S VOICE

Montreal, Canada: University of Quebec.

Gardner, H. (1991). The unschooled mind: How children think and how schools should teach. New York, NY: Basic Books.

Giorgi, A., Knowles, R., \& Smith, D. L. (Eds.). (1979). Duquesne studies in phenomenological psychology. Pittsburgh: Duquesne University Press.

Giroux, H. A. (1988). Teachers as intellectuals: Toward a critical pedagogy of learning. Westport, CT: Bergin and Garvey.

Glass, T. F. (2004). What gift? The reality of the student who is gifted and talented in public school classrooms. Gifted Child Today 27(4): 25-29.

Golden, D. (2003, December 29). Brain drain: Initiative to leave no child behind leaves out gifted. Wall Street Journal, p. A1.

Grant, B. A. \& Piechowski, M. M. (1999). Theories and the good: Toward childcentered gifted education. Gifted Child Quarterly 41: 4-12.

Gust, K. L. (1996). Assessing the social and emotional needs of the gifted. Gifted Child Today 19(September/October): 38-40.

Hall, R. M. \& Clark, D. L. (1960). The gifted student: Research projects concerning elementary and secondary students. Washington, DC: United States Department of Health, Education and Welfare.

Harris, T. (2002, August 8). How spiders work [Webpage]. Retrieved from http://science.howstuffworks.com/zoology/insects-arachnids/spider.htm.

Heifetz, R. A. (1994). Leadership without easy answers. Cambridge, MA: The Belknap Press of Harvard University Press.

Heller, K. A., Monks, F. J., \& Passow, H. A. (Eds.). (1993). International handbook of 
FINDING THE GIFTED CHILD’S VOICE

research and development of giftedness and talent. Tarrytown, NY: Pergamon Press, Inc.

Hertzog, N. B. (1998). Open-ended activities: Differentiation through learner responses. Gifted Child Quarterly 42(4): 212-227.

Hollingworth, L. S. (1930). Playmates for the gifted child. Child Study 8: 103-104.

Hollingworth, L. S. (1939). What we know about the early selection and training of leaders. Teachers College Record 40: 575-592.

Hollingworth, L. S. (1942). Children above 180 IQ: Stanford-Binet origin and development. Yonkers-on-Hudson, NY: World Book Company.

Huff, R. E., Houskamp, B. M., Watkins, A. V., Stanton, M. \& Tavegia, B. (2005). The experiences of parents of gifted African American children: A phenomenological study. Roeper Review 27(4): 215-221.

Hycner, R. H. (1985). Some guidelines for the phenomenological analysis of interview data. Human Studies 8: 279-303.

Jessiman, M. (2001). Philosophers at the policy table: A theory of schooling confronts real school reform. Philosophy of Education Yearbook: 241-251.

Johnson, K. S. (2000). Affective component in the education of the gifted. Gifted Child Today 23(July-August): 36-40.

Jolly, J. L. \& Kettler, T. (2008). Gifted education research 1994-2003: A disconnect between priorities and practice. Journal for the Education of the Gifted 31(4): $427-446$.

Karnes, F. A. \& Nugent, S. A. (Eds.). (2004). Profiles of influence in gifted education: Historical perspectives and future directions. Washington, DC: Prufrock Press, 
FINDING THE GIFTED CHILD’S VOICE

Inc.

Kennedy, D. M. (1995). Glimpses of a highly gifted child in a heterogeneous classroom. Roeper Review 17(3): 164-168.

Lee, S.-Y. \& Olszewski-Kubilius, P. (2006). The emotional intelligence, moral judgment and leadership of academically gifted adolescents. Journal for the Education of the Gifted 30(1): 29-67.

Levering, B. (2006). Epistemological issues in phenomenological research: How authoritative are people's accounts of their own perceptions? Journal of Philosophy of Education 40(4): 451-462.

Lewis, R. B., Kitano, M. K., \& Lynch, E. W. (1992). Psychological intensities in gifted adults. Roeper Review 15(1): 25-31.

Lopez, K. A. \& Willis, D. G. (2004). Descriptive versus interpretive phenomenology: Their contributions to nursing knowledge. Qualitative Health Research 14(5): 726-735.

Lovecky, D. V. (1992). Exploring social and emotional aspects of giftedness in children. Roeper Review 15(1): 18-25.

Lundsteen, S. W. (1987). Qualitative assessment of gifted education. Gifted Child Quarterly 31(1): 25-29.

Maker, C. J. \& Nielson, A. B. (1995). Teaching models in education of the gifted. Ipswich, MA.

Marland, S. P. J. (1972). Education of the gifted and talented: Vol. 1 report to the Congress of the United States by the U.S. Commisioner of Education. U. S. Department of Education, Washington DC: U.S. Government Printing Office. 
Moon, S. M., (Ed.). (2004). Social/emotional issues, underachievement and counseling of gifted and talented students. Essential Readings in Gifted Education. Thousand Oaks, CA: Corwin Press.

Morelock, M. J. (1996). On the nature of giftedness and talent: Imposing order on chaos. Roeper Review 19: 4-12.

Moustakas, C. (1994). Phenomenological research methods. Thousand Oaks, CA: Sage Publications, Inc.

Neihart, M., Reis, S. M., Robinson, N. M., \& Moon, S. M. (Eds.) (2002). The social and emotional development of gifted children. Waco, TX: Prufrock Press, Inc.

Nelson, K. C. (1989). Dabrowski's theory of positive disintegration. Advanced Development 1: 1-14.

Newland, T. E. (1976). The gifted in socioeducational perspective. Englewood Cliffs, NJ: Prentice-Hall, Inc.

Norton, J. K. \& Selke, G. A. (1950). Education of the gifted. Washington, DC.

O'Connell-Ross, P. (1993). National excellence: A case for developing America's talent. Washington, DC: Office of Educational Research and Improvement, U.S. Department of Education.

O'Connor, K. J. (2002). The application of Dabrowski's theory to the gifted. In M. Neihart, S. M. Reis, N. M. Robinson and S. M. Moon. (Eds.), The social and emotional development of gifted children: What do we know? Waco, TX: Prufrock Press, Inc.: 51-60.

Olenchak, R. F. (1999). Affective development of gifted students with nontraditional talents. Roeper Review 21(4): 293-297. 
FINDING THE GIFTED CHILD'S VOICE

Oregon Department of Education. (2004). Summary report: Talented and gifted (TAG) education in Oregon public schools. Retrieved February 20, 2006, from http://www.ode.state.or.us/teachlearn/specialty/tag/pdf/summaryreportTAGEd.pd f.

Passow, H. A. (1982). Differentiated curricula for the gifted/talented. Ventura, CA: Ventura County Superintendent of Schools Office.

Pfeiffer, S. I. \& Jarosewich, T. (2007). The gifted rating scales-school form: An analysis of the standardization sample based on age, gender, race, and diagnostic efficiency. Gifted Child Quarterly 51(1): 39-50.

Piechowski, M. M. (1997). Emotional giftedness: The measure of intrapersonal intelligence. In N. Colangelo and G. A. Davis. (Eds.), Handbook of gifted education. Boston, MA: Allyn and Bacon: 366-381.

Piechowski, M. M. \& Cunningham, K. (1985). Patterns of overexcitability in a group of artists. Journal of Creative Behavior 19: 153-174.

Pritchard, M. C. (1951). The contribution of Leta S. Hollingworth to the study of gifted children. In P. A. Witty. (Ed), The gifted child. New York: Heath.

Reis, S. M., Westberg, K. L., Kulikowich, J. M., \& Purcell, J. H. (1998). Curriculum compacting and achievement test scores: What does the research say? Gifted Child Quarterly 42(2): 123-129.

Reis, S. M., Westberg, K. L., Kulikowich, J. M., \& Purcell, J. H. (2004). Curriculum compacting and achievement test scores: What does the research say? In C. A. Tomlinson. (Ed.), Differentiation for gifted and talented students. Thousand Oaks, CA: Corwin Press: 105-116. 
Renzulli, J. S. (1978). What makes giftedness? Reexamining a definition. Phi Delta Kappan 60(5): 180-184, 261.

Renzulli, J. S., Ed. (2004). Identification of students for gifted and talented programs. Essential Readings In Gifted Education. Thousand Oaks, CA: Corwin Press.

Renzulli, J. S. \& Purcell, J. H. (1996). Gifted education: A look around and a look ahead. Roeper Review 18(2): 173-178.

Renzulli, J. S. \& Reis, S. M. (1985). The schoolwide enrichment model: A comprehensive plan for educational excellence. Mansfield, CT: Creative Learning Press.

Renzulli, J. S. \& White, W. L. (1987). A forty year follow-up of students who attended Leta Hollingworth's school for gifted students. Roeper Review 10(2): 89-94.

Rogers, K. B. (2007). Lessons learned about education the gifted and talented: A synthesis of the research on educational practice. Gifted Child Quarterly 51(4): 382-396.

Schmitz, C. C. \& Galbraith, J. (1985). Managing the social and emotional needs of the gifted. Minneapolis, MN: Free Spirit Publishing Co.

Schultz, R. A. (2002a). Understanding giftedness and underachievement: At the edge of possibility. Gifted Child Quarterly 46(3): 193-208.

Schultz, R. A. (2002b). Illuminating realities: A phenomenological view from two underachieving gifted learners. Roeper Review 24(4): 203-212.

Silverman, L. K. (1983). Issues in affective development of the gifted. A practical guide to counseling the gifted in a school setting. Reston, VA: The Council for Exceptional Children. 
Silverman, L. K. (1993). The gifted individual. In L. K. Silverman. (Ed.), Counseling the gifted and talented. Denver, CO: Love: 3-28.

Silverman, L. K. (1994). The moral sensitivity of gifted children and the evolution of society. Roeper Review 17(2): 110-116.

Silverman, L. K. (1997). The construct of asynchronous development. Journal of Education 72(3-4): 36-58.

Smith, T. E. (2005). IDEA 2004: Another round in the reauthorization process. Remedial \& Special Education 26(6): 314-319.

Sokolowski, R. (2000). Introduction to phenomenology. New York, NY: Cambridge University Press.

Sternberg, R. J. (Ed.). (2004). Definitions and conceptions of giftedness. Essential Readings in Gifted Education. Thousand Oaks, CA: Corwin Press.

Story, C. M. (1985). Facilitator of learning: A micro-ethnographic study of the teacher of the gifted. Gifted Child Quarterly 29(4): 155-159.

Strang, R. (1951). Mental hygiene of gifted children. In P. Witty. (Ed.), The gifted child. Lexington, MA: DC Heath and Company: 131-162.

Terman, L. M. (1931). The gifted child. In C. Murchison (Ed.), A handbook of child psychology. Worcester, MA: Clark University Press: 568-584

Terman, L. M. (1954). The discovery and encouragement of exceptional talent. American Psychologist 9: 221-230.

The National Commission on Excellence in Education. (1983). A nation at risk: The imperative for educational reform. Washington, DC: United States Department of Education. 
Tieso, C. L. (2003). Ability grouping is not just tracking anymore. Roeper Review 26(1): 29-36.

Tolan, S. (1989). Special problems of young highly gifted children. Understanding Our Gifted 1(5): 1, 7-10.

Tomlinson, C. A., Ed. (2004). Differentiation for gifted and talented students. Essential Readings in Gifted Education. Thousand Oaks, CA: Corwin Press.

Tomlinson, C. A., et al. (2002). The parallel curriculum: A design to develop high potential and challenge high-ability learners. Thousand Oaks, CA: Corwin Press, Inc.

Trawick-Smith, J. (2006). Early childhood development: A multicultural perspective. Upper Saddle River, NJ: Pearson Education, Inc.

U.S. Department of Education. (2002). No Child Left Behind: A desktop reference. Washington, DC: Office of Elementary and Secondary Education.

Van Manen, M. (1990). Researching lived experience: Human science for an action sensitive pedagogy. Albany, NY: State University of New York Press.

Van Tassel-Baska, J., Ed. (1983). A practical guide to counseling the gifted in a school setting. Reston, VA: The Council for Exceptional Children.

Van Tassel-Baska, J. (2006). A content analysis of evaluation findings across 20 gifted programs: A clarion call for enhanced gifted program development. Gifted Child Quarterly 50(3): 199-215.

Van Tassel-Baska, J., Zuo, L., Avery, L. D., \& Little, C. A. (2002). A curriculum study of gifted student learning in the language arts. Gifted Child Quarterly 46(1): 3044. 
FINDING THE GIFTED CHILD’S VOICE

Van Tassel-Baska, J., Zuo, L., Avery, L. D., \& Little, C. A. . (2004). A curriculum study of gifted-student learning in the language arts. In C. A. Tomlinson. (Ed.), Differentiation for gifted and talented students. Thousand Oaks, CA: Corwin Press: $165-190$.

Ward, V. S. (1961). Educating the gifted: An axiomatic approach. Columbus, OH: Charles Merrill.

Winebrenner, S. (2001). Teaching gifted kids in the regular classroom. Minneapolis, MN: Free Spirit Publishing.

Wojnar, D. M. \& Swanson, K. M. (2007). Phenomenology: An exploration. Journal of Holistic Nursing 25(3): 172-180. 
FINDING THE GIFTED CHILD'S VOICE

Appendix A.

RESEARCH TIMELINE

Proposed Research Timeline

PROTOCOL PROCESS

Protocol Agenda

INTERVIEW PROTOCOLS

P1-Interview Protocol \#1

P2WS-Works Session Instruction Protocol

P2I-Interview Protocol \#2

P3-Interview Protocol \#3

RESEARCHER'S EPOCH AND FIELD NOTES

Researcher's Epoch and Field Notes Journal 
FINDING THE GIFTED CHILD'S VOICE

\section{Research Timeline/Agenda:}

May 2012

- Obtained approval from PSU Human Subjects Committee-5/15/2012

- Notified families of study $-5 / 20 / 2012$

- $\quad$ Selected participants-5/20-31/2012

June 2012

- Consent received from participants and parents-6/1-12/2012

- Consent received from building principal-6/14/2012

- First interview (Interview protocol \#1)—6/15/2012

- Pilot study for work session-6/18/2012

- Analyzed first set of data—ongoing

- Work session for narratives/artwork-6/20-21/2012

- Analyze narratives/artwork and create protocols for second interviewongoing

July 2012

- Second interview (Interview protocol \#2) - 7/12-19/2012

- Analyze second set of data-ongoing

August 2012

- Third interview (interview protocol \#3)—8/7-20/2012

- Participant celebrations-8/20-30/2012

September-November 2012 
- Final analysis of data, determine and communicate findings—ongoing 


\section{Protocol Agenda:}

INTERVIEW \#1 PROTOCOL—Baseline Data Collection Interview

Purpose: Participant will describe the underlying attitudes, perceptions and experiences of a gifted child in elementary school.

P1-Interview Protocol \#1

WORK SESSION PROTOCOL_-Instructions for Narrative/Art Product

Purpose: Participant will describe in their own words their lived experiences in elementary school, using a written narrative and/or picture(s) they have created to personally reflect on their lived experiences.

P2WS—Work Session Instruction Protocol

INTERVIEW \#2 PROTOCOL_Lived Experience Picture/Narrative Interview

Purpose: Participant will have the opportunity to share their narrative and/or pictures while being guided by questions developed directly from their work session product.

P2I-Interview Protocol \#2

INTERVIEW \#3-Data check and transcript verification with participants

Purpose: Participant verifies their experiences have been appropriately captured and the summaries presented are accurate. Participant has the ability to correct the data presented in this interview, as well as add anything missed from any prior interviews.

P3-Interview Protocol \#3

\section{RESEARCHER'S REFLECTION—Epoch/Field Notes}

Purpose: Researcher will describe preconceptions of the participants and subject being studied, allowing for a more objective interaction with the process and data collected. This process will be ongoing from the very beginning of the study, through data collection and into analysis.

Researcher's Epoch and Field Note Journal 
INTERVIEW PROTOCOL \#1-P1 Participant Code:

Finding the gifted child's voice in the elementary school setting:

A phenomenological exploration

Time of Interview:

Date:

Place:

Interviewer: Keely S. Porter

This phenomenological study will explore, through interviews and participant drawings/narratives, the lived school experiences of gifted elementary school children in a suburban public school in the Pacific Northwest.

Please answer the following questions giving me as many details as possible. Think about your experience and knowledge as a gifted child to help guide your responses. YOUR ANSWERS WILL REMAIN CONFIDENTIAL and will be used for research purposes only. PARTICIPATION IS VOLUNTARY and you may stop at any time.

Q1--What is gifted? If someone were to ask you what it is, how would you explain it to them? Can you share some experiences you have had in school that reflects this?

Q2-Tell me some of your favorite stories about school.

Q3-So I can learn about your experience all day at school, can you tell me about being gifted in terms of your experience during specific things like recess, lunch, PE, Music, Technology, Math, Reading, etc...? 
Q4-Tell me about being gifted in terms of your relationships with friends and teachers?

Q5-Are there any other stories you would like to share about school?

Q6-What would you change about school if you could?

Please share with me examples of experiences that you have had in school that influence this decision. 
WORK SESSION PROTOCOL-P2WS

Participant Code:

Finding the gifted child's voice in the elementary school setting:

A phenomenological exploration

Time of Interview:

Date:

Place:

Interviewer: Keely S. Porter

This phenomenological study will explore, through interviews and participant drawings/narratives, the lived school experiences of gifted elementary school children in a suburban public school in the Pacific Northwest.

Using writing and/or drawing please capture (on paper) your experiences in elementary school. You can give me bits and pieces, just one picture, a whole story, however you want. I am not judging your drawing or writing ability, I just want you to have something to help capture or explain your experience in elementary school.

Think about your experience and knowledge as a gifted child to help guide your pictures or stories. YOUR ANSWERS WILL REMAIN CONFIDENTIAL and will be used for research purposes only. PARTICIPATION IS VOLUNTARY and you may stop at any time. 
INTERVIEW PROTOCOL \#2-P2I Participant Code:

Finding the gifted child's voice in the elementary school setting:

A phenomenological exploration

Time of Interview:

Date:

Place:

Interviewer: Keely S. Porter

This phenomenological study will explore, through interviews and participant drawings/narratives, the lived school experiences of gifted elementary school children in a suburban public school in the Pacific Northwest.

Using writing and/or drawing please capture (on paper) your experiences in elementary school. You can give me bits and pieces, just one picture, a whole story, however you want. I am not judging your drawing or writing ability, I just want you to have something to help capture or explain your experience in elementary school. Think about your experience and knowledge as a gifted child to help guide your pictures or stories. YOUR ANSWERS WILL REMAIN CONFIDENTIAL and will be used for research purposes only. PARTICIPATION IS VOLUNTARY and you may stop at any time.

Questions directly tied to the product created in the work session inserted here.

Allow participant to explain product further on their own. 
INTERVIEW PROTOCOL \#3-P3 Participant Code:

Finding the gifted child's voice in the elementary school setting:

A phenomenological exploration

Time of Interview:

Date:

Place:

Interviewer: Keely S. Porter

This phenomenological study will explore, through interviews and participant drawings/narratives, the lived school experiences of gifted elementary school children in a suburban public school in the Pacific Northwest.

Please answer the following questions giving me as many details as possible. Think about your experience and knowledge as a gifted child to help guide your responses. YOUR ANSWERS WILL REMAIN CONFIDENTIAL and will be used for research purposes only. PARTICIPATION IS VOLUNTARY and you may stop at any time.

First of all, I want to thank you for all your time and honesty during this experience. I have learned a lot and I hope the work that we have done together will help to inform and influence the future of gifted education.

Follow up question from our previous interviews:

Questions here.

The following are the thoughts that I have regarding the experiences you have shared with me. When I read them to you please let me know if I have captured what you are trying to share or if we need to change anything and, also, please add anything I may have missed during the process.

Summary presented here.

I am asking all the participants to answer the following questions, kind of like a closing activity for our experience together...

If you were to choose one word to represent your elementary school experience, what would it be? Tell me why you chose that word.

If you were to choose one word to represent yourself as a gifted child, what would that word be? Tell me why you chose that word. 


\section{Epoch}

According to Moustakas (1994), "Epoch is a Greek word meaning to refrain from judgment, to abstain from or stay away from the everyday, ordinary way of perceiving things...[it] requires a new way of looking at things..." (p. 33). Through this process I will be able to put my preconceptions aside and look at the children's stories with a naïve perspective. This process is very important because of my many years of working with gifted children as well as their teachers and parents. I, myself, was a gifted student; however, I attended a small rural school during my elementary years and do not remember any special opportunities until my middle and high school years. In middle school and high school I was advanced in math, science and business classes.

What is gifted? Because I have always taught the kids that it means different, not worse or better than anyone else, I think they are all probably going to say it means to think differently — it will be really important to get their perspective of gifted experiences.

I also believe that my view of what is gifted is tainted as well by all my research and focus in this area for the past 14 years. I feel that so much I have read about in my studies focuses on the plight of gifted students and the struggles they have endured for equitable treatment and programming for almost a century. On the other hand, I also have read in many professional journals and magazines great success stories of how positive change is happening in areas of academic enrichment, increases of identification in children from underrepresented populations and attempts at helping students understand their unique social and emotional characteristics. 
When I ask myself, "What is gifted?", I think that it is a child who experiences their environment in a way that is different from the typical student. This difference could be positive or negative and could be recognizable by the student and others or not. I think giftedness is something that shouldn't be held back for those indentified but should be shared with all parents, students, and teachers, so a better understanding can be shared by the entire education community. This way everyone can look for signs of giftedness in children and we can also recognize that being a great student, who is well rounded, is a blessing.

Tell me your favorite stories. I am thinking that the word "favorite" will weigh this question a bit and I won't be able to get any negative stories from them that we can learn from. I am curious if their stories will be more TAG based or if their favorite stories come from their "typical” elementary school experiences. I'm concerned that since they know I work with TAG students they might be more inclined to tell TAG stories versus typical stories. I need to figure out a way to help them be comfortable with either.

My favorite stories as a TAG teacher are those that happen when I either get the students afterschool, so I have 2 hours of uninterrupted learning bliss or I get the same kids for multiple days in a row, so we can really hammer through a learning experience. I love having an experience that can go through the entire gamut of the learning process: pre-teaching, teaching, and reflecting and, as a TAG Specialist, I don't get those opportunities very often.

One of my favorite activities to do with the kids is our annual Invention Convention. We save up all our recycling from our homes around the holiday season and 
bring it to school and see what kind of wonderful invention we can create out of our reclaimed treasures. It is so fun to teach the kids about inventions and how some inventions are really mistakes from other ideas or experiments that end up solving real problems and becoming very helpful. As the kids are attempting their inventions it is so fun to see the wheels turning, the dialogue that is happening and the coping strategies that are being tried and developed as they learn to work together and through failure. The culminating parade of inventions, on display in the library for all to see, is wonderfully creative and, sometimes, silly. You can really see their little personalities come through in anything from a satellite that is going to improve communication with Mars to the robot that is going to help do your chores in a matter of minutes to a security device that bops little brothers on the head if they try to sneak into an off limits bedroom of an older sibling. Giving the kids the opportunity to fail in a safe environment opens the door for so many great lessons.

Experiences in other parts of the day. I am curious how they will answer this question as I believe some only "feel" gifted when they are in the academic parts of the day or in TAG class. I hope this question makes them think about their giftedness $24 / 7$. I think many of the students will say the rest of their day, outside of academics, is pretty "normal"; however, the one area I can see them maybe addressing is in their relationships or in making friends. I think that their giftedness influences their entire school experience, in fact my previous principal and I have discussed this several times, and it is also discussed in gifted literature.

My favorite part of the day was recess in elementary school. I loved playing with my friends and because I lived in a rural community, school was often the only time I got 
to play with other children my age. I was a real tomboy, so I loved to run and play and loved every type of sport with a ball. The only thing I didn't like about recess was being teased because I wore glasses and some kids could be very mean. I didn't like being so noticeably different than the other kids.

Giftedness related to friends and teachers. I think this will be the area where we could see some negative comments. Based on my experiences working with gifted kids, this is often an area of struggle - albeit for some more than others. I think that their comments regarding teachers may be a mixed bag due to the balance between relating to adults more than peers and feeling aspects of boredom during some classroom instruction. I have found that many of the negative interactions with peers have not necessarily been due to poor social skills (however, there is a group that struggles greatly in this area), but a lot of the problems stem from jealousy from peers because they want to be identified and in the program. Therefore, many negatives, almost bullying/teasing like, are directed towards the gifted students from their friends or classmates due to an inherent lack of understanding of the entire identification. And, the TAG student just wants to belong in the "crowd". I think this is true for relationships with teachers alsothe TAG student often seeks out an intellectual equal in their teacher and, in that process, looks either needy or a teacher's pet, hence creating a possible awkward environment.

I was a very social kid and I don't remember hanging out with other smart kids as much as hanging out with the jocks and, truly, we all pretty much hung out together because we were such a small school district that all of us knew each other really well. Out of 99 graduating seniors, 90 of us had gone from $1^{\text {st }}$ grade to $12^{\text {th }}$ grade together. We still had our cliques, but I felt like I belonged in the ones I was interested in and intellect 
didn't really seem to matter in elementary school. That was something that manifested in Middle School when it was "recognized" and along with it came noticeable opportunities.

Any other stories. I'm hoping we will get some stories that have come to mind during the interview and hopefully balance out a perspective that is reflective of the “entire" gifted experience in school.

I loved teachers who did things differently, like Mrs. Graham, in third grade, had us write a recipe for a cookbook for our moms on Mother's Day, it was a great lesson in writing and math and we didn't even know it. I like teaching kids about descriptive writing by making PB\&J sandwiches — nothing better than their giggles when I smash the bread with the peanut butter jar or try to balance the jar on the knife. Good stuff!

Anything you could change. I'm guessing they will want TAG to be restored and programming to be like it was in the previous years. I'm thinking they will also want more challenges in math and reading and more time to learn through projects in the other subjects because these are things they enjoyed when they came to the TAG room for activities and enrichment.

When I was a kid, I don't think I would have changed anything because I loved school. As an adult, I would make the school year and school day longer. I think we try to jam too much into our current time frame which creates stress for both teachers and students. I think we need to create more "time" so we can all enjoy the journey. And, of course, reinstate TAG Programming to a fully funded position and program. 
One word to capture your elementary school experience. I added this section later and I know this is not necessarily a phenomenological question; however, after spending the time with the kids, I really wanted to know what they would say.

Great! I really liked every part of it. I liked to learn, I loved playing with my friends and I thought my teachers were nice, particularly my primary grade teachers. I liked being a strong student because I liked getting my work done and being able to help others and I loved projects that used my imagination. I was pretty creative and crafty.

One word to capture your experience as a gifted child. Advantage. I appreciate, particularly now, the advantage I had by being gifted in math, science and business. My earlier career path was enhanced by the ability of having advanced business classes later in my school career. My understanding of math and science were helpful in school because I could move through the classes at an accelerated rate, but I also think that it helps me when I am teaching those subjects because those subjects came easy for me and I created a love for them that I think shows up when I teach those subjects now.

Researcher disclosure. Outside of the questions that will be asked during the interview, I also need to disclose that I have entered into this project with an underlying concern that TAG students are underserved in the school in the study. Due to budget cuts and the cutting back of TAG programming, the services that are being provided to TAG students currently is, at best, half as much as they used to receive. TAG students are very unique individuals and there is a very broad spectrum between the academically talented, the intellectually gifted, those with multiple identifications and those who are twice 
exceptional as TAG and SpEd. I have a negative perspective, currently, in regards to how TAG students experience elementary school. 
FINDING THE GIFTED CHILD'S VOICE

Appendix B.

Consent Forms

Consent Form-Parents

Consent Form-Students

Consent Form-Principal of Elementary School

Profile Questionnaire

Student Profile Provided by Participant 
Finding the gifted child's voice in the public elementary school setting: $A$ phenomenological exploration ${ }^{1}$

Your child is invited to participate in a research study conducted by Keely Porter from Portland State University, Graduate School of Education. This study is being conducted in partial fulfillment of the requirements for a doctoral degree in the area of Educational Leadership specializing in Curriculum and Instruction. This study is being supervised by Christine Chaille, who is on faculty with Portland State University. Your child was selected as a possible participant in this study because they are a Talented and Gifted student in the $5^{\text {th }}$ grade at Byrom Elementary School.

Research purpose: the researcher hopes to learn more about the gifted child's experience in the elementary school setting.

If you decide to let your child participate, he/she will be asked to meet with the researcher for 3 interviews over the course of three months. Each interview will take place after school and will last no longer than 30 minutes. The data collected will be audio taped and transcribed for analysis. The questions being asked in the interview will be related to your child's overall school experiences. In addition to the interviews, your child will be asked to participate in a work session (again, after school in the TAG room) to complete a narrative and/or pictorial project that will capture their lived experience in school. This narrative and/or pictorial will be used to guide our discussion during interview number two. While participating in this study, it is possible your child will miss some afterschool activities; however every effort will be made to avoid this happening by making appointments that fit your child's already established calendar. In addition to the possibility of helping others in the future, your child will receive afterschool opportunities provided by the researcher at the conclusion of their interview and work sessions. The additional activities will be explained in advance and your child can choose to participate or pass on these opportunities.

Any information that is obtained in connection with this study and that can be linked to your child or identify your child will be kept confidential. Subject identities will be kept confidential by assigning pseudonyms to children being studied. The only person who will know the true identity of the subjects will be the researcher named above and this information will not be divulged in the dissertation; however, the dissertation will be published and while all safeguards will be in place, there are no guarantees that those reading the dissertation will not be able to figure out which stories belong to your child. This is a risk that should be discussed and decided upon with your child before they agree to participate in the study. The data collected will be kept in a locked cabinet with the only access belonging to the researcher.

Your child's participation is entirely voluntary. You do not have to take part in this study, and it will not affect your relationship with the researcher, your Elementary 
School, or Portland State University in any way. You may choose to withdraw at any time without affecting your relationship with the organizations listed above.

If you have concerns or problems about your participation in this study or your rights as a research subject, please contact the Human Subjects Research Review Committee, Research + Strategic Partnerships (RSP), PO Box 751, Portland, OR, 97207, 503-725-4288 (1-877-480-4400), 503-725-8170 (fax), hsrrc@lists.pdx.edu. If you have questions about the study itself, contact Keely Porter, 11105 SW Garrett Street, Tualatin, OR, (503) 692-9616.

Your signature indicates that you have read and understand the above information and agree that your child has permission to take part in this study. Please understand that you may withdraw your consent at any time without penalty, and that, by signing, you are not waiving any legal claims, rights or remedies. The researcher will provide you a copy of this form for your own records. 
FINDING THE GIFTED CHILD'S VOICE

Finding the gifted child's voice in the public elementary school setting: $A$ phenomenological exploration ${ }^{2}$

Dear

Your parents (or guardian) have said that it is okay for you to take part in a project about Talented and Gifted (T.A.G.) student's school experiences. If you choose to do it, you will be asked to meet with Mrs. Porter (the researcher) to answer questions about your elementary school experiences. These meetings will happen after school and will last no longer than 30 minutes. There will not be any extra homework attached to this research project. All efforts to ensure confidentiality will be made during all meetings. The data collected will be audio taped and transcribed (which means taking your words from the recording and typing them out onto paper so they can be read) for analysis (which means after reading your words, the researcher will try to find common themes and ideas to help explain your experiences).

After your stories are collected and written down, they will be published for others to read-while the researcher will use all safeguards in an effort to protect confidentiality, there are no guarantees that the readers of this paper will not be able to figure out what stories are yours. This is a risk that you need to be aware of and think about before agreeing to participate and is something you should discuss with your parents to make sure you are in agreement about this risk.

If you decide to participate and you want to rest, or stop completely, just tell the researcher-you won't get into any trouble! In fact, if you don't want to do it at all, you don't have to. Just say so. Also, if you have any questions about what you will be doing, just ask the researcher to explain.

If you want to try it, please sign your name on the line below. Remember-you can stop to rest at any time, and if you decide not to take part anymore, that is okay too, just let the researcher know.

Please mark the appropriate answer with an "X":

Yes, I would like to be in the study No, I prefer to pass on the study

Signed: Date: 
Finding the gifted child's voice in the public elementary school setting: $A$ phenomenological exploration ${ }^{3}$

You are invited to participate in a research study conducted by Keely Porter from Portland State University, Graduate School of Education. This study is being conducted in partial fulfillment of the requirements for a doctoral degree in the area of Educational Leadership specializing in Curriculum and Instruction. This study is being supervised by Christine Chaille, who is on faculty with Portland State University. You are being asked for permission to conduct this study because you are the principal of the chosen participant school.

Research purpose: the researcher hopes to learn more about the gifted child's experience in elementary school. As part of the study, the researcher is interested in the opinions and attitudes of the gifted children at your elementary school and their experience in a typical elementary school setting. This study is NOT meant to be a measurement of effective teaching or to scrutinize the performance of the school in any way.

If you decide for your school to participate, the chosen participants will be asked to meet with the researcher individually to engage in three interviews as well as one work session to develop a narrative and/or pictorial representation of their school experiences. In these activities, their participation will involve answering questions about their overall elementary school experience. The data collected will be audio taped and transcribed for analysis. The entire study will happen over the course of 3 months, with their time commitment totaling no more than approximately 3 hours and no individual session will last over 30 minutes.

Any information that is obtained in connection with this study and that can be linked to the participants or the school will be kept confidential. Subject identities will be kept confidential by assigning pseudonyms to children being studied and the school and district is only referred to as a district or school in the Pacific Northwest. The only person who will know the true identity of the subjects and location will be the researcher named above and this information will not be divulged in the dissertation; however, this dissertation will be published and while all safeguards will be in place, there are no guarantees that those reading the dissertation will not be able to figure out which school is being studied. This is a risk you should be aware of and consider in your decision to participate. The data collected will be kept in a locked cabinet with the only access belonging to the researcher.

Your participation is entirely voluntary. You do not have to take part in this study, and it will not affect your relationship with the researcher or Portland State University in any way. You may choose to withdraw at any time without affecting your relationship with those named above.

If you have concerns or problems about your participation in this study or your rights as a research subject, please contact the Human Subjects Research Review Committee, Research + Strategic Partnerships (RSP), PO Box 751, Portland, OR, 97207, 503-725-4288 (1-877- 
480-4400), 503-725-8170 (fax), hsrrc@lists.pdx.edu. If you have questions about the study itself, contact Keely Porter, 11105 SW Garrett Street, Tualatin, OR, (503) 692-9616.

Your signature indicates that you have read and understand the above information and agree to take part in this study. Please understand that you may withdraw your consent at any time without penalty, and that, by signing, you are not waiving any legal claims, rights or remedies. The researcher will provide you a copy of this form for your own records. 
PROFILE QUESTIONNAIRE Participant Name:

Finding the gifted child's voice in the elementary school setting: A phenomenological exploration

Participant Code:

(to be given by researcher $\overline{O N L Y \text {-please leave this line B }} L A N K$ )

This phenomenological study will explore, through interviews and participant drawings/narratives, the lived school experiences of gifted elementary school children in a suburban public school in the Pacific Northwest.

For this research paper, I want to be able to describe you without using your real name-your TAG identification, and your interests (hobbies, sports, favorite pastimes, favorite people, topic of study, etc...) So, please tell me a little about yourself.

Here is an example: Keely loves to golf and is fascinated with learning more about how TAG students think and experience the world around them. She loves the Beavers and can often be found tinkering around in her backyard. She has a passion for working with kids and loves making math interesting, fun and real.

YOUR ANSWERS WILL REMAIN CONFIDENTIAL and will be used for research purposes only. During the research process, your actual name will be replaced with a pseudonym and all data will be kept in a safe place that will protect your confidentiality. PARTICIPATION IS VOLUNTARY and you may choose to not participate without any concern of repercussions. 